1968

\title{
Sources of Utility in Rorschach Interpretation
}

\author{
Charles R. Potkay \\ Loyola University Chicago
}

Follow this and additional works at: https://ecommons.luc.edu/luc_diss

Part of the Psychology Commons

\section{Recommended Citation}

Potkay, Charles R., "Sources of Utility in Rorschach Interpretation" (1968). Dissertations. 955.

https://ecommons.luc.edu/luc_diss/955

This Dissertation is brought to you for free and open access by the Theses and Dissertations at Loyola eCommons. It has been accepted for inclusion in Dissertations by an authorized administrator of Loyola eCommons. For more information, please contact ecommons@luc.edu. (c) $($ ) $(9)$

This work is licensed under a Creative Commons Attribution-Noncommercial-No Derivative Works 3.0 License. Copyright (C) 1968 Charles R. Potkay 
Sources of Utility in Rorschach Interpretation

by

Charles R. Potkay

A Dissertation Submitted to the Faculty of the Graduate school of Loyola University in Partial Fulfillment of the Requirements for the Degree of Doctor of Philosophy

February

1968 


\section{ACKNOWLEDGMENTS}

The author wishes to express his gratitude to Dr. Frank J. Kobler, who directed the research. The teachine influence of Dr. Kobler, and of Dr. H. J. A. Rlmold1, provided the essentlal framework for the particular combination of Rorschach and problem-solving techniques employed in the study. The author is indebted to the participant clinicians whose generous cooperation made the study possible. Appreciation is extended to Dr. Roder1ck w. Pugh and Dr. LeRoy A. Wauck, members of his committee. Thanks are expressed to Mrs. Mary Anne Connelly who assisted in the typing and proofreading of the manuscripts. Speclal thanks are given to my wife, Catherine, who alded in programming the data for computer analysis, and who has shared in the realization of the research since its inception. 


\section{LIFE}

Charles Raymond Potkay was born on May 29, 1939, in Bridgeport, Connecticut.

He was graduated from Milford High School, Milford, Connecticut, in June of 1957. He graduated from Loyola University of Los Angeles in 1961. With the degree of Bachelor of Arts in Psychology.

lir. Potkay began his graduate studies in the Department of Psycholoey of Loyola University, Chicago, in September, 1961. Between September, 1961, and June, 1963, he was member of the staff of the Loyola Center for Guidance, where he completed his clerkship trainine. He then entered the clinical training program of the Veterans Administration. He recelved the Naster of Arts degree in Clinical Psychology from Loyola University in June. 1965. He completed his internship in September. 1966. after clinical training at Downey and West Side Hospitals, and the fental Hyglene Clinic, all in the Chicago area.

From October, 1966, to the present, Mr. Potkay has been a research associate with the Heasurement Research division of the Industrial Relations Center, at the University of Chicago. 
Dedication--to the participant clinicians who made this study possible.

Arnold Abrams

Charlotte H. Altman

Jack Arbit

Bernard $M$. Aronov

Edward J. Barnes

Robert P. Barrell

Samuel J. Benveniste

Frederick A. Braucher

Alvin G. Burstein

Alan S. Deholfe

Frank Dinello

Bernard H. Gold

Morton Hammer

Shirley J. Heinze

William A. Hunt

Victor A. Jackson

Joseph C. Kaspar

Harold Klehr
V1ta Krall

Ernest A. Kurtz

Charles E. Lane

Re1d I. hartin

Robert L. HoFarland

Narv L. Meyer

Gerald P. Motz

Ralph A. Nelson

Donala PauIl

Nelvin L. Periman

M. Henry P1tts

Roder1ck $W$. Pugh

W1IIIam G. Sh1pman

faul R. Singer

Fred E. Spaner

Lekoy A. Wauck

George K. Yacorzynsk1

Robert I. Yuf1t 
Table of Contents

Chapter

PaEe

I. Statement of Furpose . . . . . . . . . . . . 1

II. Survey of the Iiterature... . . . . . . . . 7

III. Description of Sample and Nethodology. . . . . 60

IV. D1scussion of the Results. . . . . . . . 72

V. Summary and Conclusions. ........... 131

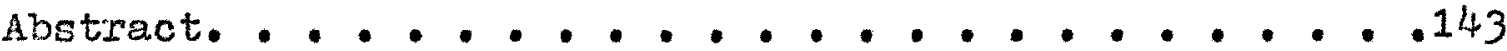

Bibliography. . . . . . . . . . . . . . . .144

Appendices

I. Apparatus used in the Present Study. . . . . .155

II. Question Forms for Protocols I. II, and III. . .157

III. Naterials Available for use by Clinicians. . . .161

IV. Research Information Form. . . . . . . . 166

V. Form Used to Record Interpretation Sequence. . .168

VI. Statistical Formulae .... . . . . . . 170 VII. Table of Item Abbreviations. . . . . . . . .173 
List of Tables

lable

Page

1. Description of clinical Sample. ....... 61

2. Utility Level of Each Item for Three Questions

Combinsd .......... 75

3. Sequential Rank of Each Item for Three Questions Combined ........ 75

4. Spearman rho Correlations between Utilsty

Indices and liean Ranizs of Ten Suberoups

of Cards for Three Protocols Combined. . . . 84

5. Summary Results for Cards Selected and Time

Taken per Question........ 85

6. Utility Indices and Utility Levels for

Information Items within Catecories. . . . 88

7. Rean Ranks and Relative Ranks for Sequential

Selection of Information Items by Categories . . 102

8. Utility Indices and Mean Ranks of Information

Catecories for Three Questions . . . . . 117

9. Some Items Showing Differential Utility

Amone Questions. . . . . . . . 118

10. Kendall Coefficients of Concordance for Three

Questions Based on Sequence of Card

Selections . . . . . . . . . 121

11. Percentage of Cliniclans Answering Each

Alternative for Three Questions. . . . . . 127 


\section{STATELENT OF PURPOSE}

Experimental studies have falled repeatedly to provide satisfactory evidence of Rorschach validity. Yet the Rorschach continues to find widespread application in academic settings and in clinical practice. Although the Rorschach has not proven itself to be experimentally valid, it has shown itself to be clin1cally useful. The need for research which might clarify the validity-utility discrepancy characterizing the Rorschach is clear.

The Iine of approach taken in the present study is based on findings and trends from recent Rorschach 11 terature in the area or clinical judgment. This approach involves taking a closer look at the interpretative procedures employed by experlenced Rorschach clinicians. For, despite the wealth of evidence contradicting the validity of Rorschach's technique. it is the clinlcian who continues to affirm the value of this technique. It Is the clinician who continues to employ the Horschach as the basic projective tool in his professional work. Relnforced by the behavioral support of many of his psychiatrist associates who continue to refer patients for psychological--typically Rorschach--evaluation, it is the clinician who claims that the Rorschach is successful in clinical applications. 
The ldea of 1nvestigating the cliniclan as he implements the Rorschach in practice is not new. Armitage et al. (1955). for example, cited the need for further explorations into the utility of the Rorschach. Hertz (1959). who has placed much of the blame for past Rorschach validation failures on clinicians, expressed a similar sentiment.

Indeed there is a need to do research on selection and trainine methods, on the clinician himself, and the clinical process.... In the interpretation of a record, it is clear that Rorschach clinicians must exercise some self-discipline, standardize procedures to the extent to which they can be standardized, develop a consistent body of normative data, and train clinicians to handle the Rorschach as it should be handled (p. 47).

In the present study, clarification of the discrepancy between Rorschach validity and ut1lity will take the form of providing answers to the fundamental question as to how, in practice, the experienced clinician uses the Rorschach. The primary aim of the study, therefore, w1ll be to ident1fy the sources and patterns of Rorschach ut111ty. Identification of the sources of utility relates to the question "Whet data do cliniclans use in Rorschach interpretation?" Identification of the patterns of utility relates to the question "How do clinicians use data in Rorschach interpretation?" Analyses will be made of the types of Rorschach data used by clinicians and of the relative importance these data hold for clinicians, especially in relation to different clinical questions. Interactions between quantitative and qualitative approaches to Rorschach interpretation will be considered, alone 
With the clinicians' theoretical orlentations (Beck or Klopfer). Clarification of the secondary question in this study, that of Horschach validity, will take two forms. First, the actual ovtcomes of Rorschach interpretation will be enalyzed and related to the type of clinical question asked, to the criteria against which the outcomes have been evaluated, and to ant1c1rted differences anone clinicians in their interpretative procedures. Second, some of the Rorschach data traditione.11y hypothesized to have value in answerine particular clinical questicns vill be analyzed in order to determine whether such value actually is revealed in forschach practice. For example, Rorschech shading deteminants traditionally have been hypothesized to be anxiety "Indicators," while location scores have been vieved as "estimators" of intellectual functioning. The attempt here will be to determine thether the relationship between hypothesized and actual use of these scores appears.

The present investigation of Rorschach implementation will ellow some determinations to be made as to whether the clinIcian's practice is consonant with the theoretical Borschach franework on which his interpretat1ve processes are based, the framework which has been the starting point for a good deal of unsuccessful research. Answers to other questions of stylistic differences among clinicians, differences in approach between successful and unsuccessful cliniclans, relative influences of deterninant and content approaches, card preferences, etc. also 
might be suggested by data obtalned from the study. These latter questions, however, will not be dealt with in the present study, but will be reserved for future consideration.

In sum, anong the aspects of Rorschach interpretation to be anelyzed in this study are the following:

1) the type of data selected (background data, locations. determinants, content, numerical scores, verbalizations and behavioral observations, etc.);

2) the order in which different data are selected;

3) the data which are not selected;

4) the number of items selected, both totally and with in separate scorling categorles:

5) the accuracy of flnal outcome,

6) the time taken to arrive at the final outcome.

The following hypotheses will be tested in the study, General Hypothesis I. The sources of data used by clinicians in Rorschach interpretation w111 vary in their levels of ut111ty. Information categorles based on location scores, determinants, contents, numerical summaries and ratios, background data, etc. w111 not show equal levels of usage. Variations will be observed both within a single proto$\operatorname{col}$ and amone different protoools. The utility levels of the different sources of information will vary primari1y as a function of the type of clinical question asked in relation to each of the Protocols I. II. and III.

Protocol I (diagnosis): Qualitative data will be given greater emphasis in interpretation on Protocol I, as compared with Protocols II and 
III. Greatest emphasis w1II be on the qualitative form of the response, the response per se (e.g." "a bat"), and on verbelizations and behaviorel observations. Some initial emphasis may be given to quantitative data but this emphasis mill be temporary only, geared toward cainine a general orientation to the protocol. The ut1lity level of the hockeround data will be hichest for Protocol I, as compared with protocols II and III.

Erotocol II (anxiety), Quantitative data will be given ereeter emphesis in interpretetion on Protocol II, as compared with Protocol I (but not vith Erotocol III). Initial quantitative emphasis w111 occur (as in Protocol I), and will persist (in contrast to Protocol I). Greatest emphasis will be on determinants as a source of information. Sequentially later enphasis will be given to qualitative data. principally to the responses per se. This sequential change in emphesis w111 be influenced by two factors, 1) the relative absence of theoretical anxiety indicators from the determinant scores, and, 2) the request in the cinlcal question for conclusions that would link anxiety with heightening events and defenses. Quantitative and qualitative usages will show greater balance on Protocol II, overalI, in contrast to the qualitative emphasis predicted for Protocol I and the quantitative emphasis for Trotocol III. The utility level of background data will be lover for Protocol II than for Protocol I, but higher than for Protocol III.

Erotocol III (inteli1gence): Quantitative data will be given greatest emphasis in interpretation on protocol III, particularly locetions as a source of information. Final conclusions will be reached on the basis of less data. es compared with Protocols I and I.. The utility level of background data w111 be least for Protocol III.

General Hypothesis II. Clinicians w111 show distinguishable patterns of approach to Rorschach inter-

petation.

Hypothesis IIA CIinicians generally will proceed from qualitative to quantitative sources of Rorschach data in their interpretations, apart from some brief, initial quantitative focus for purposes of general orientation. 
1yonthesis II CInicians characterized by a quantitative approach to interpretation w11?

show a reletively lover ievel of success 11 estlnating the severity of enxicty on Protocol II than clinicians characterizod by a qualitat \&ve epproach, becavse of the abse ce of theoretical determinant indicators of anxiety in the protocol (shoding. Inanimate movement).

Cenere? Hyoothesis III, CIIntcal sccuracy w11] vary for the different orotocols, as a result pri-

marily of the troe of clinical question asked.

Eypothes1s IIIA: Clinical accuract W111 be nicher at the nore general levels of interpretation then at more specific levels.

Wyothesis IIIB CIinical accuracy will be nicher for protocoI III than for Protocols I and II.

Eypothesis IIIC, CIinicians interpreting from Beckian and Hopferian orientations W111 show similar levels of success in their final conclusions. General Hyoothesis IV: CIiniclans in the present study Will show a lower derree of self-constancy across protocols than was shown by clinicians in Tabor's (1952) study. because of the three different clinical questions asked. 


\section{SURVEY OF THE LITERATURE}

A. Current Status of the Rorschach

Forty-f1ve years have passed since Hermann Rorschach first published his ink-blot experiment. Today, Rorschach's technique is among the most used, and useful, of the instruments in the clinician's projective armamentarium.

Sundberg's (1961) survey of 185 clinical agencles and hospitals in the United States revealed the Rorschach technique to be outstripping all other psychological tests, both in the number of places that used it and in the amount of such usage. Mills' (1965) survey of the Journal of Projective Techniques and Personal1ty Assessment, 1947-1964, showed the technique to be retainIng its leadership position through 1964. He reported a correlation of .60 between the degree of clinical usage c1ted by Sundbere for the Rorschach and the degree of research usage appearing in the above Journal. Jackson and Wohl's (1965) survey of 96 chaimen of selected psychology departments throuthout the United States and Canada Indicated clearly that the Rorschach was the most emphasized clinical techrique in the graduate curriculum, principally at the introductory level.

Rorschach's blots have exhibited a far less favorable status on the research psychologist's register. Desplte the accumulation 
of some 3,000 research studies and texts in which countless features and relationships of the blots have been explored, the validity findings remain inconclusive. Rorschach's inkblots have introduced unconventional probiems and have required statistical methods which are still imperfectly developed (Cronbach, 1949). All too often the blots have proven to be inaccessible to empirical treatment. Thus, whlle the Rorschach is currently favored as the most widely used test and holds claim to the largest number of publications for a sinele test, its validity has yet to be demonstrated by a statistical means under conditions of controlled observation.

The inability of experimental researchers to demonstrate Rorschach validity represents the recurring theme in Rorschach evaluations. Hertz $(1942,1952)$ twice has concluded critical reviews of Rorschach 11terature by stating that pest evidence for Rorschach valldity at best has been uncoordinated, tentative, and suggestive. Hunt (1950), writing in the first Annual Review of Psychology, judged traditional Rorschach technique to be inapproprlate as a clinical method. Cronbach (1956) never has regarded the instrument as sufficiently precise or livarlant for use in clinical decision-making. His own attempts to break down the technique's experimental resistances have galned little reinforcement from Rorschachers. Improvements in research designs and statistical methods in Rorschach studies have been minimal. Jensen (1958) stated outright that the Horschach was worthless as a research instrument, having nothing to show for its 
applications in the personality field. Ainsworth (1954), in tones far gentler than those of most evaluators, has cited the need for this "partiy finished" Instrument to be brought to a more finished state. Eysenck (195\%) has compared the clinical accuracy of the Rorschach technique with the chancy effectiveness of a diagnostically-labeled d1e. Wrote Jackson and Wohl (1965).

One becomes very curious as to what specific effects research has had. In spite of voluminous studies with negative findings and research reviews which are extremely critical (Buros, 1959, pp. 276-279), [psychology] instructors supported Rorschach practices in a manner expected of those who reject such research as inappropriate and 1rrelevant to Rorschach work (p. 132).

The discrepancy between clinical-academic utilization of the Rorschach and experimental fallures to demonstrate Horschach validity has been assoclated in recent years with a number of turnabouts in psychologists' thinking about the blots. Alternative inkblot instruments have been developed (Holtzman, 1958, Levy, 1948, Harrower, 1945, Zul11ger-Behn, 1952), each accompanied by 1 ts om cache of research. Studies by Lazarus (1949) and Silpola (1950) have stimulated dramatic reconsiderations of the significance of color and color shock in Rorschach theory. Stimulus qualities of the blots have been given increasing attention (M1tchell. 1952, George, 1955; Baughman, 1954, 1965).

Comparisons may be made between traditional Rorschach thinkIng and current trends in support of the conclusion that there have been "turnabouts" in Rorschach thinking. In Psychodiagnostics. Hermann Rorschach introduced his inkblots by stating that 
they lent themselves to interpretation as "accidental forms. that is, of non-specific forms" (1942, trans., p. 51). Most workers today do not accept the ldea that the blot stimuli are neutral. They regard the separate blots as having distinct "card pull" (Ranzoni, crant, and Ives, 1950; Klopfer, et al.. 1954), and may refer to specific areas of the blots as being symbollcally meaningful (Brown, 1953), or even clinlcally predictive (Sapoleky, 1963).

In another statement, Rorschach also wrote that

In scoring the answers given by the subject, the content is considered last. It is more important to study the function of perception and apperception. The expertment depends primarily on the patterm $(p, 19)$.

Yet Zubin (1956), pialniy reversing Rorschach's original intention, has made a strone plea for shiftine the emphasis from the perceptual to the content aspects of the blots. Zubin's shift would eliminate the perceptual scorings on which Rorschach based his test, and would lead to a conceptualization of the test as a "systematic interview behind the veil of ink-blots" (p. 189). Other recent workers have favored a content approach to Rorschach interpretation (Elizur, 1949, wheeler, 1949; Lindner, 1950; Brown, 1953).

According to Gordon (1959), Rorschach responses are cons1dered "samples of verbal behavior." The influence of some stimulus component, such as color, thus may hola less importance than the test subject's ablilty to verbalize the stimulus itself. No one-to-one correspondence is assumed between actual and ver- 
balized determinants. The Rorschach response is therefore not defined as directly perceptual. When a test subject spontaneousIy reports some instance of bizarre content, the principal meaning this holds for Gordon is that of "poor soclal judgment," the latter always being of Interest to Rorschach examiners.

Wagoner (1963) reformulated the thinking of Zubin and Gordon

along a severer I1ne by suggesting that response patterns are "really nothing but the number of times $S$ has used nouns, verbs, and adjectives" (p. 419). A rejoinder to his proposal to stress the primary grammatical aspects of responses was made by Arnold Binder (1964). However, Binder, admittedly blased in favor of the perceptual framework, was able to offer only his personal feeling that Wagoner's approach was misdirected.

Sarason (1954), In what Cronbach lauded as "the first major report on Rorschach which simultaneously adheres to the standards of scientific psychology and reflects falthfuliy the clinloal use of the test" (1956, p. 183), descr1bed Rorschach test performance as purposeful problem solving. The latter description conveys an emphasis on the cognitive aspect of personality functioning not origlnally conveyed by Rorschach himself.

Underlying the turnabouts in Borschach thinking have been the repeated fallures of traditional frameworks to provide def1nitive evidence of val1d1ty. The Rorschach, however, survives. The situation is similar to one described by Frank (1961) who. while writing of the difficulties psychoanalysts have had in attempting to validate their slightly older theory and clinical 
procedures, reports that successful cases strengthen the underIyinE conceptual scheme while fallures seem not to shake it. Nor, to be sure, do other of the projective instruments commonly employed in clinical settings stand in better stead (Murstein, 1963). In the case of the Rorschach, one may legitimately wonder whether the method has remained unshaken (Challman, 1951, p. 241). The following criticism made by one prominent Rorschach expert of another may be considered representative of the existing state of Rorschach confusion.

Except for the use of Rorschach's ink-blot figures and some of his letter symbols, the technique has now so little in common with Rorschach's test, either in method or in some important basic presuppositions, that it represents a quite different approach.... It would go far in clearine up the present state of confusion if Klopfer and his associates ceased to Identify their method by the term "Rorschach" (Beck, 1959, pp. 273-4).

The starting point of the present study was the recognition that there was a major discrepancy between Rorschach ut1lity and Rorschach validity. The theoretical supposition was that before clinical Rorschach theory could be translated more intelligently Into experimental design as adduced by Cronbach (1956), clinical Implementation would first heve to be examined more closely. particularly as this implementation came about through the act1vities of the professional clinician. Deeper understanding of Rorschach utility must precede more meaningful understending of Rorschach validity.

It would not appear to be colncidental in this regard that Beck, after hav1ng produced three instructional texts grounded 
in "sound, normative method" (1945, 1952, 1961), and after having conducted extensive normative samplings of schizophrenic and normal populations, wrote in his 1960 text that his effort was "not to prove the test's validity but to demonstrate 1ts working processes" (p. 8). While commenting upon the experimental nature of his Rorschach venture, he conditionally dismissed the dearth of validating data as an incldental shortcoming.

Ainsworth (1954) has stated that "there is no sharp dividing Iine between valication research and the clinlcal use of the Rorschach technique" (p. 406). She sees the two as golng hand In hand. Her thesis that the Rorschach can be investigated most productively by classifying it less as a "test" of personality and more as a method of observation and appraisal reflects the lack of clear differentation between the two outlooks. Her view touches upon Zubin's (1954) conceptualization of the Rorschach as a velied interview.

Recent Rorschach studies have shown increased consideration for the slgnificance of the concept "clinical use" in their designs. Chambers and Hamlin (1957). for example, are among those who have reiterated that "As the Borschach is used in actual clinical practice, the cliniclan and the tool are an entity" (p. 105). Alnsworth would be in agreement here.

In sum, there are two general areas relevant to questions pertaining to Rorschach validity. Each area may be viewed as preceding actual validity study. Both have remained relatively unexplored in Rorschach research. The first area has to do with 
the interpretative processes of clinicians as the latter put the Rorschach to use. The second area concerns the nature of the interaction which occurs between formal and content approaches to Rorschach interpretation. The writer's belief was that these two areas could be meaningfully combined into a sinele research study. The study, while bearing a relation to the question of Rorschach validity, would be primarily concerned with Rorschach utility. The study would attempt to determine what the Rorschach cIinician uses in Rorschach interpretation and how he proceeds in his utisuation of Rorschech information.

B. Interpretative Processes of Cliniclans

Interest in clinical judgment appears to be on the increase In this country. Honry Murray (1943) was amone the flrst to direct attention to "psychology's forgotten instrument," the clin1clan. Hunt $(1946,1965)$ and Hamlin et al. (1954, 1958) have since been active on the problom of validating the clinician. Hunt has directed his investigations toward the clinical use of Wechsler's intelligence scales. Nost of Hamlin's investigations of the clinician as judge have employed the Rorschach. It is ev1dent, however, that as a ceneral treno research interest in clinical judgment on the Rorschach has lagged behind longtime recognitions of the instminent as being "a highly complex multidimenslonal instrument which requires the full ut1lization of the sk1IIs of the cilnician" (Hertz, 1959, p. 46). 
As phrased by Hortz, it is the critical eye of the clinician which leads to appropriate understandins of an individual's personality structure and the dynamies underlyine his behavior. Individuals show wide-rancing, often subtle, levels of adaptive and defenslve behavior. Appropriate understandine thus must taise into account a larce nuber of personality varlobles, inclvding intellectual functionine, anxiety, inter-personal relationships, enotional stability, degree of integration or disintegration, and the direction and scremity of ans personality deviation that may be manifester.

Although many of the relationships between traditional Rorschach variables and an individual's needs and behavior remain hypotheticel, these assumed relationships are applled regularly, often routinely, in clinical settings. Contraindications for routine application of Rorschach responses and scores have come from nemerous fronts. Rorschach workers themselves are quick to acknowledge that sincle test factors or test conficurations carry a variety of interpretative meanings, depending upon the total context of the test data (Sarsent, 1954) and the personality of a given subject (Beck, 1935). They recognize that the same psychological trait nay not be equivalent in the personalities of different individuals. Rule-or-thumb "signs of normality" were termed "inadequate" on an empirical basis by Brockway, Gleser, and Ulett (1954). One specific alcoholism "Indicator"-water responses-was found to operate successfully in Kentucky, but not in hassachusetts or Washington (Griffith, 1961). Inkblot perceptions may 
be affected by sex, age, race, intelligence, education, soc1oeconomic background, test situation, examiner characteristics, and other Influences whose importance is only beginning to be evaluated systematically. The end result of this awesome Rorschach complexity has been to make the effectiveness of the Rorschach technique highly dependent upon the skills of 1 ts clinical users.

...the user of the method must rely upon a body of guesses as to the relationships involved--including those which have accumulated in the 11terature, plus his om experience with the test in particular, and knowledge of normal and abnormal personality in ceneral (Schnelder, 1950, p. 493).

One study whose results bear out the practical import of the above discussion was done by Chambers and Hamlin in 1957. Twenty psychologists were asked to Identify Rorschachs according to cIInical Eroups. Each psychologlst recelved one record from each of five out-patient groups: involutional depression, anxiety neurosis, paranoid schizophrenia, brain damage from neurosyphi11s, and adult mental deficiency. Twenty sets of flve Rorschachs thus were used, each record belng judged four times, ylelding a total of 100 judements for the study. Under the type of favorable forced-cholce conditions employed, ldentifications were found to be at a level signiflcantly better than chance. However, intergudge differences were large. Five judges contributed nearly 50 per cent of the correct Ident1fications (25/58), while six judges contributed less than 10 per cent $(6 / 5)$. The authors did not consider this degree of success to justify "expansive claims" for the Rorschach as a technique for ldentifying patient groups. But they did feel 
"reasonable claim" to be justifiable, particularly when the psychologists were broken down into subgroups according to their degree of success in making diagnostic judgments.

A number of relevant observations on Rorschach interpretation may be derived from Chambers and Famlin's findings. First, highly successful use of "blind" Rorschach protocols is possible for some clinicians. Second, successful judges reveal interpretative approaches that differ from those of unsuccessful judges. Success ful judges, for example, tend to reach a higher level of abstraction from the raw data. They show conslderable flexib111ty in shifting from one level of interpretation to another, sugeesting Ereater capacity for adaptiveness and selectivity in relation to the data. They tend to be free of adherence to textbook statements and traditional "siens." They use fewer words to communlcate their thinking. Third, significant differences can be noted in the level of diagnostic difficulty for the various clinical sroups. Mentally retarded adults, for example, were show to be ldentifled correctly in 90 per cent of the cases. The remaining four groups were ldentifled with only 51 per cent correctness. The authors noted that the hichest single misinterpretation occurred between the organic and paranold groups, organic patients being misjudged "paranold" in seven out of twenty instances.

Other variables influencing Rorschach interpretation may be c1ted. Iamlin (1954) reviewed ten studies dealing with the clinIclan as judge. He reported the pattern of results in these studies as confirming his hypothesis that positive or negative 
outcomes in Rorschach research are directly related, first, to the simplicity or complexity of the material to be judged and, second, the adequacy of the experimental conditions in allowing the clinician to derive judgments from the material. In general, the more complex the materlal to be judged, the more negative the outcome. Among his conclusions was that

... Increasing complexity beyond a certain point probably does not lead to meaningful global understanding. except under 1deal conditions or in a clinical situation where data can be cross-checked, discarded as not pertinent, or synthesized in a manner that eventually results in a simpiffled picture derived from complexity (p. 235).

The relationship Hamlin cites between the complexity of the Horschach material and final outcome holds obvious meaning for Rorschach validity res arch. Interpretat1ve conclusions arrived at from exanination of minimal data may not be directly comparable to those arrived at on the basis of maximal data. Differences in levels of clinical specification and the degree of subjective certainty of Rorschachers may have to be given greater consideration than they have been given in the past. As for the adequacy of the experimental conditions in allowing the clinlcian access to the material to be judged. Hamlin's conclusion may be interpreted to mean that there should be reasonable opportunity for stylistic and Individual differences among Rorschachers to operate in interpretation.

Cummings (1954) also reviewed the 11terature in the area of Rorschach judgement. He concluded that of the studies employing projective techniques, those most closely approximating the 
operation of the clinician-in-action often yielded positive relationships, although not uniformly so. Cummines conducted his ow investication, Imiting the avaliable data to single Rorschach card performences. He reported his elght judges to show moderate success in their judgements of adjustment for fifty white males, ten of whom were not patients. Comparing his essentie.2y positive results with the negative results obtained in simliar studies (Grant, Ives, and Ranzon1, 1952; Newton, 1954). Cummines pointed out that the latter studies utilized total Rorschach protocols as the judgment unit. He concluded that his less complex, single-card units probably enhanced his Judges opportunities for intensive coverage of the data. The latter observation supports Hamlin's (1954) two conclusions about the influence of complexity of materlal and adequacy of experimental conditions as variables in Rorschach studies. Powers and Hamlin (1957) 11m1ted the amount of data to be judged even further than did Cummings. They presented six experienced judges with Card-I. responses of a 34-year-old male out-patient. They found that their clinicians were able to make "reasonably valid statements" from this limited data. Two levels of the judgment process were designated. one descriptive and one speculative. In support of Symonds' (1955) rindings, soon to be discussed, it was found that cliniclans tended to rely more on content factors than traditional determinant scores to back up their inferences. Determinant scores 
were called upon secondarily. Powers and Hamlin further noted that success in Rorschach judgment was more characteristic of some areas of personality than of others. The latter finding parallels, on an intraclinician level, what Chambers and Hamlin (1957) observed on an interclinician level. To quote from Powers and Hamlin,

Agreement with the criterion measures was fairly good for the variables of intellectual level, intellectual efflciency, self concept and self attitudes, identification, and anxiety level; and agreement was least adequate for the variables of way in which subject relates to others and attitudes toward others. type of symptomatology, diagnostic category, and emotional control (p. 289 ).

Symonds (1955) sought to determine which aspects of Rorschach data expert clinicians would respond to in making "blind" judgments about a 27-year-old, female, high school teacher. Seven experienced judges were presented with a single Rorschach protocol. Iarge differences were observed in the fullness of the submitted reports and in the accuracy of the interpretations although there was 65 per cent correctness overall. Interpretative accuracy was checked against material revealed during individual therapy interviews. Only 44 per cent of the 204 interpretations were based on traditional Rorschach signs and determinants (accuracy $=59$ per cent), whereas 56 per cent were based on content (accuracy $=74$ per cent). Rorschach Judges again exhibited large individual variations in their patterns of determinant and content usage.

The finding that clinicians at times may rely more heavily 
on content than on determinants in their lorschach interprete tions nay be claripled somewhat by the following statements. First, determinant scores are derived from content responses-the "free associations." A clinician using content may therefore make implicit deterninant scorings which he does not forrally record. Second, the test subjects verbalizations can play ar important role in evaluating their approaches to real1ty and their perceptions. It is Lorenz's (1959) belief that "the formeI pattern of the lenguage response can be used as an index to the perceptual modes congenial to the individual" (p. 440). As the information contained in language patterns is made discernible through analysis of the classes of predicates an 1ndividual selects to represent his perceptions, patterns of emphasis can be determined. alone with special mental states and the degree to which the individual's awareness of external details of stimuli is integrated into his experience.

Rodgers (1957) was another who attempted to ldentify the sources of information entering into forsohach interpretations. He had beginning graduate students prepare descriptive and self-concept Q-sorts from blind Korschach evaluations of two mon-patient males. Although two months of course training prere shown to have a significant influence on the students' interpretations, this influence was quite small (4 per cent of the totel varlance). The protocols themselves accounted for 
20-23 per cent of the variance. Individual aiferences accounted for 15-19 per cent. The remaining 50-58 per cent was unaccounted for, and was considered to be error variance. Rodgers saw the latter as having "sobering import," but indicated that the error variance would be expected to be lowered markedly for experienced clinicians. Course instruction seemed neither to increase nor decrease stereotypy of interpretation.

Newton (1954) compared judgments of adjustment made by ten clinical psychologists with those made by psychiatrists. Figh reliability was obtained in all the judging tasks. The psychologists and psychiatrists were found to be nearly equal in their judgments of clinical case material (.94, .91). Intergroup reliability was lower $(.86)$ but still significant. So too with psychologists in judging Rorschach protocols (.73). However, judgments stemming from Rorschach material were not found to correlate meaningfully with psychologists' juagments of case waterial (.09). Nor did the Rorschach judgments correlate significantly with diagnostic placement of the fifty subjects, ten of whom were described as "socially adequate."

Corsini (1955) related adequacy of clinical judgment to the length of time spent on the judging process. Three psycholoBists were asked to rank Rorschach records of 50 prisoners and 50 hired guards along a continuum of adjustment. One of the psychologists was requested to work rapidly. He tended to make "snap" judgments which proved to be least adequate in comparison 
with the judgments of the two other psychologists. The psychologist who took the longest anount of time showed the greatest adequacy of juabment, reaching a level of accuracy that was silghtly higher than that obtained by a fourth psychologist who had administered the Rorschachs. All three judges performed better than an objective Rorschach checklist in separating the two groups. The importance of length of time spent in interpretation as a varlable in Rorschach analysis was elven mention by Richards and Nurray (1958) in their study. Three clinical psychologists, advanced eraduate students, and nonpsychologists were asked to maire global judgments of masculinity or femininity for 30 horschach protocols. Better than chance sortings were found for the trained psychologists, especially when "adequate time" was provided for making the judgments. No relationship was apparent between theeler's slisns of homosexuality and tendencles toward femininity for males.

The amount of infornation required to arrive at a Rorschach diagnosis proved to be one of the most variable factors in Tabor's (1959) study of 30 clinicians. The variability seened related more to the personal needs of the clinicians than to differences among the three diagnostic problems employed in the study. Intraindividual consistency nevertheless remained high. Int 311 igence estimation represents an area of Rorschach re8earch thich has been of considerable interest to cliniclans because of the consistently more favorable outcomes obtained in 
these investigations, specially when compared with diagnostic outcomes.

In a study done by Bialick and Hamlin (1954), valid and re$112 b l e$ Judgments of intelligence were made by four VA staff psychologists and four trainees. The judgments were based on five Rorschach W responses, from each of twenty-five white, outpatient males. Intelligence was chosen as the fudgment variable because the authors believed it to be the variable that the fudges knew best. Highest correlations were obtained by experienced psychologists, .68 with Wechsler-Bellevue I.Q.'s and .84 anong thernselves.

Davis (1961) too investigated the ability of clinicians to estimate intelligence. In addition to total Rorschach records, he employed summary profiles alone, and lists of vocabulary words taken from the Rorgchach responses. All three of the judges proved to be better than chance $(P<.01)$ in estimating the Stanford-Binet lavels of intelligence of seventy white, male, young adults. Judgments based on the vocabulary lists tended to be slightly more successful than those coming from the total Rorschach records (supporting a similar observation by Trier, 1958). Judgments made solely from the summary profiles were least effective.

Expectediy, not all of the research seeking to determine whether postulated relationships between Rorschach varlables and I.Q. exist has been successful (Klopfer, AlIen, and Etter, 1960; 
Pauker, 1963). "Usually, when low, significant correlations between Rorschach factors and $I Q$ have been found, they have failed to hold up under cross-validation" (Trier, 1958, p. 289). An illustration of this type of fallure is the study by Armitage, Greenberg, Pearl, and Daston (1955). These authors found thirteen out of nineteen Rorschach variables to correlate with Wechsler-Bellevue I.Q.'s at the .01 level of significance (N = 503 patients). However, when they applied their multiple regression equation based on the six variables showing the highest correlation with I.Q. to 207 new patients, no better than chance accuracy in estimates resulted. The authors suggested that vocabulary and quality of perceptual organization may have provided the cues to which their judges were responding. Their judges made fairly accurate estimates when given access to the total protocols.

Trier's (1958) interest was directed toward Rorschach response cues. Twelve near-Ph.D. graduate students were employed as judges, divided equally into three groups. Group I was given sixteen Rorschach protocols, asked to list the seven "most sophif ticated" words from each protocol, and then make I.Q. estimates from these word Iists. Each of the Group II judges, who had no access to the protocols, were given one of the four sheets of word lists compiled by the Group I judges, along with information about how the lists were derived. They were asked to make I.Q. estimates using only the word lists. Judges in Group III 
were given the 16 protocols and then told only to make intellectual estimates from them. Of the 16 protocols, four each were obtained from a diagnostically mixed group of patients in the following I.Q. ranges: 89 and below, 90-109, 110-119, and 120 and above. Estimates of I.Q. also were made from ThorndikeIorge word frequency counts. (The Thorndike-Lorge word count indicates the frequency with which a given word appears among one million words). A number of conclusions were drawn from the study.

1. Estimates of intelligence can be derived accurately from Rorschach vocabulary lists.

2. Judgments based on total Rorschach protocols are no more accurate than those based solely on vocabulary. (This is not in agreement with the conclusion of Armitage et al., 1955).

3. Estimates based on the Thorndike and Iorge word frequency counts resulted in accuracy roughly comparable to that achleved by the juages.

4. Results for Group III are in agreement with those of Armitage et al. (1955), who reported a median correlation of .69 for estimates based on evaluations of total protocols.

Sommer (1958) studied the relationship between Rorschach M responses and intelligence. Test records of 77 male patients who had been given both the Rorschach and the Wechsler-Bellevue were selected for analysis. The Wechsler-Bellevue scores were IItted Into nine I.Q. categories, at 20-point intervals. The correlation between $M$ and I.Q., assumed to be close by Rorschach workers, was supported. The correlation also was supported when Rorschach $R$ and $H$ variables were held constant. A further 
attempt was made to determine whether M responses given by subjects of varying verbal I.Q. could be distingulshed on other than quantitative bases. The $M$ responses were ranked as to intelligence level by three groups of judges: senior psychologists interns, and secretaries. Similar to Armitage et al. (1955) before him, and to Trier (1958), Sommer also noted the influence of such cues as grammar and vocabulary level in contributing to judges' estimates of intelligence. The interns and secretaries, for example, were able to rank qualitative differences in verbatim $M$ responses at a level that exceeded chance expectancy. Unlike the other investigators, however, Sommer showed that when the verbatim cues were removed, only psychologists were able to make successful I.Q. estimates. This suggested that cues other than vocabulary and grammar are present in Rorschach $M$ responses.

\section{Approaches to Rorschach Interpretation}

Approaches to Rorschach interpretation may be classified broady into two categories: the numerical or "sign" approach and the descriptive or "content" approach. The sign approach is best represented by Buhler, Plotrowski, and Klopfer. Piotrowski's ten signs of organicity, for example, are well known to clinical Rorschachers, as are the quantitative determinant formulae and ratios of Klopfer. The content approach may be represented by Phillips and Smith, Schafer, and Beck. Schafer's emphasis is on thematic analysis, while Beck stresses sequential 
analysis. Although neither approach remains exclusive in clinical practice, Beck (1942) has indicated that the criteria of the two are different and that validation is within two totally different spheres of reference. Armitage and Pearl (1957, p. 479) have written along similar lines.

Investigators report varying success in relating test characteristics to specific diagnostic categories. Some of these characteristics are the preaence or absence of certain of the Rorschach determinants, their relative strength, patterns, ratios and their adherence to acceptable criteria. Other methods have relied more heavily upon the content of the record and its characteristics, while still others have employed both content and determinants in various combinations.

The Jackson and Wohl (1965) survey of Rorschach teaching in American universities indicated that half of the academic respondents (47 per cent) relied on both psychogram and content data in making Rorschach interpretations. When each was considered separately, however, content data reportedly were given four times the emphasia given to psychogram data (38 per cent: 9 per cent). The secondary emphasis reported for the psychogram data Is especially noteworthy because 69 per cent of the respondents wrote that they typically constructed formal psychograms as part of their Rorschach preparation.

The question of whether it is the determinants or the contents that possess greater importance in interpretation is consldered by Shapiro (1959) to be unanswerable. Each dimension 18 required for optimal understanding of the other. Maximum interpretative accuracy results from consideration of both dimene10ns. Shap1ro does not suggest, however, that determinant and 
content interfretations correspond in any fixed, one-to-one relationship.

My aim is not to convince you that you should rely just equaliy on content and on determinant interpretation in Rorschach work. It seems to me that perfectly legitimate differences of interest, natural inclination or background will tend to cause each one to give more weight to one side than to the other. Also, there is no doubt that there are differences in this respect among different Rorschach protocols; some, quite legitimately I think, seem to co.ll for more emphasis on content interpretation. The aim here is, rather, to show that there is no reason intrinsic to the test to consider one aspect more important than the other, and, in addition, to show that each aspect can be properly understood only in the light of the other (p. 368).

Few protocols illustrating the actual working processes by which clinicians evaluate Rorschach responses have appeared in the journal Ilterature, although they have appeared relatively more frequently in Rorschach textbooks. Those protocols which have been offerred as illustration have tended to highlight the clinician's use of nonclassical, nonquantitative variables in the interpretative process. Hamlin and Powers for example, concluded in their 1958 study that experienced clinicians draw upon "a wide variety of cues, many of which show little relation to traditional Rorschach scoring categorles" (p. 242). Such cues might not be identical from case to case, or from judge to judge Levine's (1959) objective was to explain why investigators were unable to obtain positive findings when the Rorschach was used to make prognostic predictions of patient status following a period of hospitalization. He suggested that fallures in this area may have been the result of an unselective empirical 
approach. "It is possible that these unsuccessful investifators have been scoring the Rorschach for 'traditional' Rorschach categories while clinicians utilize different variables, perhaps without scoring them, in their day-to-day work" (p. 439). Levine's view challenges that of Zubin and Windle (1953), who concluded flatly that the Rorschach had no value in making prognostic predictions.

The question of which Rorschach data and cues clinicians may be utilizing in their interpretative analyses is an important one. Most validity studies done on the Rorschach have been based on the assumption that traditional variables are the ones being used most weightedly by Rorschach workers. Yet it is not at all clear that Rorschach workers do utilize traditional variables in theoretically directed ways. As seen in the statements of Hamlin and Powers (1958), Levine (1959), and Armitage and Pearl (1957), there is evidence to the contrary. Utilization of Rorschach data is a complex process. The process is not always a consistent one. When investigating clinical implementation of the Rorschach, therefore, it would be essential "to ascertain those aspects of Rorschach utilization which contribute to [success] and to determine whether or not these aspects vary...." (Armitage and Pearl, 1957, p. 479).

Hamlin and Powers (1958) recorded the running comments of experienced judges as they made diagnostic judgments between paired psychotic and nonpsychotic responses to single Rorschach 
cards. Included in the responses were inquiry information, time notations, and some minimal behavioral data. The judges were requested to write a brief report for each pair of responses. The report was to indicate the judges' reasoning as they proceeded in thein snalyses, the specific elements that influenced the development of their diagnostic choices, the final choices made, and the degree of confidence the judges had about each of their choices. Each of the three clinicians made fifty judgments, twenty-five independently, and twenty-five in joint conference. Immediate feedback was provided regarding the correctness of each judgment as it was made. The results of one protocol analysis, termed "representative" by the authors of the study, suggested that expressive response material was the variable chiefly drawn on by the psychologists to provide them with clinical cues. The psychologists were found to give little emphasis to "unconscious factors" or to classical stmuctural indicators. The general interpretative procedure that was seen to emerge went as follows:

In this example, the judge selects the non-psychotic tentatively, but correctiy, on the basis of the first few words. This rapid, often correct, "hunch" was characteristic in the majority of the 100 choices. The judge then builds up several general inferences: (a) the non-psychotic is reacting to the examiner with affect, and with patterned defenses; and her expressions of uncertainty are related to this pattern; (b) the psychotic is uncertain of his perceptions; (c) the psychotic becomes "typically" both vague and concrete in groping for detalis to elaborate his responses; and (d) the psychotic cannot keep track of what he has communicated to the examiner ( $p .242$ ). 
Artificial limitations present in Fanlin and Powers' study need to be considered in evaluating the generality of their findings. One limitation involved having the judges hase their evaluations only on pairs of single responses. In actual Rorschach practice, analysis is based on the total number of responses given by a subject, in the context of an entire protocol. The observed reliance on "the first few words" thus could be expected to be peculiarly enhanced by the experimental setting. With little of the usual data available on which to base their judgments, the psychologists' educated "hunches" might have been practical necessities. A second limitation centered about the psychologists' receiving iminediate feedback regarding the correctness of their selections. Exterral feedback of this type seldom is available to clinicians in a clinical setting. "Learning," peculiar to the experimental setting, may have been in operation. A further point of interest had to do with the extent to which the representative judge in this study oriented her interpretative framework toward the test subjects' interpersonal relationship with her. If representative, the example suggests that psychology's forgotten instrument may not be "forgotten" after all, at least as far as the Rorschach is concerned. Armitage et al. (1955) undertook a clarification of some of the variables contributing to accurate estimations of four Wechsler-Bellevue intelligence levels from Rorschach data. Two approaches were employed: an objective statistical procedure and 
subjective judgments by three VA staff psychologists, steming from either psychograms or complete protocols. Predictions of intellectual level were found to be least accurate for the strictly objective method of analysis. The "unproductive" results of the latter were found both when the analjsis was confined to single Rorschach variables and when combinations of variables were used, as in a multiple regression equation. The authors concluded that it was doubtful whether any objective prof cedure could prove useful for individual prediction.

Greater accuracy of prediction resulted from the judgmental approach, which allowed for "the integrating factor of the clinif cian." Judgments based on the psychogram data yielded less accuracy than those based on the entire protocols, but more than that yielded by the objective approach. The difference in accuracy occurred despite utilization of the same Rorschach information in both approaches.

This suggests that the clinician makes use of these factors in a somewhat different way than can be accomplished through the objective analysis. It seems probable that he may be able to assign more subtle weightings to constellations of these factors than was possible in the objective aspect. Furthermore, the clinician probably capitalizes on inferences from such additional, subjective factors as (a) the use of specific content categories (e.g., science), (b) the kinds of blends utilized, and (c) the apparent presence of extreme anxiety (p. 327$)$.

The Judges' estimates, termed "fairly accurate" for most instances, were not sufficiently great for individuet proctotion. or for serving as substitutes for Wechsler-Bell fore scores. UNIVEFSITA 
Intrajudge and interjudge consistencies generally were favorable Individual differences among judges were highest in relation to neurotic protocols. When asked to list the reasons and methods underlying their intelligence estimates, the protocol judges cited qualitative factors of vocabulary and perceptual organization as having aided them most.

The inclusion by Armitage et al. of protocols obtained only from pathological samples would be expected to complicate the making of accurate intelligence estimates. The judges first would have to evaluate emotional status and relate the influence of this to intellectual potential and efficiency. From the standpoint of objective estimators in judgment studies, one factor which would have to be taken into account is that of access to past "experience." A continuing objective process, such as an updating computor program which would provide feedback from past successes and unsuccesses, would offer a broader, more "realist1c" framework for increasing accuracy than that found in the "stat1c" type of objective approach used by Armitage et al. The updating feedback program would be analogous to "clinical experience."

Armitage's finding that judgments made from total protocols were more productive than those made from psychograms supported an earlier suggestion by Caldwell et al. (1952) that there was a tendency for clinicians' ratings based on maximum information to agree more closely with psychiatric ratings than with those 
based solely on scoring summaries. As the amount of Rorschach data available to the clinicians was reduced, the degree of psychologist-psychlatrist discrepancy was increased.

The discrepancy between the psychologists and psychiatrists in Caldwell et al.'s study, was not a major one. Also, surprisingly little loss in Rorschach sensitivity occurred as the level of data was reduced. The authors had hypothesized that certain of the specific item contents would be vital for correct diagnostic interpretation, and that without these contents, analysis would be hazardous indeed. Three levels of data availability were defined. Level I included the subject's entire behavior: speciflc responses, scoring symbols, and test behavior. Level II included the response protocol only, as it would be given in "blind" diagnosis. Level III included only the scoring summary, as it would be given in a psychogram. What surprised the authors of the study was that the quantitative categories, by themselves, could be utilized meaningfully by the three psychologists, each of whom had had at least three years experience. Whlle individual Rorschach items did show differing degrees of success in final ratings, sole reliance on the quantitative data appeared to sacrifice little information.

Findings from a 1957 study by Armitage and Pearl supported those of the caldwell study. Armitage and Pearl used five VA staff psychologists who had had four to nine years diagnostic experience with the Rorschach. Each psychologist was asked to 
make 180 diagnostic judgments of patients distributed among four psychiatric classifications: neurosis, character disorder, and paranoid and unclassifled schizophrenia. Sixty judgments were made under each of three conditions--psychogram, protocol, and the combination of both. The number of judgments was limited to ten per day, in order to relieve boredom and to minimize possible distribution biases. (No significant differences later were observed between the judges in their use of a particular diagnosis.) The psychologists were informed that they could employ any method of judgment they desired and use any cues they could obtain from the material presented to them.

...no significant differences were found between judg-
ments based on either psychograms, protocols, or both.
Although missing the criteria of significance, some
indications were present that the psychograms were
somewhat better for the prediction of the neurosis and
that the protocols permitted a somewhat more accurate
judgment of paranold schizophrenia (p. 482$)$.
Thus, it has been recognized that some types of Rorschach data may possess greater differentiating value than others in the evaluation of different psychlatric groups. The greater variability that occurred among judges with regard to the neurotic records compared to the schizophrenic ones raises the question of whether diagnostic category has been controlled for as a variable in past research designs.

Sherman (1952) tested the hypothesis that formal Rorschach factors have greater value than content factors in differentiatIng schizophrenic from normal groups. His hypothesis generally 
was supported, although less so when level of education was controlled, and only when the total number of responses was low ( $R$ less than 19). The results were not found to hold for similar interpretations of sentence completion tests, which had been administered with the Rorschachs. The chief implication of the study was that "schizophrenics and normals do not differ as essentially in the literal context of their expression (content factors) as they do in their manner of organization of expression (formal factors)" (p. 230). For Rorschach diagnosis of specific psychiatric groups, therefore, the clinician sometimes would be expected to direct his attention to data pertaining to personality structure, and sometimes to data related to the more manifest meaning of a patient's expressions. Second, with regard to research design, the influence of high $R$ and low $R$ in Sherman's study again points to the need for Rorschach $R$ to be controlied in Rorschach ralidation studies.

In a sign study of deviant quantitative and qualitative factors, Bradway and Heisler (1953) were unable to find any Rorschach determinant or content score that might have an exclusive relationship with a single diagnostic category. Some statistical trends did appear. Among the 100 protocols, for example, no protocol with an $R$ greater than forty, nor with a $P$ greater than seven, proved to by psychotic. A disproportionate number of cases with an $R$ less than eight were found to be depressive. Irequency of occurrence of "eyes" and self-reference responses 
were slightly above expectancy for the paranoid patients. These trends are consistent with some of the standard thinking which has developed regarding the interpretative significance of single Rorschach scores. On the other hand, other trends reported by Bradway and Helsler contradict traditional lines of interpretation. Bradway and Heisler concluded by cautioning that no Rorschach factor or Rorschach content be considered pathognomic in itself. They renewed the emphasis on the need for integrated, holistic evaluations of Rorschach data.

Sherman's hypothesis was not supported by Bower, Testin, and Roberts (1960), who investigated the diagnostic capabilities of three types of quantified Rorschach scales to differentiate among groups of hospitalized patients. The scales were derived from content, thought processes, or determinants, and were believed to be sensitive to different levels of ego functioning. The conceptual framework for the latter originated in a positions-on-continua theory of emotional illness in which the various psychiatrlc classifications were seen as representing differing levels of maturity in object relations.

The scales were applied to thirty cases each of obsessivecompulsives, personality trait disturbances, psychotic depress1res, and catatonic and paranoid schizophrenics. The content Bcales appeared to differentiate the schizophrenic groups better than did the determinant scales, but they did not differentiate depressives. The determinant equation alfferentiated the non- 
schizophreric groups, selecting out depressives, but tended to misclassify the schizophrenic groups. The thought process scales contributed to diagnoses in a general wey, but lost their power when broken down into subscales. When relevant background variables such as age and education were introduced and combined with the Rorschach data, the agreement of Bower, Testin, and Roberts' discriminant function equation with original diagnosis was elevated from 56 per cent to 76 per cent.

The influence of educational background data in enhancing diagnostic efficiency is mentioned in the studies of Sherman and of Bower et al. The desirability of controlling for such background influences in Rorschach research thus is reinforced. This control was present in the 1957 study by Chambers and Hamlin, in which the ages of the patients whose protocols were judged were intentionally withheld. It was felt that age might serve as a clue to the identification of particular diagnostic groups.

Grant, Ives, and Ranzoni (1952) conducted a study in which three Rorschach experts rated four levels of adjustment of normal eleven-year-old boys $(N=71)$ and girls $(N=75)$. Each protocol was sorted three times, into four adjustment classifications: I--very maladjusted, II--moderately maladjusted, III--fairly well adjusted, and IV--very well adjusted. Rorschach information was provided in successive increments, with the diagnostic sorts being made, first, according to formal scoring categories, 
second, according to the distribution of the formal categories among the ten inkblots, and, finally, on the basis of the whole protocol.

The Rorschach ratings were correlated with criterion ratings of case workers, derlved from interview and case history material. The authors could conclude only that the Rorschach, used blindly, was of little value in predicting external ratings of adjustment. "Our confldence in the ability of the Rorschach workers to analyze records of normal subjects for use in group research has suffered" (p. 17). Their conclusion stemmed from correlations that were low positive, and from consistent placements of 60 to 70 per cent of the apparently normal protocols into "maladjusted" categories.

Grant, Ives, and Ranzonl explained that the Rorschachers' predictive ab1l1ty had suffered because it had been grounded in a basic set toward conventionalized indicators of maladjustment. Rorschacherg' lack of famillarity with the patterns and divergencles of normal individuals was criticized. Further study of adequately functioning individusls was suggested as the means necessary to overcome this clinical deficiency, and to counteract biases toward the abnormal in Rorschach interpretation.

The conclusions of Grant et al. merlt closer examination. The conclusions are important ones. In part, they require qualif flcation. They are also open to question with regard to the subJect sample from which the conclusions may be generalized. One 
qualificution relates to the use of interview and case history nuterial as an external criterion in Rorschach studies. One of the questions has to do with blind use of the Rorechach. Anothef question concerns the use of subjecte whose personality is in a transitional "storm-and-stress" phase of development, at least in our culture. These points will now be elaborated.

In an earlier study by the sume authors, Ives, Grant, and Funzoni (1952) found no consigtent decline of neurotic signs over the adolescent age range of 11-18 years. They concluded that the sign method could contribute little to any systematic or frultful understanding of the Rorschach as applied to their sample. This conclusion may represent an appropriate criticiam of the gign nethod. It is also possible, however, that expectations related to neurotic sign decline through adolescent age ranges still remain more hypothetical than ostablished.

By wey of 1llustration, Bosquet and Stanley (1956) worked with 175 boys, aged seven to thirteen, in a ch11d guidance center and found that such deterninants as FM, $M$, and sum $C$ failed to show traditionally assumed changes over developmental stages. Brockway, Gleaer, and Ulett (1954) reported that less than 2 per cent of their psychiatricelly screenod, adjusted nomals wore Wthout evidence of color shock, and that leas than 8 per cent were without evidence of shading "ahock" as defined by Munroe (1944). They also reported that Rorschach $K$ and $m$ scores, traditional indices of anxiety, were used as much by their adjusted 
group as by their anxious patient group. One pertinent generalization by Beck is that the Rorschach test has been "turning over evidence that immaturity marks the average American, male and female" (1952, p. 52).

Blind Rorschach approaches to personality investigation raise objections as to whether theoretical needs for holistic interpretation really are fulfilled. Rorschachers themselves believe that interpretation is most fruitful when it occurs in the context of a full test battery, including some background knowledge of the test subject. "Blind" Rorschach interpretations admittedly impose artificial Iimitations on both the instrument and the worker. Nevertheless, evidence supporting the successful utilization of the Rorschach in blind diagnosis is available as discussed earlier in this paper (Chambers and Hamlin, 1957; Beck, 1960). Supportive evidence may be traced to Rorschach himself, who wrote of a record "sent to me by my friend, E. Oberholzer, for 'blind' diagnosis. Only the age and sex of the patient was indicated on the record" (1942, trans., p. 186).

The most critical point made by Ires, Grant, and Ranzoni-that Rorschachers are characterized by a set toward the abnormal In interpretation--1s well taken, as is their implication that Rorschachers too often exhibit inadequate understanding of normal personality patterns. These criticisms are not limited to Rorschach practice but extend to personality theory more generally. In the Brockway, Gleser, and Ulett (1954) study, striking 
evidence of discrepant Rorschach frameworks of normality was presented. The psychogram that these authors derived from the protocols of 126 adjusted white males, aged seventeen to thirty-six, educated at least at the elghth grade level, showed sharp contrasts with the hypothet1cal psychogram for normals proposed by Bell in 1948. Two obvious discrepancies involved FII and $\mathrm{CF}>\mathrm{FC}$, both of which differed even in direction from the ratios seen in Bell's psychogram. Beck's (1961) sample of 157 middle-status Chicaco ma1l-order personnel adds further to the nornative confusion. His findings with regard to $\mathrm{CF}$ and $\mathrm{FC}$, whlle consonant with those of Brockway et al. for normative adults, CF>FC (1.4411.36), contrad1ct the concept of Inear progression often assumed for personality development.

In Rorschach analysis, content interpretation frequently is at a symbolic level. A given content response may convey a variety of meanings, dependine upon the context in which $1 t$ appears (Phill1ps and Sm1th, 1953) and the clinician making the interpretation. Personality theories, particularly those with a psychoanalytic orientation, provide the interpretative foundations for many of these meanings, as do past clinical cases. The response "rock," to take one example, is thought by Halpern (1953, p. 37) to symbolize "security" (not glven by Ph1li1ps and Sm1th). Expla1ns Rychlak (1959, p. 456). 
... what the clinician must mean in this suggestion is that a meaning is conveyed by the construct Fock. He-the clinician--has learned to identify this less frequent assoclation which people have between feelings of security (object) and rocks (sign).

Rychlak wanted to determine the extent to which content interpretations could be generalized without losing their valid1ty. He adapted a method employed by 0sgood (1952) to assess whether or not subjects would agree in their cholces of clin1cal meanings of ten assigned to contents. If Rorschach constructs really signifled the content meanings so often ascribed to them, the various experimental Eroups would be expected to show consistencies in the makine of forced asscciations to the constzucts.

Twelve famillar Rorschach contents were investigated, Boots, Smoke, Bear, Nask, Fur, Flre, Clouds, Hocks, Halr, Bat, Island, and Mountain. Subjects were asked to assign a positive or negative valence to each of the above constructs. They were also asked to assign to each construct one of six arbitrary meanings, Ambition, Love, Security, Depression, Fear and Anger. The 160 subjects included introductory psychology students, extension students, and state hospltal mental patients, with the distribution of males and females nearly equal. 
Allowing for expected differences between psychologists and unsophisticated subjects, the major prediction in Rychlak's study was verified. Consistencies in the forced associations were reflected by the groups, cutting across such lines as sex and mental health. Many of the clinical interpretations were found to hold. Among the more typical findings, for example, were (1) that "Security" was associated to "Rocks" by both the normals ( 62 per cent) and the patients ( 63 per cent), (2) that a positive valence to "Fur" was more likely to be assigned by women ( 94 per cent) than men ( 80 per cent), and (3) that male patients chose "Security" and "Love" more frequently in assigning meanings than did normal males, who selected "Ambition" more frequently (significant at .01 level). Ilttle reversal was noted in the valence assigned to any of the constructs.

The semantic differential was employed by Goldfrled (1963) In order to determine the connotative meaning of some Rorschach animal symbols among college students. Forty male and forty female undergraduates rated ten animal symbols on each of twelve b1-polar adjective scales. The results failed to confirm the generality of symbolic meanings with "universal" consistency. Some of the interpretations presented by Phillips and Smith (1953) were confirmed: Alligator as active and destructive, Butterfly 2 passive-feminine. Most of the interpretations, however, were -1ther only partially confirmed (Spider as wicked, but not feminine) or not confirmed at all (Ape not as a threatening, destruc- 
tive figure).

A different approach to clinical hypotheses about the meaning of specific Rorschach responses and test behavior was adopted by Halpern (1957). He converted his own interpretative reactions to his subjects' percepts into questions, which he asked of his subjects directly. What he was seeking was "a simple, face-value attempt at checking what the psychologist feels his $S$ is communicating" (p. 16). The questions represented a variety of experiential levels, including personal history, feelins, fantasies, impulses, and behavior. Two types of "impressive evidence" were claimed by Halpern as favoring his idea that examiner questions reached a deep, meaningful level for his patients. The first type of evidence was the appearance of metaphors similar to a subject's original percept, while the second had to do with the enthusiastic reactions of his subjects to the questions put to them.

Halpern's procedure is open to criticism as being heavily subjective, directively leading, and more representative of intervlew techniques than of Rorschach techniques. On the other $h_{a}$ Id, his procedure is reminiscent of Allport's (1955) belief that one too frequently overlooked approach to gaining understanding of an individual is to allow him opportunities to tell about himself. "We are st11l in the dark concerning the nexus of John's life. A large share of our (clinical) trouble lies in the fact that the elements we employ in our analyses are not 
true parts of the original whole" (p. 21). Halpern did ask his subjects about particular areas in their experience, as they perf celved them. Although open to criticism, Halpern did attempt to provide a reallstic relationship between an individual's Rorschach performance and his characterlstic feelings and ways of coping with and expressing these feelings.

Schafer (1953) distingulshes between static conceptions of content interpretation and the more dynamic thematic analysis of content, which is based in psychoanalytic theory. While foreseeably running the risk of "wild psychoanalysis," thematic analysis is required because it integrates the interplay that occurs among ink blot, perceptual sytle, and personal imagery. The risk of naive psychoanalysis can be partlally offset by standardization of context in interpretation, and avoidance of one-to-one interpretations between individual responses and pathognomic categories.

The influence of a static content approach on interpretation proved to be disruptive to the general findings in a dissertation study by Tabor (1959). Tabor obtained process analyses of thirty $\mathrm{Ph} . \mathrm{D}$. clinicians as they interpreted three Rorschach protocols. The content approach, which occurred only for a single cliniclan, was sufficiently unusual to disrupt the clinlclan's subgroup agreement with other subgroups in the study. Elimination of the performance of this clinician who "proceeded largely on the basis of content analysis" raised the level of 
comparability of the subgroup quite markedly.

The above observation would not be in conflict with Schafer's ldeas concerning the meaningfulness of content analysis. The content data available to Tabor's clinicians were limited to major content categories, in quantitative form, and did not lend themselves to thematic treatment. Schafer's approach relies on specific response contents, evaluated in sequence, and related to card, preresponse, and postresponse contexts.

D. The Clinical Question

The role of the Rorschach in clinical diagnosis has been the subject of controversy both in the literature and in clinical settings, both among psychologists and among psychiatrists. From a formal and theoretical standpoint, the keynotes have been those of caution and conservatism--"It is to be understood that the test is primarily an ald to clinical diagnosis.... It can be of some service to the psychoanalyst" (Rorschach, 1942, trans., pp. 121, 123; 1talics mine). Ross (1950) cited a committee report from the Group for Advancement of Psychiatry which stated that psychological tests, Iike any other laboratory procedures, do not make a psychiatric diagnosis but only contribute to it. From a practical and applied standpoint, however, the keynotes have tended to lose their cautious tenor in the direction of more expansive claims. "The test can clear up those unpleasant Ituations arising when one has an analytic patient in whom 
there is a suspicion of schizophrenia which cannot be dispelled" (Rorschach, p. 123).

Ross analyzed some of the expectations and limitations associated with Rorschach interpretation. He concluded that many Rorschach expectations were naive, and that the Iimitations too often were overlooked. To quote,

The author has been impressed with the wide variations in regard to what is being attempted by clinical psychologists using the Rorschach method, and what is expected of them by psychiatrists and other physicians using their services. There has not been sufficient recognition of the limitations of an ingenious tool in the hands of an ingenuous operator, with good intentions, but with inadequate training, either in the special technique or in clinical diagnosis generally. In other instances some of the most gkillful of Rorschach workers are succumbing to the temptation to assume the role of psychiatric diagnostician, either because of their own ambitions, or because of pressure from physicians, all too ready to grasp at an apparent short-cut, with their own lack of time and surfeit of patients $(p \cdot 5)$.

Ross especially objected to an overemphasis on diagnosis

when combined with a minimization of personality description. For him, "the most valuable contribution of the Rorschach report" Is the description of the total personality in action.

Armitage and Pearl (1957) referred to the diagnostic impreslons resulting from Rorschach interpretation as "unimportant byproducts." They claimed that many cliniciang would object to the use of the Rorschach primarily as a diagnostic tool. "Its most effective use lies in such areas as personality description, its prognostic value, and its indications for treatment possibilit108" (p. 479). 
Rorschach's own thinking concerning diagnostic evaluation clearly included an owareness that "incorrect diagnoses were and still are made." Justifications offered by him in relation to diagnostic evaluation with the Rorschach revolved around interpreter responsibility in seeing to it that sufficient experience and practice had been gained from which to make valid integrations of test data. He recognized, for example, that it would be possible for clinical symptoms considered to be of primary importance to psychoanalysts to appear unimportant in the over2II Rorschach results. Even when the symptoms were described correctly, there could be a faulty putting-together of the descriptions in forming a final diagnosis. "Experience and practice with the test play a great role in the evaluation of quantitative importance of symptoms...." (p. 120).

The majority of the clinical judgment studies reviewed in this paper have had in common requests for Rorschachers to reach diagnostic conclusions. As seen above, however, diagnostic questions have never been regarded as easy ones to answer, neither fully appropriate nor even desirable. As attested to by McCully (1965),

Ambiguity in projective findings may be confusing for purposes of nosology, but which may nevertheless accurately reflect conditions existing in the inner world (p. 436).

A survey of past Rorschach research, from the specific orientation of diagnosis, may reveal a direct relationship between positive or negative outcome of studies and the type of clinical 
questions asked. Outcomes surely have been influenced by the general diagnostic group from which the Rorschach records were obtained. A parallel influence regarding the nature of the clinical question would seem equally likely.

Future research explorations of Rorschach judgment might be encouraged to consider the potential influence of both of these variables-the clinical question asked and the psychiatric makeup of the subjects. For example, a variety of questions could be asked of Rorschach workers in a single study and the relative outcomes compared for success. Diagnostic differentiation might be retained as one of the clinical questions in a study. However, it would seem feasible to include other, more descriptive questions, perhaps having to do with emotional controls, or anxiety, or the degree of immaturity characterizing the personal1ty. Another possible question might be one calling for an estimate of intellectual functioning, especially since the latter question has reappeared in past Rorschach studies, lends itself more realistically to application with nonpsychotic subjects, and provides an operational form of criterion.

Second, different levels of specification for a question night be requested of the clinical participants. In addition to general ratings, specific clinical impressions and conclusions might be obtained, and the point of relative breakdown in accuracy determined. Intelligence estimation, for example, potentialf if lends itself both to general and specific levels of fuagment. 
The ceneral level might include the judgment of "average," "below average," or "above average." The specific level might include the giving of an estimated I.Q., plus or minus a few points. Again, intelligence estimation has the added advantages of permitting a relatively objective type of verification of results (intelifgence test scores) and of providing a type of criterion which differs from that of psychiatric judgment, interview findings or therapy material.

Th1rd, future Rorschach deslgns might allow for freer operation of the stylistic approaches of cliniclans. The purpose of the latter would be to determine, first, whether clin1clans tend to rely more on contents or on determinants in their general approach to Rorschach interpretation; second, whether content and determinant approaches vary accordine to the type of clinical question asked and, third, whether certain Rorschach cards are "preferred" for particular clinical questions or during different stages of interpretation. The possible applications here would be numerous.

\section{E. Rimoldi's Problem-Solving Technlque and Summary}

In an unpublished doctoral dissertation. Tabor (1959) conducted process analyses of 30 clinical psychologists as they attempted to determine the diagnosis of psychiatric patients throuch blind Rorschach Interpretation. Tabor's atudy implemented a problem-solving technique developed by 
Rimold1 (1955), who orisinally employed it to investigate the diagnostic processes of physicians (1956, 1958).

The major feature of the Rinold1 technique rests in the step-by-step procedural recording it permits as isolated increnents of information are selected, gathered together, and synthesized by a clinical worker. Data related to a specific c11nical problem are written on separate information cards, one un1t of data per card. The vorlser is requested to arrive at answers to specified cinical questions by deriving his information from the available data cards, one at a tine, in a manner whlch then is left to the worker to declde upon for himself. Instructions emphasize that the worker select only information cards deemed "necessary and sufficient" in order to maximize the more systematic features of his approach and to minimize the inclusion of relatively irrelevant data. The technique allows the experimenter to control the problem, the types of questions that may be asked, and the amount of information givon in answer to each question.

The Rimoldi technique has been used in a variety of contexts. Haley (1963) used it to assess the effects of training on medical diagnostic skills. Rimoldi and Devane (1961) assessed the influence of training on problem-solving. The technlque has been used to study thinking processes through differont ages (Rimoldi et al., 1962), mathemat1cal ab1l1ties (Reidel, 1963), and changes in the course of psychotherapy (Meyer, 1963). 
The approaches of psychlatrists, psychologists, and soclal workers in diagnosing minimal brain pathology in children were inrestigated by liohrbacher (1961). Gunn (1962) studied psychologists and social workers as they solved problems involving interpersonal conflict. The reader is referred to Gunn's excellent review of clinical judgment 11terature from the medical, psych1atric, and Wechsler-Bellevue perspectives.

some of the ceneral findings resulting from the studies just cited are listed below. Clinical experts select information items which have the highest utility value for the group as a whole. Clinical experts select a smaller number of information items to answer clinical questions than do less experienced workers. Workers following different procedures of interpretation nevertheless nay reach slmilar conclusions. There is a high degree of correspondence in outcome shown by physlcians sciving medicel problems as well as by Rorschach experts interpreting Rorschach protocols, despite the emergence of greater personal style shom by more experienced workers. Physicians from different schools perform in similar ways for a particular case. Junior redical students select information not valued by the generaI mealcal group. Senjor medical students are more crit1cal in their diagnostic approach than are Junlors. reflecting the sentors' increased knowledge.

In Tabor's study, a definite lawfulness was found in the sequence in which Rorschach data were accumulated by Rorschach 
experts. The clinicians gercrally proceeded from quantitative data to nore symbolic, qualitative data. The latter finding is not in agreement with those of Symonds (1955), Powers and Hamlin (1957). and Hamin and Powers (1958). The Inconsistency may be related to a limitation in Tabor's study having to do with the way in which Rorschach data were made avallable to the cliniclans. That is, the content of the response was available only In summary form, under general content categorles.

The self-consistency of each of Tabor's clinicians was at a high level, with little individual variation occurring across the three protocols. This finding would seem less expected under conditions in which cliniclans would be asked to answer clin1cal questions which were not all directed toward diagnosis, as w111 be the cases in the present study. R. F\%, and $\mathrm{F}+\%$ were found to represent the basio orientation data necessary for diagnostic Rorschach interpretation by the clinicians in Tabor's study. Minor variations peculiar to Individual protocols were noted. For example, the rigldity of the Schizophrenic personality elicited greater concern with Dd, S, and d. The Normal record elicited ereater seeking of evidence of rormality with regard to FK and Fc. The sterility of the Organic protocol gave rise to susplcions regarding depres810n, $C^{\prime}$, and the basic question of degree of contact with real1ty. F. While 1t also was noted that two-thirds of the clinlclans were "basically correct" in their diagnostic statements 
about the three protocols presented to them, diagnostic accuracy showed iso relationship with the amount of information from which diagnoses were derived, or to sequential selections of infornation, or to the efflolency level of selection. Tabor explained these negative observations by indicating that arbitrary and excessive accumulation of information could influence efficiency scores in one direction only in his study, that of reducing efficlency. He suggested that finer differentiation of the Rorschach data in 1 ts initial format stage might result in more positive findings.

Items might be classified according to types of scoring categories, for exariple, (1) location scores, (2) determinants. (3) content categories, and (4) numerical ratios. The relative enphasis in these various areas by different analysts might yleld some fruitful findings. A tentative exploration of this problem lindicates cons1derable differences among analysts. Some explore one area thoroughly, for example, location scores, before moving on to another, for example, determinants. There appears to beaquite deliberate, though perhaps unconsclous, concentration on one area at a time. Others. on the other hand, transfer continually from one area to another, suggesting a more macroscopic view of the Rorschach (p. 109).

The Rimoldi technique is consonant with the general research findings reported in the present survey of the 11terature. Especially as it is to be stmuctured in the present design, the technique will allow for the fullest possible operation of the oritical eve of the clinician (Hertz, 1959) and the integrating Lactor of the clinician (Armitage et al.. 1955). In Rorschach interpretation. Fuller freedom of operation for the cilnician oould result only by providing the latter with entire Rorschach 
protocols. However, experimental control of the clinician's processes of interpretation would then be sacrificed.

Within the limits of Rimoldi's problem-solving technique and of "blind" diagnosis, the clinician is free to select as little or as much Rorschach data as he wishes. No restrictions are placed on the order of his selections, although once an information card is selected. Its sequential position then is detexmined. The clinician is allowed to make written notations as he proceeds in his evaluations, constructing psychograms or other formal summarles acoording to h1s own preferences or needs. Introspections also are encouraged in order to provide a running description and explanation of the deta selections, I1m1ted only by the clinician's own willingness to verbalize them. Although It is true that the clinicians in the present study will not be able to gain an immediate holistic overview of the Rorschach record, the possibility of their geining such an overview nevertheless is open to them. The cliniclans would have only to select all of the data cards. Thus, it may be seen that the interpretation of Rorschach protocols under the conditions of the present design may occur in a way which is as maximally similar to the natural Rorschach setting as possible, linited only by the experimental goal of maintaining step-by-step control of the interpretative process.

The present study is consonant with Hamlin's (1954) judgments that outcomes in Rorschach research are directly related. 
to the simplicity or complexity of the material to be judged and to the adequacy of the experimental conditions in allowing the clinician to dorive judgments from the material. The study is elso seen to be consistent with cummines' (1954) conclusion that Rorschach atudies most closely approximeting the operation of the clinicien-in-action nost often yielo positive relationships in their outcomes. In the present proposal, the cliniclan w111 be able to detemine his om limits of simplicity or complexity of the materlal to be judged. Each clinician will be able to determine for himself the amount and type of Rorschach data necessary to reach clinical conclusions. He will be rree to ut1lize part of the avallable data, or all of 1t. Fe vill be free to rely on content factors or on traditional determinant scores, accordine to his om desired emphasis, the latter recoenized as a variable by symonds (1955).

Success in clinical judement has been shom to be more characteristic for some areas of personality than for others (Powers and hamlin, 1957). In the present desicn, three different types of clinical question w1II be asked. One question will request a psychiatric diagnosis, another an estimate of severity of anyiety, and the final one an estimate of current inteliectual functioning. Lower self-constancy for Iridividual cliniclans across the three protocols than was found in Tabor's study W11 be predicted. Differential emphasis on content and determinant scores also will be predicted, according to the type of 
clinical question asked. These predictions are specifled in the hypotheses of the study.

In the study, an attempt will be made to control for possible cues assoclated with language, Dehavloral observations, and background data. Responses per se will be separated from accompanying verbalizations and examiner observations. Backeround data vill be arailable to the olinlolens, with separate 1tems of bacigground information appearing on separate cards, in keeplng with the design format (Sherman, 1952, Chambers and Iamlin, 1957, Bower. Testin, and Roberts, 1960).

Each clinlcian in the present stuay will be able to make some relative determination of "adequate time" for his interpretat1ons (Corsint, 1955, Richards and Hurray, 1958).

Iwo levels of interpretation will be considered in the study for each protocol, one ceneral and one specific.

Combinations of alfferent types of criteria will be employed In determining the Inal accuracy of the cliniclans ' interpretations, including results from other projective tests, psychiatric judgments, and results from the stanford-Binet intelilgence tast. 


\section{DESCRIPTION OF SAIPLE AND NETHODOLOGY}

Thirty-six experienced clinical psychologists were asised to interpret three Forschach protocols, under the conditions of Rimoldi's data-selection technique. An experienced clinical psychologist was defined as a person 1) holding the Ph.D. degree in clinical psychology, 2) having at least four years clinical experience since the time the Ph.D. decree was conferred, 3) havIne utilized the Rorschach technique in clinical investigation, and 4) willine to participate in the study, which required approximately one and onemalf hours time.

The attempt to obtain two suberoups of clinicians representine both Beck and Klopfer orlentations to the Rorschach was partially successful. Both orientations were represented in the sample, but unequally. The predominant orientation was that of Beck $(N=25)$ and accounted for 69 per cent of the clinlclans in the sample. The remaining 31 per cent was comprised of cliniclans following Klopfer's orlentation $(N=11)$. A single clinlolan who ldentifled his orfentation with that of Plotrowsk1 was grouped with the Beck sample on the basis of his greater use of Beck scores than of Klopfer scores in the study. The total clinloian sample thus was defined as two-thirds Beck and one-third Kopfer in orientation. The effect of this two-to-one ratio 
TATHE 1

DESCRIPTION OF CLINICAL SAMPLE

$$
N=36
$$

Variables

Mean

$S D$

Range

Ase in Years

44.7

8.1

$32-65$

Years since Ph.D.

13.4

$7 \cdot 6$

$4-30$

Estimated Rorschachs

For Pasi Five Years

265.6

310.1

$25-1500$

Number

Per Cent,

AFA Fembership

36

100

Diplomate in Clinical

18

50

Rorschach Orientation

Beck

25

69

KIopfer

11

31 
was to limit generalizations of comparative findings between the two major Iorschach approaches used in this country. However, It is belleved that the subgrouping served to control for influences associated with differences in academic training and practicum experiences.

Each of the three Rorschach protocols used in the study was brolken down into its component parts. The resulting information units were written on $2 \frac{3}{3} 3$ inch cards which then were inserted into pockets on a $3 \times 4$ foot cardboard folder and positioned into one of elght vertical columns which were labelled according to traditional Rorschach catecorles. Written on the front of each card was the traditional Rorschach symbol, word, or rat1o ind1cating the type of information that could be obtained by removIne the card from 1 ts pocket and reading what was on the reverse side. Backeround data describing each of the three Rorschach subjects also was included among the cards, as was data related to the subject's verbal elaborations and comments, and the horschach examiner's observations of behavior, where available. There were 329 cards for each protocol, although many of the cards represented equivalent forms of sinllar Rorschach data for the Beck and Klopfer scoring methods.

The cardboard folder was self-supporting when presented in an upright, open-book fashion. This upright presentation made it posolble for the clinician to view all of the information cards rap$1 \mathrm{~d} I \mathrm{y}$ and comprehensively, and fac1litated ready access to the data 
cards. Appendix I provides a picture of the apparatus used in the study.

As soon as one of the three cardboard folders had been presented to the clinician, the following written instmetions were giver to him.

This study is an attempt to determine how the clinician goes about evaluating Rorschach data in answering clinical questions.

In front of you is a cardboard folder into which data cards have been set. Each folder represents an authentic Rorschach protocol. Each data card indicates an item of Rorschach information generally ut1lized in Rorschach analysis. The information can be obtained by selecting any card, turning it over, and reading what is on the back.

When you select a card, draw it from its pocket, read the information on the reverse side, and lay it on the desk. Do not replace any card in the pockets of the board after you have drawn it from its pocket. Proceed in this fashion for all the cards that jou find necessary to select. As soon as you feel quite sure of your answer to the clinical question that will be presented to you shortly, write it on the paper. Stop drawing further cards.

You are asked to select those cards you belleve to be necessary and sufficient to arrive at answers to the clinical questions. Avoid selecting a card unless you feel you really need it in order to answer a particular question. According to jour clinical judgment, you may select as few or as many cards as you wish. Not all of the information will be positively given; that is, information may be made available through omission, the reverse side of a selected card being found blank. You are asked to make your data selections in the manner consistent with what you have found to be the most sotisfactory, on the basis of your own Eorschach exper1ences, however personal.

Feel free to reread any card previously drawn. Feel free also to utilize any of the materials that have been placed on the desk in connection with this study. The raling of rotations is encouraged. You g.lso may 
wish to make comments as you proceed, perhaps verbalizing your thinking, which would be welcome.

There will be three clinical guestions, and protocols, In all. The estimated time is about $1 \%$ bours, total.

You are requested to read all the 1tems on the board, and to familiarize yourself with its format, before selecting any card.

Note: The techniques of both Beck and Klopfer frequently are given separate representations on the board, in order to reflect and make avallable their different dimensions. Feel free to select any of the cards, at any time in your analyais.

After the clinician had read the instructions and familiarized himself with the data board, the experimenter verbally added the following:

If you would like to know the reaction time to any of the cards, or the specific location for any of the responses, ask me and I will indlcate it to you.

Reaction times were indicated verbaliy to the clinician, upon request. The location areas were indicated graphically by the experimenter who circled appropriate response areas on a atandard location chart. These two exceptions to the general cards-in-pockets format of the design were necessitated by the limlted board space. The desirability of lncluding all relerant data was weighed against the desirability of maintaining a workable apparatus.

After the clinician indicated his familiarity with the data board and his understanding of the procedure, the experimenter presented him with a written question form containing the clinioal question which corresponded with the protocol before him. 
Wach protocol was accompanied by a different type of clinical question. Protocol A involved clinical diagnosis, Protocol B an estimate of severity of anxiety, and Protocol $C$ an estimate of present level of intellectual functioning. Illustrations of the three written question forms appear in Appendix II.

Two levels of interpretative judgment were requested of the clinician for each question. The first level was the more general one, and called for the clinician to make a pencil check next to one of a number of broad categories. The second level was the more specific one, and called for some detailed clarification of the clinician's earlier general conclusion. It was thought that this differentiation between general and specific levels of Interpretation would prove useful in evaluating the accuracy of the clinicians' final judgment, by highlighting points at which clinical agreement remained high or at which agreement broke down.

The order in which the three protocols were presented was rotated in order to control for potential errors associated with position effects, familiarity with the experimental procedure, and general interpretative context.

The supplementary "materials" referred to in the instructlons were placed on the desk for use by the clinician, if dealrod. These materials included blank paper, klopfer summary and psychogram forms, Beck summary forms, and standard location charts. A complete set of Rorschach inkblots was available upon 
request. The reader is referred to Appendix III for 1llustrations of these forms.

As the clinicians in the study proceeded in their interpretations, the experimenter made written notations of the sequence In which the data cards were selected. Descriptive and explanatory comments relevant to the interpretative process also were recorded.

This general experimental procedure was maintained for the presentation of the second and third protocol folders. At the end of each session, the clinician was asked to provde some general information regarding his Rorschach background and experience. The standard information form used for this purpose appears in Appendix IV. Brief discussion then was encouraged by the experimenter, in order to obtain the retrospective comments of the clinician, to determine whether any of the protocols had been recognized by the clinician, and to provide whatever feedback might be requested by the cliniclan regarding either the protocols or the study.

The three protocols employed in the study were selected from existing Rorschach records published in the ifterature. The protocols thus were authentic, obtained in actual clinical practice by experienced cliniclans. Some advantages were seen as a result of this selection procedure. Hrst, potential blases arociated with a single examiner's having administered and soored all three Rorschach protocols were lessened. Protocol B. 
for example, was scored by Beck, and Protocol $\mathrm{C}$ by Bochner and Halpern. Second, background and interpretation material were available for all three cases, including psychlatrist reports and, for Protocols $A$ and $C$, findings from other psychological tests. Third, as the number of Rorschach responses, $R$, has been shown to have a significant influence on some of the major Rorschach scoring categories (Fiske and Baughman, 1965), it was thought that desirable control of $R$ would be facilitated by selection of protocols from the literature. $R$ in the present study ranged from 33 (C) through 34 (B) to 37 (A).

Protocol A was The Case of Gregor, a study presented by John Bell at a 1949 APA symposium. Gregor appeared in two issues of the Rorschach Research Exchange (1949, vol. XIII) as part of an extensive research project undertaken to investigate interrelationships among multiple projective and objective techniques. Data from 22 different psychological tests were avallable for Gregor, with each test interpreted by a different clin1cal specialist. The Rorschach, for example, was interpreted by Bruno Klopfer. A psychiatric evaluation also was included In the case material, as was a final integrative diagnostic sumnary by the symposium's moderator, Frederick Wyatt: "schizophren1a... seems to express the most fundamental fact of Gregor's dicease....Gregor's fundamental disturbance is a disturbance of thinking" (p. 467).

Although the Rorschach interpretation of Gregor was done 
by Klopfer, the original response scorings were not indicated on the published protocol. The final protocol scorings used in this study were derived from a joint conference of five advanced VA interns in clinical psychology. For all protocols, translations of the primary scorings into the alternate Beck or Klopfer scorings generally were direct and literal (e.g., FY $\left.=F^{\prime}\right)$, with the exception of more unique categories such as FM, $m$, and $\mathrm{F+}$, where appropriate adjustments among other categories were made. For all protocols, of course, the original scorings were probably more true to their own specific theoretical orientation than were the alternate scorings to theirs. However, it was believed that the alternate scorings st1ll would be more meaningful and reliable to the clinician working within the context of his own theoretical framework than would scorings from a framework which, while the original, would be unfamiliar to him.

Protocol B was taken from Beck (1945), The Classic Signs. "The record points to a central anxiety that must be deeply distressing....a pervasive emotion in her. Also, it is the more intense in a person as introversive as she is....the anxiety from which she suffers deeply" (pp. 244-245). The record was unique in that despite the severe anxiety and the disintegrating offects of the "heavy blacks" of the blots there was no appearance of shading used as a determinant in the record. Beck did not specify events related to the possible heightening of anxioty in Classic Signs, apart from affective arousal, but he did 
mention a number of psychological defenses which were being employed to handle the anxiety: fantasy, disregard of reality, regressive tendencies, resignation, inadequate affective response, autiatic solutions, and intellectual contact.

Protocol $C$ was a record of an essentially normal Adolescent Girl which was taken from Bochner and Halpern (1942). A Stanford-Binet intelligence test score of 118 was reported for Adolescent Girl. A brief amount of case history material accompanied the record, Including a psychletrist's diagnostic note which indicated essentially healthy personality features for the subject. The protocol was scored by Bochner and Halpern from a Klopferian framework.

It was considered unlikely that any of the protocols would be recognized by the clinicians participating in the study. The fragmentation of the Rorschach data under the experimental conditions employed, and the improbabllity of there being any "set" among the participants toward protocols from the literature, were seen as supporting this assumption. Specific response contents would present the most obvious clues to recognition (e.g., the "flying red horse" in Protocol A or the "two seeds...carried away on the wind" in Protocol B). Determinants and numerical ratios would provide less obvious clues. In order to provide a check on this assumption, however, the clinicians were asked at the end of the experimental session whether the protocols were fariliar to them. None of the clinicians in the study indicated that they had recognized any of the three protocols. 
Two assumptions were made in determining the relative ut1lity value of the data avallable for Rorschach interpretation in this study. First, 1tems and categories perceived as more useful by cliniclans would be selected more frequently than those perceived as less useful. Second, more useful 1tems and categorles would be selected earlier in the interpretation sequence than those percelved as less useful. These two assumptions correspondingly permitted the data to be vlewed from the dual perspectives of what was used and how or when it was used.

The measure of what data cliniclans used was the Ut1lity Index. 1 This index, expressed as a percentage, represented the ratio of the number of times an ltem was selected to the total number of cliniclans doing the selecting. As each of the thirtysix clinicians in the study was free to select any given card, the maximum Utility Index for a card would be $100.0 \%$ and the minimum Utility Index would be $0.0 \%$.

In order to provide a general framework for evaluating the relative emphasis given to the data selected by the cliniclans, each card was grouped under one of six levels of ut111ty, accordIng to the magnitude of the card's Utility Index. The six utility levels were based on cumulative percentage divisions of

1The statistical formula for this Index, and for other of the techniques to be discussed in this chapter, may be found in Appendix VI. 
the normal curve, approximating \pm 3 standard deviations, as 11Iustrated in Fioure 1.

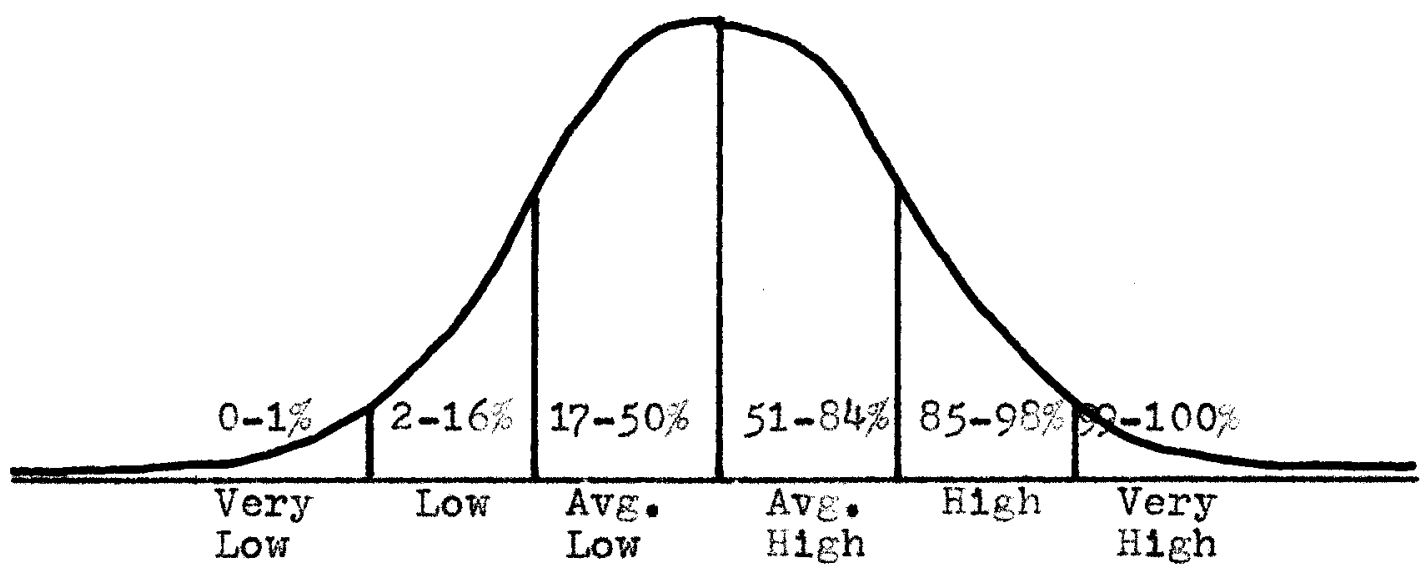

Fig. 1. Six levels for classifying utility of Rorschach inforration.

The principal measure of how data were used by the clinlclans in this stuojy was the Mean Rank. As each card had been assigned a rank indicatine its orainal position in the selection sequence on each protocol for each clinician, it was possible to sum the ranks assigned to a given card and divide the resultine fleure by the total number of clinicians doing the selectine. Cards which rad not been selected by a cliniclan were assiened the average rank of all remainirg cards in the protocol, based on the statistical assumption that each card had a equal probabil1ty of being selected next. The naximum Mean Rank for a given card would be 1.0 (selected first by all clinicions) and the minimum lean Rank would be 329.0 (selected last by all cliniclans). 


\section{DISCUSSION OF THE RESULTS}

The various sources of Rorschach information were classifled according to six utility levels: Very High (VH), High (H), Average High (AH), Average Low (AL), Low (L), and Very Low (VI). Reforence to lable 2 wlI show that of the 329 separate information liems avajlable for selection, no item was found to be singularly high in utility by the clinicians interpreting the three protocols in this study. This finding was observed for the results of the three protocols combined, as well as for the Intelligence tasi in particular. Highest uililty obtained (y) was for two free associations, given to horschach Cards II and III on the Diagnosis tasir, and to the Age item on the Anxiety task. Average H1gh (AH) utility was observed for 27 of the 329 1 teus for the three protocols combined, and represented elght per cent of the total number of 1tens. The cards selected at this level contained data from four catezories: personal Data, Quelitative Responses, Totals (Beck), and Determinants (Beck). The pattern of initial data usage most often followed by the clinlcians in this study was, ilrst, to gain e brief non-Ror8chach orientation to the test subject based on Personal Data (Age, Sex, Education), and then to focus on the subject's Qualitat1ve Rorschach responses--the traditional free assoclations. 
Dccasional summary or determinan: scores--F+\%, in, R-were included amons the data selections at this High Average level. However, most forms of quantitative Rorschach iniormation had lower Ievels of utility, secondary to qualitative data, the latter including subject Verbalizations and Examiner observations. The findings are in support of Hypothesis $I_{A}$ that cliniclans generally w1II proceed from qualitative to quantitative Rorschach data in their interpsetations.

The sequential appearance of Qualitative responses $t 6$ and it? following responses if and 72 in rable 2 nay be cited as examples of the iniluence of Individual Rorschach cards on data selections. Clinlolais evidenced less interest in exhaustine a.1 responses eiven to Rorschech Card $I$, for example, then in deteruining the first one or two responses eiven to each of the early Rorschach cards. For purposes of evaluatine this lattew infinence, it may be noted that the numbers of Rorschach responses given to card I in each of the three protocols were five, eight, and four, respectively.

The information items seiected at the Low level of utility represented 56 per cent or the total and largely included later Verbalizations, Quantitative scorines and Locations of individual responses, and Content sumary scores. Appearine at this Low level were specific iters such as reaction tines (Beck and Klopfen. Klopier's BumC, $W$, and $P$, and Beck's $F_{0}, x F$, Additional responses and $\mathrm{Zf}$. 
Table 3 presents the liean Rank findings for each card on the threa protocols combined, indicatine the sequential polnt at whlch a given card generally was selected by the cliniclans. The relative position of each card in relation to all of the other carts also is presented, ranging from first to three-hundred-twenty-nintin (Relative Renis). It nay be seen that the cards selected earliest in the interpretation sequence--at the upper fifteen por cent level--again are mainly from the qualitative response and Personal Data categorles, with occaslonal appesrances of Beck Sumary $(F+R, R, P)$, Determinant ( $V, C, C F, F C)$, and Iocation (W) scores. In fact, ntnety per cent of the free assoclations are selected earliest, whin the upper fliteen per cent range, along w1th nearly fifty per cent of the backgrnund information cards. The 1nclusion of the Varltal and sexual linformation cards highlights the utility that sexual and interpersonal naterlal tends to have in clinical interpretation.

Tables 2 and 3 have been presented adjacent to each other In order to facliltate cross coinparisons between the bro sets of data. The Utility Index (UI) reprosents tho frequency dimension of selection, while the Mean Ravis (MR) represents the sequence dinension. The close correspondence of these two utility measures nay be observed visually by the reader. A rho of .939 was obtained between the two sets of data. Th1s correlation was 1gmificant at the .001 level, using Student's t with $\mathrm{N}-2$ decrees of freedom $(\underline{z}=49.37)$. It is interesting to note, howver, that the correlation between the two sets of data in 
TAELE 2

UTIIITY LEVEL OF EACH ITEM FOR THREE QUESTIONS COMBINED*
TABLE 3

SEQUENTIAL RANK OF EACH ITEM

FOR THFEE QUESTIONS COHBINED

\begin{tabular}{|c|c|c|c|}
\hline Items & $\begin{array}{l}\text { Utility } \\
\text { Indices }\end{array}$ & Items & Ranks \\
\hline \multicolumn{2}{|c|}{ Average High Utility, 51-84, } & \multirow[b]{2}{*}{$\begin{array}{ll}\text { Age } \\
\text { Sex } \\
\text { Qual } & 1 \\
\text { Qual } & 2 \\
\text { Ed } & \\
\text { Qual } & 6 \\
\text { Qual } & 3 \\
\text { Qual } & 4 \\
\text { Qual } & 7 \\
\text { Qual } & 5 \\
\text { F+\% B } \\
\text { Qual } 9 \\
\text { Qual } & 8 \\
\text { Qual } & 10 \\
\text { B B } & \\
\text { M B } & \\
\text { Qual } & 11 \\
\text { Qual } & 13 \\
\text { Qual } & 15 \\
\text { Qual } & 16 \\
\text { Qual } & 12 \\
\text { Qual } & 14 \\
\text { Occ } & \\
\text { Qual } & 21 \\
\text { Qual } & 20 \\
\text { Qual } & 19 \\
\text { Qual } & 28\end{array}$} & \multirow[b]{2}{*}{$\begin{array}{l}1 \\
2 \\
3 \\
4 \\
5 \\
6 \\
7 \\
8 \\
9 \\
10 \\
11 \\
12 \\
13 \\
14 \\
15 \\
16 \\
17 \\
18 \\
19 \\
20 \\
21 \\
22 \\
23 \\
24 \\
25 \\
26 \\
27\end{array}$} \\
\hline $\begin{array}{ll}\text { Age** } \\
\text { Qual } 1 \\
\text { Sex } \\
\text { Qual } & 2 \\
\text { Qual } & 6 \\
\text { Ed } & \\
\text { Qual } & 7 \\
\text { Qual } & 3 \\
\text { Qual } & 5 \\
\text { Qual } & 4 \\
\text { Qual } & 9 \\
\text { Qual } & 10 \\
\text { F+\% B } \\
\text { Qual } & 8 \\
\text { Qual } & 11 \\
\text { Qual } & 13 \\
\text { Qual } & 15 \\
\text { Qual } & 16 \\
\text { N B } & \\
\text { Qual } & 21 \\
\text { Qual } & 14 \\
\text { R B } & \\
\text { Qual } & 12 \\
\text { Qual } & 20 \\
\text { Qual } & 28 \\
\text { Qual } & 29 \\
\text { Qual } & 19\end{array}$ & $\begin{array}{l}80.6 \\
75.9 \\
75.0 \\
71.3 \\
69.4 \\
68.5 \\
66.7 \\
65.7 \\
64.8 \\
63.9 \\
58.3 \\
57.4 \\
55.6\end{array}$ & & \\
\hline
\end{tabular}

- No item was selected at the Very High (99-100\%) or H1gh $(85-98 \%)$ levels of utillty.

* Item abbreviations defined in Appendix VII. 
TABLE 2 continued

UTILITY LEVEL OF EACH ITEM FOR THREE QUESTIONS COWBINED

\section{6}

TABLE 3 continued

SEQUENTIAL RANK OF EACH ITEM FOR TEREE QUESTIONS CONBINED

\begin{tabular}{|c|c|c|c|}
\hline Items & $\begin{array}{l}\text { Utility } \\
\text { Indices }\end{array}$ & Items & Ranks \\
\hline \multicolumn{2}{|c|}{ Average Low Ut1l1ty, 17-50\% } & & \\
\hline $\begin{array}{ll}\text { Qual } & 22 \\
\text { Qual } & 30 \\
\text { Occ } \\
\text { Qual } 18 \\
\text { Qual } 24 \\
\text { Qual } 25 \\
\text { Qual } 17 \\
\text { Qual } 26 \\
\text { Qual } 31 \\
\text { Qual } 32 \\
\text { Qual } 27 \\
\text { Qual } 23 \\
\text { Sexual } \\
\text { Nar } \\
\text { Qual } 33 \\
\text { P } 3 \\
\text { W B } \\
\text { CF B } \\
\text { Verb } 2 \\
\text { Verb } 1 \\
\text { C B } \\
\text { Qual } 34 \\
\text { Verb } 3 \\
\text { FC B } \\
\text { xF+\% B } \\
\text { F\% B } \\
\text { Int } \\
\text { Mo } \\
\text { FY B } \\
\text { Fa } \\
\text { A\% B } \\
\text { Res } 3 \\
\text { Y B } \\
\text { App B } \\
\text { YF B } \\
\text { Verb } 8 \\
\text { Verb } 4 \\
\text { Verb } 7\end{array}$ & $\begin{array}{l}50.9 \\
50.0 \\
40.1 \\
48.1 \\
\\
47.2 \\
46.3 \\
45.4 \\
43.5 \\
42.6 \\
39.8 \\
38.0 \\
37.0\end{array}$ & $\begin{array}{l}\text { Qual } 18 \\
\text { Qual } 29 \\
\text { Mar } \\
\text { Qual } 22 \\
\text { Sexual } \\
\text { Qual } 17 \\
\text { Qual } 24 \\
\text { Qual } 30 \\
\text { Qual } 25 \\
\text { Qual } 26 \\
\text { Qual } 23 \\
\text { Qual } 31 \\
\text { W B } \\
\text { Qual } 27 \\
\text { Verb } 1 \\
\text { Qual } 32 \\
\text { P B } \\
\text { Verb } 2 \\
\text { C B } \\
\text { CF B } \\
\text { Verb } 3 \\
\text { FC B } \\
\text { Qual } 33 \\
\text { Fo B } \\
\text { xF+\% B } \\
\text { Int } \\
\text { A\% B } \\
\text { FY B } \\
\text { Fa } \\
\text { Mo } \\
\text { Y B } \\
\text { YF B } \\
\text { App B } \\
\text { Qual } 34 \\
\text { Verb } 4 \\
\text { DA B } \\
\text { D B } \\
\text { Nty }\end{array}$ & $\begin{array}{l}28 \\
29 \\
30 \\
31 \\
32 \\
33 \\
34 \\
35 \\
36 \\
37 \\
38 \\
39 \\
40 \\
41 \\
42 \\
43 \\
44 \\
45 \\
46 \\
47 \\
48 \\
49 \\
50 \\
51 \\
52 \\
53 \\
54 \\
55 \\
56 \\
57 \\
58 \\
59 \\
60 \\
61 \\
62 \\
63 \\
64 \\
65\end{array}$ \\
\hline
\end{tabular}




\section{TABLE 2 continued}

UTILITY LEVEL OF EACH ITEM FOR THREE QUESTIONS COMBINED

\section{7}

TABLE 3 continued

SEQUENTIAL RANK OF EACH ITEM FOR THREE QUESTIONS COMBINED

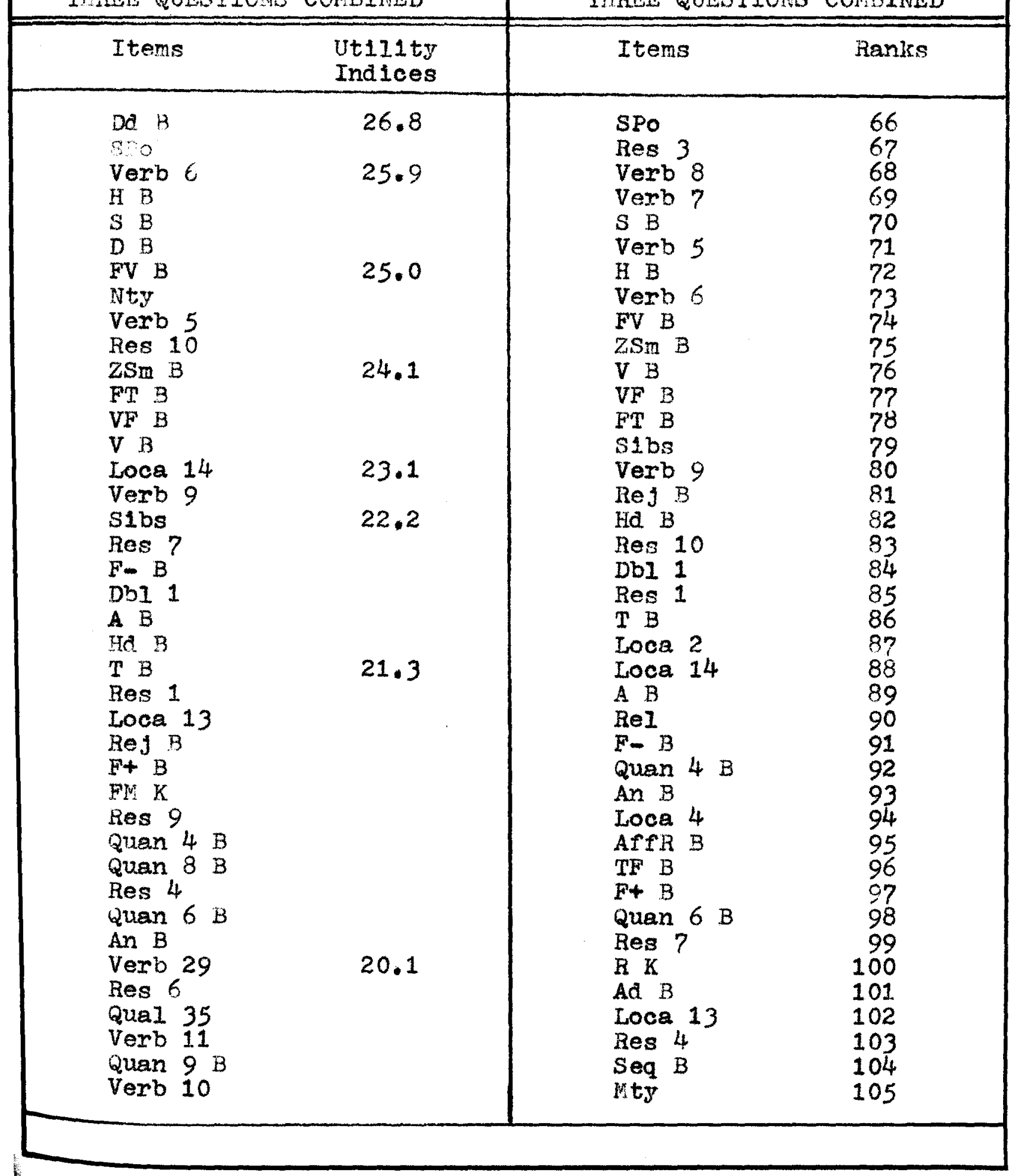


TABLE 2 continued

UTILITY LEVEL OF EACH ITEM FOR TUREE QUESTIONS CCHEINED
78

TABLE 3 continued

SEQUENTIAL RANK OF EACH ITEM FOR TIREE QUESTIONS COMBINED

\begin{tabular}{|c|c|c|c|c|}
\hline & Items & $\begin{array}{l}\text { Utility } \\
\text { Indices }\end{array}$ & Items & Ranks \\
\hline 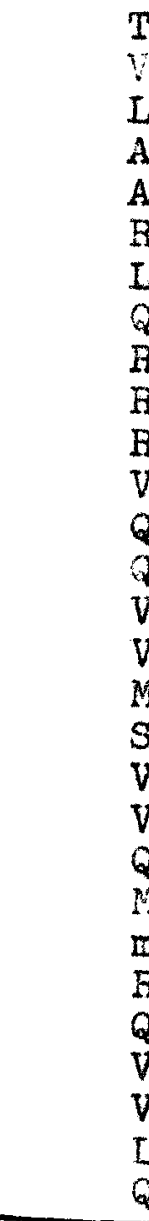 & $\begin{array}{l}\text { TF B } \\
\text { Verb } 20 \\
\text { Loca } 2 \\
\text { Ad B } \\
\text { AffR B } \\
\text { Res } 8 \\
\text { Loca } 4 \\
\text { Quan } 3 B \\
\text { R K } \\
\text { Res } 2 \\
\text { ReI } \\
\text { Verb } 18 \\
\text { Quan } 5 \text { B } \\
\text { Quan } 2 B \\
\text { Verb } 12 \\
\text { Verb } 16 \\
\text { Mty } \\
\text { Seq } B \\
\text { Verb } 19 \\
\text { Verb } 23 \\
\text { Quan } 1 B \\
\text { R K } \\
\text { W K } \\
\text { RT } 1 \\
\text { Quan } 7 B \\
\text { Verb } 13 \\
\text { Verb } 21 \\
\text { Loca } 12 \\
\text { Quan } 29 \text { B }\end{array}$ & 19.4 & $\begin{array}{l}\text { Verb } 10 \\
\text { Quan } 2 \mathrm{~B} \\
\text { FM K } \\
\text { Quan } 8 \mathrm{~B} \\
\text { Quan } 3 \mathrm{~B} \\
\text { Verb } 11 \\
\text { Res } 9 \\
\text { Hes } 3 \\
\text { Quan } 1 \mathrm{~B} \\
\text { Res } 2 \\
\text { Quan } 9 \mathrm{~B} \\
\text { Res } 6 \\
\text { Quan } 5 \mathrm{~B} \\
\text { Verb } 12 \\
\text { RT } 1 \\
\text { Loca } 3 \\
\text { M K } \\
\text { Verb } 20 \\
\text { AvgRT B } \\
\text { Loca } 12 \\
\text { Verb } 18 \\
\text { Verb } 16 \\
\text { Verb } 13 \\
\text { Loca } 5 \\
\text { Quan } 7 \mathrm{~B} \\
\text { Qual } 35 \\
\text { RT } 2 \\
\text { m K } \\
\text { Verb } 29\end{array}$ & $\begin{array}{l}106 \\
107 \\
108 \\
109 \\
110 \\
111 \\
112 \\
113 \\
114 \\
115 \\
116 \cdot 5 \\
116 \cdot 5 \\
118 \\
119 \\
120 \\
121 \\
122 \\
123 \\
124 \\
125 \\
126 \\
127 \\
128 \\
129 \\
130 \\
131 \\
132 \\
133 \\
134\end{array}$ \\
\hline \multicolumn{3}{|c|}{ Low Ut111ty, 2-16\% } & & \\
\hline & $\begin{array}{l}\text { Quan } 16 \text { B } \\
\text { AvgRT B } \\
\text { SumC K } \\
\text { Verb } 27 \\
\text { Quan } 11 \text { B } \\
\text { RT 2 } \\
\text { Loca } 3 \\
\text { Verb } 14\end{array}$ & 16.7 & $\begin{array}{ll}\text { Verb } & 19 \\
\text { Verb } & 14 \\
\text { Verb } & 23 \\
\text { Quan } & 11 \quad B \\
\text { Loca } & 6 \\
\text { SumC } & 8 \\
\text { Verb } & 21 \\
\text { Loca } & 7 \\
\end{array}$ & $\begin{array}{l}135 \\
136 \\
137 \\
138 \\
139 \\
140.5 \\
140.5 \\
142 \\
\end{array}$ \\
\hline
\end{tabular}


TABLE 2 continued.

UTILITY LEVEL OF EACI ITEM FOR THREE QUESTIONS COMBINED

\section{9}

TABLE 3 continued

SEQUENTIAL RANK OF EACH ITEL FOR THREE QUESTIONS COMBINED
Items

Verb 30

Toce 5

Verb 25

Verb 15

Verb 22

Fo B

Loce 11

Verb 28

Verb 17

W K

F1 B

Verb 24

Quan $13 \mathrm{~B}$

Qual 37

Guan $14 \mathrm{~B}$

RT 3

Iroca ?

RTAch B

Res 5

D K

Verb 33

Verb 32

Verb 31

Verb 26

RI 8

RTChr B

Loca 6

Quan $10 \mathrm{~B}$

Dbl 3

$\mathrm{Db} 12$

Loca 8

$x F$ B

Quan 24 B

Quan 12 B

Qual 36

Quan $15 \mathrm{~B}$

Loca 9

Anal B

Quan $33 \mathrm{~B}$

Quan $18 \mathrm{~B}$
13.9

$15 . ?$

14.8

Ut1I1ty

Items

Fo $B$

Loca 11

Loca 8

Loca 9

Quan $16 \mathrm{~B}$

Quan 29 B

BT 3

$X F \% B$

Fi B

Verb 15

W $k$

RTAch B

RTChr B

Verb 17

Quan $14 B$

Verb 27

Anal $B$

$\mathrm{DbI} 2$

Quan $13 \mathrm{~B}$

Db] 3

Verb 25

Res 5

BT 8

Verb 22

Quan $12 B$

Verb 24

D K

Quan $10 \mathrm{~B}$

Quan $15 \mathrm{~B}$

Verb 28

Zf $B$

Qual 37

Verb 30

Add B

Quan $18 \mathrm{~B}$

RT 10

Loca 1

Quan $24 \mathrm{~B}$

Verb 26

RT 6
Ranks

143

144

145

146

147

148

149

150

151

152

153

154

155

156.5

156.5

158

159

160

161

162

163.5

163.5

165

166

167

168

169

170

171

172

173

174

175

176

177

178.5

178.5

180

181

182 
TABLE 2 continued

UTILITY IEVEL OF EACE ITEM FOR THEER QUESTIONS COMBINED
TABLE 3 continued

SEQUENTIAL RANK OF EACH ITEM FOR THEEE QUESTIONS CORBINED

$\begin{array}{lc}\text { Items } & \begin{array}{c}\text { Ut111ty } \\ \text { Indices }\end{array} \\ \text { Quan } 31 \mathrm{~B} & 13.0 \\ \operatorname{Rign} 32 \mathrm{~B} & \\ \text { Loce } 10 & \\ \text { Quan } 28 \mathrm{~B} & 12.0 \\ \text { RT 6 } & \\ \text { Quan } 30 \mathrm{~B} & \\ \text { BT } 9 & \\ \text { RT 7 } & \\ \text { Add B } & \end{array}$

Loca 17

Quen $25 \mathrm{~B}$

Fo $\mathrm{K}$

FC K

Loca 18

Loca 29

Quan $17 \mathrm{~B}$

Quan $19 \mathrm{~B}$

RT 4

$\mathrm{RT} 5$

Quan $21 \mathrm{~B}$

Quan $20 \mathrm{~B}$

Zf $B$

T

Loca 15

Quan $22 B$

Quan $26 \mathrm{~B}$

Verb 34

Loca 27

Quan 27 B

Loca 25

C1 8

Loce 19

A $\mathrm{K}$

CF $\mathrm{K}$

A

Quan $23 \mathrm{~B}$

"if

Loca 20

Loca 16

11.1
Items Renks

Qual 36

BT?

Loca 18

Loca 17

RT 9

RT 4

CI $B$

Verb 31

RT 5

Loca 15

Quan 33 B

FC $K$

$F \%$ K

vers 32

Verb 33

Quan 17 B

Quan 19 B

Quan $31 \mathrm{~B}$

$P \pi$

Qua: $32 \frac{B}{25}$

Quan $30 \mathrm{~B}$

Loca 16

Quan 28 B

Loca 25

Loca 29

Loca 19

Quan 22 B

Loca 27

Ar $B$

$\mathrm{H} \mathrm{K}$

Quan $20 \mathrm{~B}$

Loca 31

CF K

Quan $26 \mathrm{~B}$

Loca 20

Quan $27 \mathrm{~B}$

183

184

185

186

187

188

189

190

191

192

193

194

195

196

197

198

199

200

201

202

203

204

205

206

$20 ?$

208

209

210

211

212

213

214

215

215

$21 ?$

218

219

Fd $B$

220

Loca 10

221

A $K$

222 
TABLE 2 continued

UTILITY LEVEL OF EACH ITEM FOR TIREE QUESTIONS COMBINED
TABLE 3 continued

SEQUENTIAI RANK OF EACH ITEN FOR THREE QUESTIONS COMBINED

\begin{tabular}{|c|c|c|c|}
\hline Items & $\begin{array}{l}\text { Utility } \\
\text { Indices }\end{array}$ & Items & Ranks \\
\hline 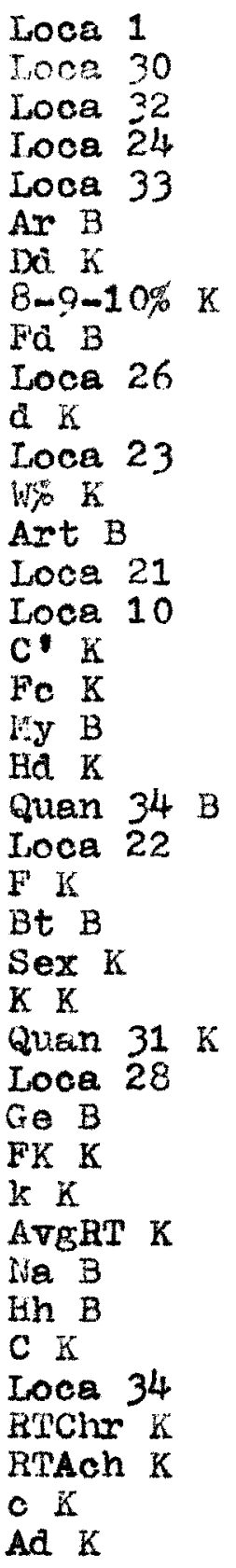 & $\begin{array}{r}10.2 \\
9.2\end{array}$ & 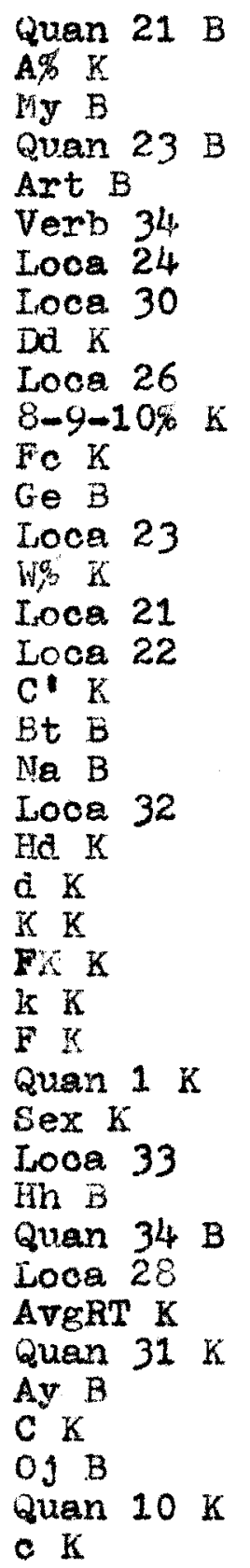 & $\begin{array}{l}223 \\
224 \\
225 \\
226 \\
227 \\
228 \\
229 \\
230 \\
231 \\
232 \\
233 \\
234 \\
235 \\
236 \\
237 \\
238 \\
239 \\
240 \\
241 \\
242 \\
243 \\
244 \\
245 \\
246 \\
247 \\
248 \\
249 \\
250 \\
251 \\
252 \\
253 \\
254 \\
255 \\
256 \\
257 \\
258 \\
259 \\
260.5 \\
260.5 \\
262\end{array}$ \\
\hline
\end{tabular}


TABLE 2 continued

UTILITY LEVEL OF EACH ITEH FOR TIREE QUESTIONS CONBINED
82

TABLE 3 continued

SEQUENRIAI RANH OF EACH ITEM FOB THREE QUESTIONS CONBINED
Items

Verb 35

$A$ B $B$

$\mathrm{PK}+\mathrm{OH}_{\mathrm{H}} \mathrm{K}$

of $B$

Succ K

Quan $1 \mathrm{~K}$

Vertb 36

$\mathrm{SK}$

Verb 37

Quan $35 \mathrm{~B}$

Quan $10 \mathrm{~K}$

Quan $23 \mathrm{~K}$

Quan $32 \mathrm{~K}$

guan $36 \mathrm{~B}$

$D \% K$

RoJ $K$

Quan 37 B

Quan $9 \mathrm{~K}$

Quan $8 \mathrm{~K}$

Quan $2 \mathrm{~K}$

Quan $11 \mathrm{~K}$

FI I

Quan $12 \mathrm{~K}$ Quan $13 \mathrm{~K}$ Quan $33 \mathrm{~K}$ Art $K$

At $K$

Quan $4 \mathrm{~K}$

Quan $21 \mathrm{~K}$

Quan $7 \mathrm{~K}$

Loca 36

Quan $15 \mathrm{~K}$

$\mathrm{Dd}+\mathrm{S} \% \mathrm{~K}$

Quan 22 is

Quan $29 \mathrm{~K}$

Quan $19 \mathrm{~K}$

Quan $3 \mathrm{~K}$

Quen $20 \mathrm{~K}$

Quan $16 \mathrm{~K}$

Quan $28 \mathrm{~K}$
6.5

5.6

4.6

$\frac{\text { Ut11ity }}{\text { Ind 1oes }}$

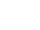

Items Ranks 


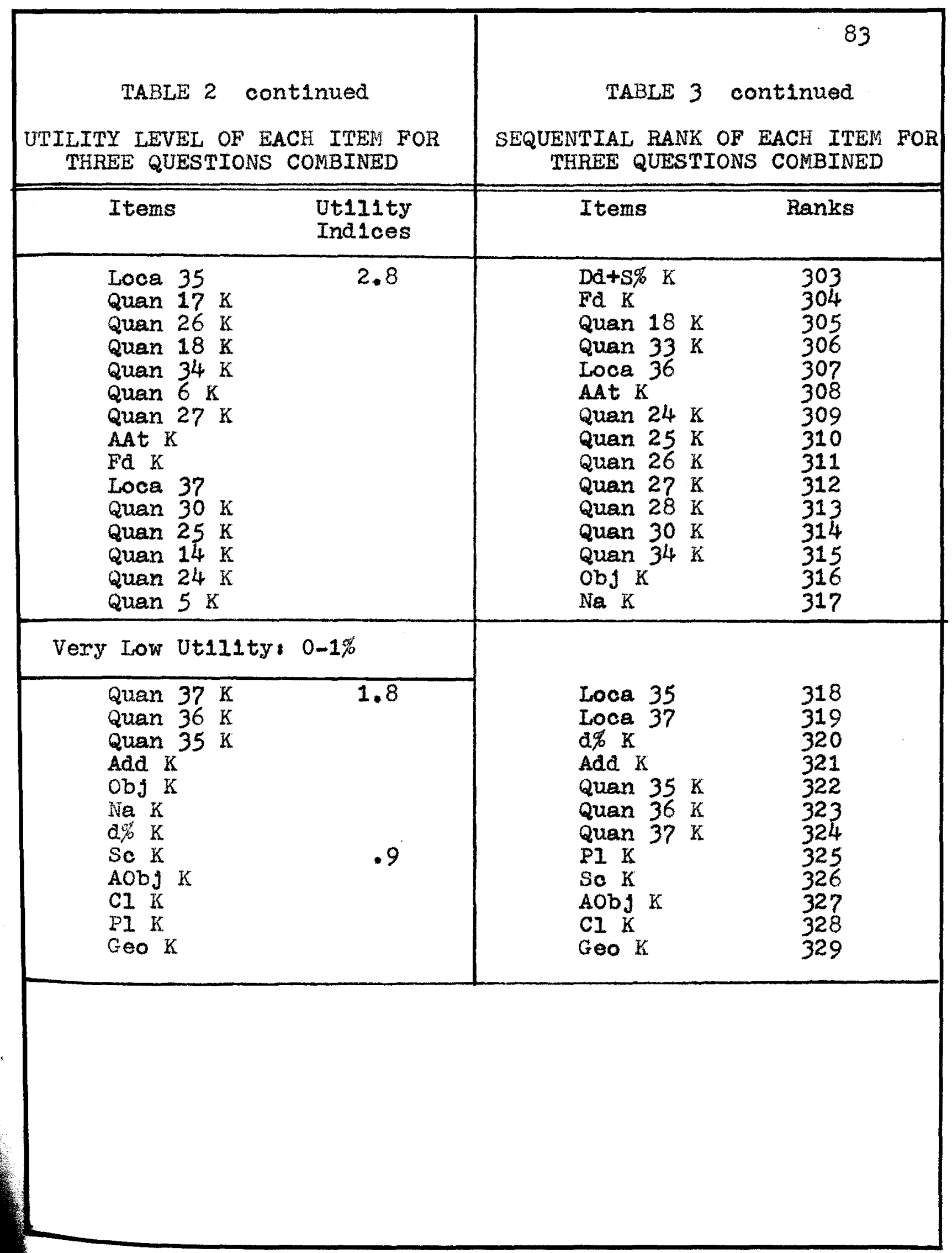


Tables 2 and 3 showed important variations, according to the phase of interpretation 1nvolved. That is, when the date were divided into tenths and separate spearman rho correlations calculated for each of the ten subgroups, different degrees of agreenent were obtained, as explained below.

The results of Tabie 4 indicate that the correspondence between frequency and sequence of information selection is highest during the inltial stages of Porschach interpretation, and at terminal stages (1ncluding information not selected at all, or information having little utility value). During the middle stages of interpretation, the correlations between what information is

\section{TABLE 4}

SPEARMAN RHO CORREILATIONS BETWEEN UTILITY INDICES AND MEAN RANKS OF TEN SUBGROUPS OF CARDS FOR THREE PROTOCOIS CONBINED

\begin{tabular}{c|ccc} 
Subgroups & rho & $t$ & $p$ \\
\hline 1 & .939 & 15.16 & .001 \\
3 & .016 & 12.69 & .001 \\
4 & .566 & 3.82 & .001 \\
5 & .237 & 1.36 & .20 \\
6 & -.155 & -.87 & $\mathrm{NS}$ \\
7 & -.629 & -4.50 & .001 \\
8 & .294 & 1.71 & .10 \\
9 & .568 & 3.84 & .001 \\
10 & .277 & 1.58 & .20 \\
\hline
\end{tabular}


used and how it is used decline to mon-significance and nesative simnificance. These midale stages Iikely represent the critical stages of variation in Rorschach interpretation, influenced by both the clinical question asked and the stylistic differences of individual clinicians.

Summary results for the number of cards selected and time taken for each of the three questions are provided in Table 5.

\section{TABIE 5}

SUPMARY RESULTS FOR CARDS SELECTED AND TIME TAKEN PER QUES PION

\begin{tabular}{|c|ccc|c|}
\hline \multirow{2}{*}{$\begin{array}{l}\text { Neas- } \\
\text { ures }\end{array}$} & \multicolumn{4}{|c|}{ Questions } \\
\cline { 2 - 5 } & I & II & III & I-II-III \\
\end{tabular}

Number Cards selected

\begin{tabular}{|l|cccc|c|}
\hline Mean & 70.8 & 71.9 & 47.9 & 63.5 & 22.96 \\
$\mathrm{SD}$ & 37.6 & 35.0 & 39.0 & 33.8 & \\
Range & $7-157$ & $12-154$ & $5-151$ & $24-431$ & \\
\hline
\end{tabular}

Number Minutes Taken

\begin{tabular}{|l|llll|l|}
\hline Mean & 26.3 & 29.7 & 14.9 & 23.6 & 31.85 \\
SD & 14.6 & 20.0 & 13.0 & 13.2 & \\
Range & $5-67$ & $7-120$ & $2-64$ & & \\
\hline
\end{tabular}

* Frdedman two-way analysis of varlance results both significant at .001 level. 
The Rorschach interpretations requined an average of sixty-four separate information items judged "necessary and sufficient," and twenty-four ninutes time with prepared data. The Friedman Analysis of Varlance results support the mejor hypothesis that interpretative approach is influenced by the type of clinical question asked.

Table 5 shows that there were significant differences in the number of cards selected and in the amount of time taken to arrive at answers to the three clinical questions. It may be noted, however, that these particular $x_{y^{2}}{ }^{2}$ sienificances are due largely to the influence of the Intelilgence question. Tests of $t$ between the means of the Diagnosis and Anxlety questions in both Instances falled to reach significance (Cards $=t$ of .34 . Minutes $=\underline{t}$ of 1.13). Intelligenoe estimation as a question presented least diffloulty for the cliniclans. The Anxiety estimation task proved to be the most difficult of the three, requiring the largest number of cerds and the most time. The question of Dlagnosis was only slightly lower in diffloulty than that of Anxiety. The high degree of individual variation among cilniclans may be seen by the relatively wide standard deviations and ranges obtained.

The Ut1lity Index and Mean Rank results in Tables 6 and 7 thow the usages of each information card for the three questions. these results are accompenied by Friedman $x_{x}^{2}$ 's to indicate which Items showed differential utility across questions. The non- 
parametric Friedman two-way analysis of variance test determines the I1kelihood of different columns of ranks having come from the same population. In computing the Friedman tests, $N$ was equal to thirty-six (clinicians) and $K$ was equal to three (protocols). The items in Tables 6 and 7 have been grouped accorcing to their traditional Rorschach categories, in the order in which the information 1tems appeared on the apparatus. Results of these two tables w111 be combined in the following alscussion of information categorles. Where applicable, the primary focus will be on the Beck categories, as the Klopfer categories generally falled to contribute significances, due to sample I1mitations. Also, the overall Utility Indices for each category will be based on the percentage of cards selected within each of the categories, In order to equalize the varying number of cards across categories (range $=9-37)$.

The first of the categorles to be discussed is the non-Rorschach Personal Data category which provided background information on each of the test subjects. It was predicted that the ut1l1ty value of Personal Data would be highest for the task on Protocol I. next highest for the task on Protocol II, and lowest for that on protocol III. The prediction was partially confirmed. The general utility value of this category was lowest for protocol III (UI = 29.2), but slightly higher for Protocol II (UI = 46.6) compared with Protocol I (UI = 46.4). The Anxiety question -11c1ted significantly greater interest in the subject's Marital 
TABLE 6

UTIIITY INDICES (UI) AND UTILITY LEVELS (UL) FOR PERSONAL DATA ITEMS

\begin{tabular}{|c|c|c|c|c|c|c|c|c|}
\hline \multirow[b]{3}{*}{ Items } & \multicolumn{6}{|c|}{ Questions } & \multirow[b]{3}{*}{$x_{r^{2}}{ }^{*}$} & \multirow[b]{3}{*}{$\mathrm{P}$} \\
\hline & \multicolumn{2}{|c|}{ Diagnosis } & \multicolumn{2}{|c|}{ Anxiety } & \multicolumn{2}{|c|}{ Intelligence } & & \\
\hline & UI & UL & UI & UI & UI & UL & & \\
\hline Sex & 75.0 & $\mathrm{AH}$ & 80.5 & $\mathrm{AH}$ & 69.4 & $\mathrm{AH}$ & 3.96 & \\
\hline Age & $77 \cdot 7$ & $A H$ & 86.1 & $\mathrm{H}$ & $77 \cdot ?$ & AH & 3.83 & \\
\hline$E d$ & 69.4 & $A H$ & 61.1 & $\mathrm{AH}$ & 77.7 & AH & $4 \cdot 59$ & \\
\hline $\mathrm{Occ}$ & 61.1 & AH & 52.7 & $\mathrm{AH}$ & 38.8 & AI & $5 \cdot 51$ & .10 \\
\hline $\mathrm{Nty}$ & 30.5 & AI & 25.0 & AI & 19.4 & $A I$ & 3.96 & \\
\hline Rel & $27 \cdot 7$ & AL & $22 \cdot 2$ & $\mathrm{AL}$ & $8 \cdot 3$ & $I$ & 5.09 & .10 \\
\hline Mar & 50.0 & AL & 66.6 & $\mathrm{AH}$ & 13.8 & $\mathrm{I}$ & 15.34 & .001 \\
\hline SPO & 33.3 & AL & 36.1 & $A I$ & 11.1 & L & 6.52 & .05 \\
\hline Sibs & 30.5 & $A I$ & 27.7 & AL & 8.3 & $\mathrm{I}$ & 5.85 & .10 \\
\hline Mo & 38.8 & AL & 38.8 & AI & 13.8 & L & 6.86 & .05 \\
\hline $\mathrm{Fa}$ & 38.8 & AI & 38.8 & AI & 13.8 & I & 6.86 & .05 \\
\hline$S x 1$ & 50.0 & AL & 63.8 & $\mathrm{AH}$ & 22.2 & AL & 10.81 & .01 \\
\hline Mty & 30.5 & AI & 16.6 & AI & 8.3 & $I$ & 5.51 & .10 \\
\hline Int & 36.1 & AI & 36.1 & AI & 25.0 & AI & 4.13 & \\
\hline
\end{tabular}

* Friedman two-way analysis of variance. 


\section{TABLE 6 continued}

UTILITY INDICES (UI) AND UTILITY LEVELS (UL) PUR LOCATION ITEMS

\begin{tabular}{|c|c|c|c|c|c|c|c|c|}
\hline \multirow[b]{3}{*}{ Items } & \multicolumn{6}{|c|}{ questions } & \multirow[b]{3}{*}{$x_{r^{2 *}}$} & \multirow[b]{3}{*}{$\mathbf{p}$} \\
\hline & \multicolumn{2}{|c|}{ Diagnos18 } & \multicolumn{2}{|c|}{ Anxiety } & \multicolumn{2}{|c|}{ Intelligence } & & \\
\hline & UI & UL & UI & UL & UI & UL & & \\
\hline \multicolumn{9}{|c|}{ Klopfer } \\
\hline$W$ & 11.1 & $L$ & 11.1 & L & 22.2 & $\mathrm{AL}$ & 4.13 & \\
\hline D & 11.1 & $L$ & 13.8 & I & 16.6 & A.L & 3.58 & \\
\hline d & 5.5 & L & 8.3 & L & 11.1 & $I$ & 3.58 & \\
\hline $\mathrm{Dd}$ & 8.3 & $\mathbf{L}$ & 11.1 & $\mathbf{L}$ & 8.3 & $I$ & 3.50 & \\
\hline 3 & 5.5 & $\mathbf{I}$ & 8.3 & $I$ & 2.7 & $\mathbf{L}$ & 3.58 & \\
\hline$w \%$ & 5.5 & $\mathbf{L}$ & 5.5 & $I$ & 13.8 & $L$ & 3.83 & \\
\hline$D \%$ & 5.5 & $L$ & 2.7 & L & 5.5 & $I$ & 3.50 & \\
\hline $\mathrm{d} \%$ & 2.7 & I & 2.7 & L & 0.0 & VL & 3.50 & \\
\hline$D d+B \%$ & 5.5 & $I$ & 2.7 & 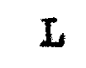 & 2.7 & $\mathbf{L}$ & 3.50 & \\
\hline Succ & 2.7 & $I$ & 5.5 & $\mathrm{I}$ & 8.3 & $\mathrm{I}$ & 3.58 & \\
\hline \multicolumn{9}{|c|}{ Beck } \\
\hline$w$ & 36.1 & AL & 30.5 & $A I$ & 47.2 & AL & 4.63 & .20 \\
\hline$D$ & 25.0 & $A L$ & 30.5 & $A \perp$ & 22.2 & $A L$ & 3.75 & \\
\hline $\mathrm{Dd}$ & 33.3 & AL & 27.7 & AI & 19.4 & AI & 4.25 & \\
\hline$s$ & 36.1 & $A I$ & 27.7 & $A L$ & 13.8 & $I$ & 5.51 & .10 \\
\hline App & 25.0 & AL & 27.7 & $A L$ & 33.3 & AL & 3.75 & \\
\hline Seq & 19.4 & AI & 16.6 & $A L$ & 19.4 & $A L$ & 3.50 & \\
\hline AfIR & 22.2 & $A L$ & 30.5 & $A L$ & 8.3 & I & 5.51 & .10 \\
\hline$z f$ & 5.5 & $I$ & 5.5 & L & 22.2 & AL & 4.97 & .10 \\
\hline Zoum & 8.3 & $\mathbf{L}$ & 13.8 & $I$ & 50.0 & $A L$ & 11.81 & .01 \\
\hline
\end{tabular}


TABLE 6 continued

UTILITY INDICES (UI) AND UTILITY LEVELS (UL) FOR DETERMINANT IMEIIS

\begin{tabular}{|c|c|c|c|c|c|c|c|c|}
\hline \multirow[b]{3}{*}{ Items } & \multicolumn{6}{|c|}{ questions } & \multirow{3}{*}{$x_{r} 2^{*}$} & \multirow[b]{3}{*}{$P$} \\
\hline & \multicolumn{2}{|c|}{ Diagnosis } & \multicolumn{2}{|c|}{ Anxiety } & \multicolumn{2}{|c|}{ Intelligence } & & \\
\hline & UI & UL & UI & UL & UI & UI & & \\
\hline \multicolumn{9}{|c|}{ Klopfer } \\
\hline $\begin{array}{l}K \\
F M \\
m \\
k \\
K \\
F K \\
F \\
F C \\
c \\
C \\
F C \\
C F \\
C\end{array}$ & $\begin{array}{r}19.4 \\
22.2 \\
13.8 \\
8.3 \\
8.3 \\
8.3 \\
8.3 \\
11.1 \\
5.5 \\
8.3 \\
16.6 \\
16.6 \\
11.1\end{array}$ & $\begin{array}{c}\text { AI } \\
\text { AL } \\
I \\
I \\
I \\
I \\
I \\
I \\
I \\
I \\
A L \\
\text { AI } \\
L\end{array}$ & $\begin{array}{r}13.8 \\
19.4 \\
22.2 \\
11.1 \\
11.1 \\
11.1 \\
8.3 \\
11.1 \\
11.1 \\
13.8 \\
13.8 \\
11.1 \\
5.5\end{array}$ & $\begin{array}{l}\text { I } \\
\text { AL } \\
\text { AI } \\
\text { I } \\
\text { I } \\
\text { I } \\
\text { I } \\
\text { I } \\
\text { I } \\
\text { I } \\
\text { I } \\
\text { I } \\
\text { I }\end{array}$ & $\begin{array}{r}22.2 \\
22.2 \\
16.6 \\
2.7 \\
2.7 \\
2.7 \\
5.5 \\
2.7 \\
2.7 \\
2.7 \\
5.5 \\
2.7 \\
2.7\end{array}$ & $\begin{array}{l}\text { AI } \\
\text { AI } \\
\text { AL } \\
I \\
I \\
I \\
I \\
I \\
I \\
I \\
I \\
I \\
I\end{array}$ & $\begin{array}{l}3.75 \\
3.50 \\
3.75 \\
3.75 \\
3.75 \\
3.75 \\
3.50 \\
3.83 \\
3.75 \\
3.96 \\
4.00 \\
4.25 \\
3.75\end{array}$ & \\
\hline \multicolumn{9}{|c|}{ Beck } \\
\hline $\begin{array}{l}M \\
C \\
C F \\
F C \\
Y \\
Y F \\
F Y \\
T \\
T F \\
F T \\
V \\
V F \\
P V \\
F+ \\
P- \\
P O \\
D D 11 \\
D b 12 \\
D D 13\end{array}$ & $\begin{array}{l}55.5 \\
52.7 \\
50.0 \\
50.0 \\
36.1 \\
36.1 \\
41.6 \\
30.5 \\
33.3 \\
36.1 \\
33.3 \\
33.3 \\
33.3 \\
27.7 \\
30.5 \\
22.2 \\
30.5 \\
30.5 \\
30.5\end{array}$ & $\begin{array}{l}\text { AH } \\
A H \\
A I \\
A L \\
A L \\
A L \\
A I \\
A L \\
A L \\
A I \\
A L \\
A L \\
A L \\
A L \\
A L \\
A L \\
A L \\
A L \\
A L\end{array}$ & $\begin{array}{l}52.7 \\
41.6 \\
44.4 \\
41.6 \\
47.2 \\
44.4 \\
44.4 \\
30.5 \\
25.0 \\
30.5 \\
33.3 \\
30.5 \\
33.3 \\
25.0 \\
25.0 \\
13.8 \\
25.0 \\
.0 .0 \\
0.0\end{array}$ & $\begin{array}{l}A H \\
A L \\
A L \\
A L \\
A L \\
A L \\
A L \\
A L \\
A I \\
A L \\
A L \\
A L \\
A I \\
A L \\
A L \\
I L \\
A L \\
V L \\
V L\end{array}$ & $\begin{array}{r}58.3 \\
16.6 \\
16.6 \\
13.8 \\
5.5 \\
5.5 \\
5.5 \\
2.7 \\
2.7 \\
5.5 \\
5.5 \\
8.3 \\
8.3 \\
11.1 \\
11.1 \\
8.3 \\
11.1 \\
11.1 \\
11.1\end{array}$ & $\begin{array}{l}\text { AH } \\
\text { AL } \\
\text { AI } \\
I \\
L \\
I \\
L \\
I \\
I \\
L \\
I \\
L \\
I \\
I \\
I \\
I \\
I \\
I \\
L\end{array}$ & $\begin{array}{r}3.58 \\
9.04 \\
8.66 \\
9.29 \\
11.06 \\
10.30 \\
11.14 \\
7.66 \\
7.53 \\
7.78 \\
7.66 \\
6.52 \\
6.86 \\
4.76 \\
5.09 \\
4.25 \\
5.09 \\
7.36 \\
7.36\end{array}$ & $\begin{array}{l}.05 \\
.02 \\
.01 \\
.01 \\
.01 \\
.01 \\
.05 \\
.05 \\
.05 \\
.05 \\
.05 \\
.05 \\
.10 \\
.10 \\
.10 \\
.05 \\
.05\end{array}$ \\
\hline
\end{tabular}


TABIE 6 continued

UTILITY INDICES (UI) AND UTIIITY LEVEIS (UL) FOR CONTENT ITENS

\begin{tabular}{|c|c|c|c|c|c|c|c|c|}
\hline \multirow[b]{3}{*}{ Items } & \multicolumn{6}{|c|}{ Questions } & \multirow{3}{*}{$x_{r} 2^{*}$} & \multirow[b]{3}{*}{$P$} \\
\hline & \multicolumn{2}{|c|}{ DLagnogia } & \multicolumn{2}{|c|}{ Anxiety } & \multicolumn{2}{|c|}{ Inte11igence } & & \\
\hline & UI & UL & UI & UI & UI & UL & & \\
\hline \multicolumn{9}{|c|}{ Kloplex } \\
\hline $\begin{array}{l}\text { H } \\
\mathrm{Hd} \\
\mathrm{A} \\
\mathrm{Ad} \\
\mathrm{At} \\
\mathrm{AAt} \\
\mathrm{AObj} \\
\mathrm{Art} \\
\mathrm{Cl} \\
\mathrm{Bd} \\
\mathrm{PLxe} \\
\mathrm{GeO} \\
\mathrm{Na} \\
\mathrm{Obj} \\
\mathrm{PL} \\
\mathrm{Be} \\
\mathrm{Sex}\end{array}$ & 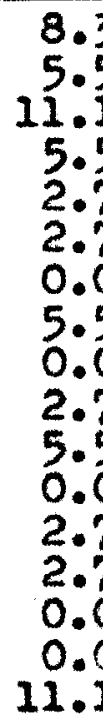 & $\begin{array}{c}I \\
L \\
I \\
I \\
I \\
I \\
V I \\
L \\
V L \\
L \\
L \\
V I \\
L \\
I \\
V L \\
V L \\
L\end{array}$ & $\begin{array}{c}11 \\
11 \\
11 \\
8 \\
8 \\
2 \\
0 \\
2 \\
0 . \\
2 . \\
5 \\
0 . \\
0 . \\
0 . \\
0 . \\
0 . \\
5 .\end{array}$ & $\begin{array}{c}I \\
L \\
L \\
L \\
L \\
L \\
V I \\
I \\
V I \\
L \\
I \\
V I \\
V I \\
V I \\
V L \\
V L \\
I\end{array}$ & $\begin{array}{r}11 \\
8 \\
8 \\
5 \\
0 \\
2 \\
2 \\
2 \\
2 \\
2 \\
2 \\
0 \\
2 \\
2 \\
2 \\
2 \\
5\end{array}$ & $\begin{array}{c}\mathrm{L} \\
\mathrm{L} \\
\mathrm{L} \\
\mathrm{L} \\
\mathrm{VL} \\
\mathrm{L} \\
\mathrm{I} \\
\mathrm{L} \\
\mathrm{L} \\
\mathrm{L} \\
\mathrm{L} \\
\mathrm{VL} \\
\mathrm{L} \\
\mathrm{L} \\
\mathrm{L} \\
\mathrm{L} \\
\mathrm{L}\end{array}$ & $\begin{array}{l}3.50 \\
3.58 \\
3.50 \\
3.50 \\
3.75 \\
3.46 \\
3.50 \\
3.50 \\
3.50 \\
3.46 \\
3.50 \\
3.46 \\
3.50 \\
3.50 \\
3.50 \\
3.50 \\
3.62\end{array}$ & \\
\hline \multicolumn{9}{|c|}{ Beck } \\
\hline $\begin{array}{l}\text { H } \\
\text { Hd } \\
\text { A } \\
\text { Ad } \\
\text { An } \\
\text { Anal } \\
\text { Ar } \\
\text { Art } \\
\text { Ay } \\
\text { Bt } \\
\text { C1 } \\
\text { rd } \\
\text { H1 } \\
\text { Ge } \\
\text { Hh } \\
\text { Iy } \\
\text { Na } \\
\text { Oj }\end{array}$ & 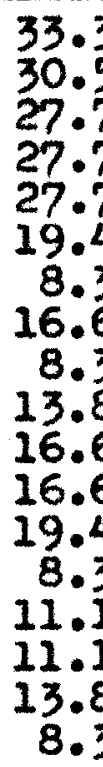 & $\begin{array}{l}A I \\
A L \\
A L \\
A L \\
A L \\
A L \\
I \\
A I \\
I \\
L \\
A L \\
A I \\
A L \\
L \\
L \\
L \\
L \\
I\end{array}$ & $\begin{array}{c}30 \\
30 \\
19 . \\
22 \\
30 \\
16 \\
5 \\
5 \\
5 \\
5 \\
11 \\
8 \\
16 \\
5 . \\
5 \\
8 \\
5 \\
5 .\end{array}$ & $\begin{array}{l}\text { AI } \\
\text { AI } \\
\text { AL } \\
\text { AI } \\
\text { AL } \\
\text { AI } \\
I \\
I \\
I \\
I \\
I \\
I \\
\text { AI } \\
I \\
I \\
I \\
I \\
I\end{array}$ & $\begin{array}{r}13 . \\
5 . \\
19 . \\
11 . \\
5 . \\
5 . \\
23 . \\
2 .\end{array}$ & $\begin{array}{l}I \\
I \\
\text { AI } \\
I \\
I \\
I \\
I \\
I \\
I \\
I \\
I \\
I \\
L \\
L \\
I \\
I \\
I \\
I\end{array}$ & $\begin{array}{l}5.26 \\
6.86 \\
3.83 \\
4.63 \\
6.52 \\
4.34 \\
3.75 \\
4.34 \\
3.58 \\
4.00 \\
3.96 \\
4.25 \\
4.00 \\
3.50 \\
3.75 \\
3.58 \\
4.00 \\
3.58\end{array}$ & $\begin{array}{r}.10 \\
.05 \\
.10 \\
.05\end{array}$ \\
\hline
\end{tabular}


TABI $\approx 6$ continued

UTIIITY INDICES (UI) AND UTILITY LEVELS (UL) FOR TOTALS ITEMS

\begin{tabular}{|c|c|c|c|c|c|c|c|c|}
\hline \multirow[b]{3}{*}{ Items } & \multicolumn{6}{|c|}{ Questions } & \multirow{3}{*}{$x_{r} 2^{*}$} & \multirow[b]{3}{*}{$p$} \\
\hline & \multicolumn{2}{|c|}{ Diagnosis } & \multicolumn{2}{|c|}{ Anxiety } & \multicolumn{2}{|c|}{ Intelligence } & & \\
\hline & UI & UL & UI & UL & UI & UL & & \\
\hline \multicolumn{9}{|c|}{ Klopfer } \\
\hline $\begin{array}{l}\text { R } \\
\text { AvgRT } \\
\text { RTAch } \\
\text { RTChr } \\
\text { F\% } \\
\text { FK+\% } \\
\text { A\% } \\
\text { P } \\
\text { SumC } \\
8-10 \% \\
\text { Add } \\
\text { Rej }\end{array}$ & $\begin{array}{r}16.6 \\
5.5 \\
8.3 \\
8.3 \\
11.1 \\
5.5 \\
11.1 \\
11.1 \\
22.2 \\
5.5 \\
2.7 \\
5.5\end{array}$ & $\begin{array}{c}\mathrm{AL} \\
\mathrm{I} \\
\mathrm{L} \\
\mathrm{L} \\
\mathrm{I} \\
\mathrm{L} \\
\mathrm{I} \\
\mathrm{L} \\
\mathrm{AI} \\
\mathrm{L} \\
\mathrm{I} \\
\mathrm{I}\end{array}$ & $\begin{array}{r}16.6 \\
8.3 \\
8.3 \\
8.3 \\
13.8 \\
8.3 \\
11.1 \\
11.1 \\
16.6 \\
13.8 \\
2.7 \\
8.3\end{array}$ & $\begin{array}{c}\text { AL } \\
I \\
I \\
I \\
I \\
I \\
I \\
I \\
\text { AI } \\
L \\
I \\
I\end{array}$ & $\begin{array}{r}25.0 \\
8.3 \\
2.7 \\
2.7 \\
11.1 \\
2.7 \\
8.3 \\
11.1 \\
11.1 \\
8.3 \\
0.0 \\
0.0\end{array}$ & $\begin{array}{c}\text { AI } \\
I \\
I \\
I \\
I \\
I \\
I \\
I \\
I \\
I \\
V I \\
V I\end{array}$ & $\begin{array}{l}3.83 \\
3.50 \\
3.62 \\
3.62 \\
3.50 \\
3.58 \\
3.50 \\
3.46 \\
3.96 \\
3.75 \\
3.50 \\
3.75\end{array}$ & \\
\hline \multicolumn{9}{|c|}{ Beck } \\
\hline $\begin{array}{l}\mathrm{R} \\
\mathrm{F} \% \\
\mathrm{XF} \% \\
\mathrm{~F}+\% \\
\mathrm{XF}+\% \\
\mathrm{~A}^{\%} \% \\
\mathrm{P} \\
\text { AVgRT } \\
\text { RTAch } \\
\text { RTChr } \\
\text { Add } \\
\text { Rej }\end{array}$ & $\begin{array}{l}58.3 \\
36.1 \\
11.1 \\
72.2 \\
30.5 \\
30.5 \\
50.0 \\
27.7 \\
19.4 \\
19.4 \\
13.8 \\
25.0\end{array}$ & $\begin{array}{l}A H \\
A L \\
I \\
A H \\
A L \\
A L \\
A L \\
A L \\
A L \\
A L \\
I L \\
A L\end{array}$ & $\begin{array}{l}52.7 \\
36.1 \\
16.6 \\
58.3 \\
33.3 \\
36.1 \\
44.4 \\
16.6 \\
19.4 \\
19.4 \\
11.1 \\
30.5\end{array}$ & $\begin{array}{l}\text { AH } \\
\text { AI } \\
\text { AI } \\
\text { AH } \\
\text { AI } \\
\text { AL } \\
\text { AL } \\
\text { AL } \\
\text { AL } \\
\text { AL } \\
\text { I } \\
\text { AL }\end{array}$ & $\begin{array}{r}55.5 \\
25.0 \\
13.8 \\
61.1 \\
33.3 \\
25.0 \\
25.0 \\
5.5 \\
2.7 \\
2.7 \\
11.1 \\
8.3\end{array}$ & $\begin{array}{l}A H \\
A L \\
I \\
A H \\
A L \\
A I \\
A I \\
I \\
L \\
I \\
I \\
L\end{array}$ & $\begin{array}{l}3.58 \\
4.13 \\
3.58 \\
4.34 \\
3.50 \\
3.96 \\
6.27 \\
5.47 \\
4.97 \\
4.97 \\
3.50 \\
5.64\end{array}$ & $\begin{array}{l}.05 \\
.10 \\
.10 \\
.10 \\
.10\end{array}$ \\
\hline
\end{tabular}


TABLE 6 continued

UTILITY INDICES (UI) AND UTILITY LEVELS (UL) FOR QUANTITATIVE SCORING ITEMS--KLOPFER

\begin{tabular}{|c|c|c|c|c|c|c|c|c|}
\hline \multirow[b]{3}{*}{ Items } & \multicolumn{6}{|c|}{ Questions } & \multirow{3}{*}{$x_{x} 2$} & \multirow[b]{3}{*}{$P$} \\
\hline & \multicolumn{2}{|c|}{ Diagnosis } & \multicolumn{2}{|c|}{ Anxiety } & \multicolumn{2}{|c|}{ Intelligence } & & \\
\hline & UI & UL & UI & UL & UI & UL & & \\
\hline $\begin{array}{l}1 \\
2 \\
3 \\
4 \\
5 \\
6 \\
7 \\
8 \\
9 \\
10 \\
11 \\
12 \\
13 \\
14 \\
15 \\
16 \\
17 \\
18 \\
19 \\
20 \\
21 \\
22 \\
23 \\
24 \\
25 \\
26 \\
27 \\
28 \\
29 \\
30 \\
31 \\
32 \\
33 \\
34 \\
35 \\
36 \\
37\end{array}$ & $\begin{array}{l}2.7 \\
2.7 \\
2.7 \\
2.7 \\
2.7 \\
2.7 \\
5.5 \\
5.5 \\
2.7 \\
2.7 \\
5.5 \\
2.7 \\
2.7 \\
2.7 \\
2.7 \\
2.7 \\
2.7 \\
2.7 \\
2.7 \\
5.5 \\
5.5 \\
5.5 \\
8.3 \\
2.7 \\
2.7 \\
2.7 \\
2.7 \\
2.7 \\
2.7 \\
2.7 \\
2.7 \\
2.7 \\
0.7 \\
0.7 \\
0.0\end{array}$ & $\begin{array}{l}I \\
I \\
I \\
I \\
I \\
I \\
I \\
I \\
I \\
I \\
I \\
I \\
I \\
I \\
I \\
I \\
I \\
I \\
I\end{array}$ & 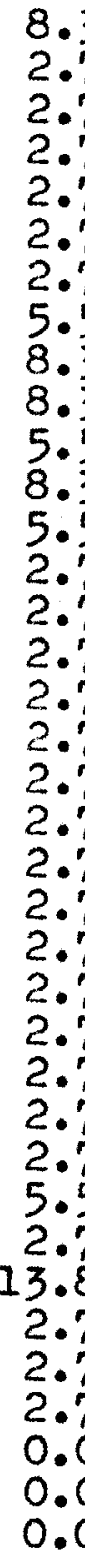 & 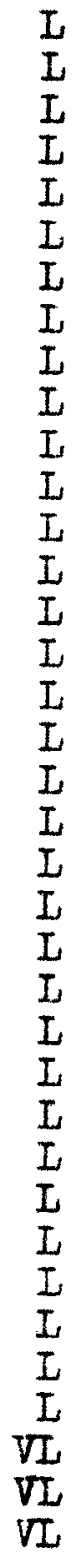 & 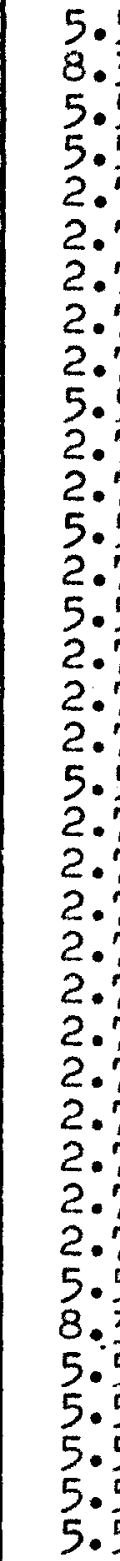 & $\begin{array}{l}I \\
I \\
I \\
I \\
I \\
I \\
I \\
I \\
I \\
I \\
I \\
I \\
I \\
I \\
I \\
I \\
I \\
I \\
I \\
I \\
I \\
I \\
I \\
I \\
I \\
I \\
I \\
I \\
I \\
I \\
I \\
I \\
I \\
I \\
I \\
I \\
I \\
I\end{array}$ & $\begin{array}{l}3.58 \\
3.62 \\
3.50 \\
3.50 \\
3.46 \\
3.46 \\
3.50 \\
3.50 \\
3.62 \\
3.58 \\
3.50 \\
3.62 \\
3.50 \\
3.46 \\
3.50 \\
3.46 \\
3.46 \\
3.46 \\
3.50 \\
3.50 \\
3.50 \\
3.50 \\
3.62 \\
3.46 \\
3.46 \\
3.46 \\
3.46 \\
3.50 \\
3.65 \\
3.62 \\
3.62 \\
3.50 \\
3.58 \\
3.62 \\
3.50 \\
3.50\end{array}$ & \\
\hline
\end{tabular}


TABLE 6 continued

UTILITY INDICLS (UI) AND UTIIITY LEVEIS (UL) FOR QUANTITATIVE SCORING ITEMS-BECK

\begin{tabular}{|c|c|c|c|c|c|c|c|c|}
\hline \multirow[b]{3}{*}{ Items } & \multicolumn{6}{|c|}{ Questions } & \multirow{3}{*}{$x_{r^{2}}$} & \multirow[b]{3}{*}{$P$} \\
\hline & \multicolumn{2}{|c|}{ Diagnosis } & \multicolumn{2}{|c|}{ Anxiety } & \multicolumn{2}{|c|}{ Intelligence } & & \\
\hline & UI & UI & UI & UI & UI & UL & & \\
\hline 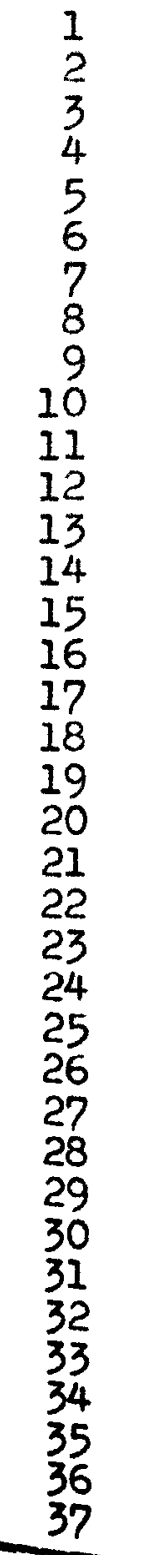 & $\begin{array}{l}19.4 \\
22.2 \\
16.6 \\
25 . \\
22.2 \\
27 . \\
19.4 \\
22.2 \\
22.2 \\
16.6 \\
13.8 \\
13.8 \\
13.8 \\
16.6 \\
13.8 \\
19.4 \\
19.4 \\
16.6 \\
16.6 \\
11.1 \\
11.1 \\
11.1 \\
19.4 \\
16.6 \\
19.4 \\
16.6 \\
13.8 \\
13.8 \\
22.0 \\
16.6 \\
13.8 \\
11.1 \\
16.6 \\
2.7 \\
0.0 \\
0.0 \\
0.0\end{array}$ & 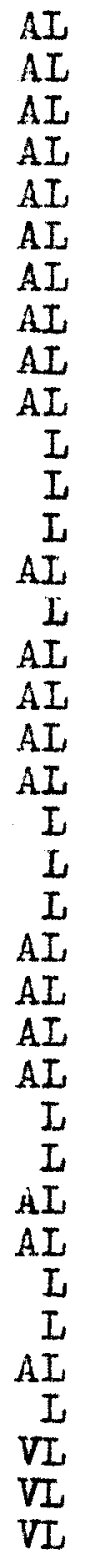 & $\begin{array}{l}22 . \\
19 . \\
25 . \\
16 . \\
16 . \\
16 . \\
16 . \\
25 . \\
19 . \\
13 . \\
22 . \\
19 . \\
25 . \\
19 . \\
19 . \\
22 . \\
13 . \\
19 . \\
13 . \\
16 . \\
16 . \\
16 . \\
8 . \\
13 . \\
8 . \\
11 . \\
13 . \\
11 . \\
13.8 \\
8 . \\
11 . \\
8 . \\
8 . \\
8 . \\
2 . \\
0 . \\
0 .\end{array}$ & 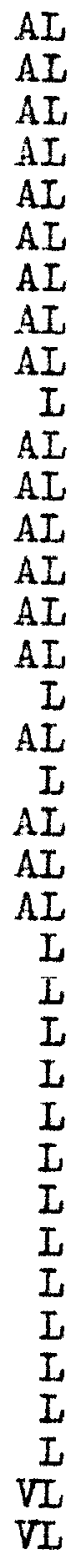 & $\begin{array}{l}13 . \\
16 . \\
16 . \\
22 . \\
19 . \\
19 . \\
16 . \\
16 . \\
19 . \\
11 . \\
13 . \\
8 . \\
5 . \\
8 . \\
8 . \\
8 . \\
2 . \\
5 . \\
5 . \\
5 . \\
5 . \\
5 . \\
2 . \\
11 . \\
8 . \\
5 . \\
5 . \\
11 . \\
16.6 \\
11.1 \\
13.8 \\
19.4 \\
16.6 \\
13.8 \\
13.8 \\
13.8 \\
13.8\end{array}$ & 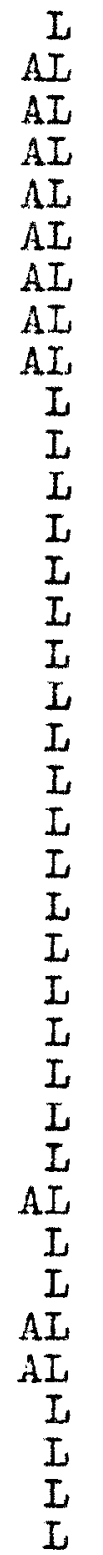 & $\begin{array}{l}3.75 \\
3.58 \\
3.83 \\
3.75 \\
3.58 \\
4.00 \\
3.50 \\
3.75 \\
3.50 \\
3.58 \\
3.83 \\
3.96 \\
5.01 \\
4.00 \\
3.96 \\
4.34 \\
4.63 \\
4.34 \\
4.00 \\
3.96 \\
3.96 \\
3.96 \\
4.63 \\
3.58 \\
4.13 \\
3.96 \\
3.83 \\
3.50 \\
3.75 \\
3.75 \\
3.50 \\
4.00 \\
3.83 \\
3.96 \\
4.34 \\
4.51 \\
4.51\end{array}$ & $\begin{array}{r}.10 \\
.10\end{array}$ \\
\hline
\end{tabular}


TABLE 6 continued

UTILITY INDICES (UI) AND UTILITY LEVELS (UL) FOR FREE ASSOCIATION ITEMS

\begin{tabular}{|c|c|c|c|c|c|c|c|c|}
\hline \multirow[b]{3}{*}{ Items } & \multicolumn{6}{|c|}{ Questions } & \multirow{3}{*}{$x r^{2}$} & \multirow[b]{3}{*}{$P$} \\
\hline & \multicolumn{2}{|c|}{ Diagnosis } & \multicolumn{2}{|c|}{ Anxiety } & \multicolumn{2}{|c|}{ Intelligence } & & \\
\hline & UI & UL & UI & UI, & UI & UL & & \\
\hline 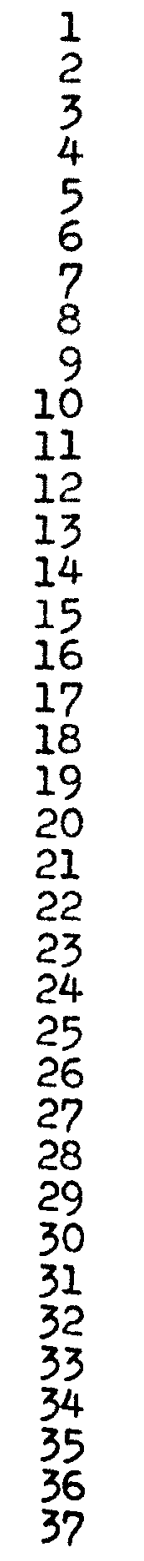 & 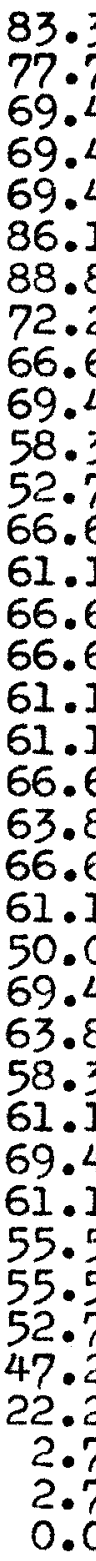 & $\begin{array}{r}\mathrm{AH} \\
\mathrm{AH} \\
\mathrm{AH} \\
\mathrm{AH} \\
\mathrm{AH} \\
\mathrm{H} \\
\mathrm{H} \\
\mathrm{AH} \\
\mathrm{AH} \\
\mathrm{AH} \\
\mathrm{AH} \\
\mathrm{AH} \\
\mathrm{AH} \\
\mathrm{AH} \\
\mathrm{AH} \\
\mathrm{AH} \\
\mathrm{AH} \\
\mathrm{AH} \\
\mathrm{AH} \\
\mathrm{AH} \\
\mathrm{AH} \\
\mathrm{AH} \\
\mathrm{AL} \\
\mathrm{AH} \\
\mathrm{AH} \\
\mathrm{AH} \\
\mathrm{AH} \\
\mathrm{AH} \\
\mathrm{AH} \\
\mathrm{AH} \\
\mathrm{AH} \\
\mathrm{AH} \\
\mathrm{AL} \\
\mathrm{AL} \\
\mathrm{I} \\
\mathrm{VI} \\
\mathrm{VH}\end{array}$ & 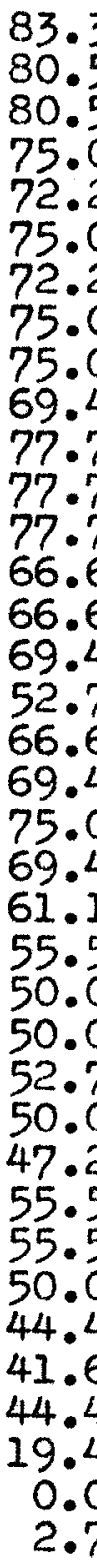 & $\begin{array}{l}\mathrm{AH} \\
\mathrm{AH} \\
\mathrm{AH} \\
\mathrm{AH} \\
\mathrm{AH} \\
\mathrm{AH} \\
\mathrm{AH} \\
\mathrm{AH} \\
\mathrm{AH} \\
\mathrm{AH} \\
\mathrm{AH} \\
\mathrm{AH} \\
\mathrm{AH} \\
\mathrm{AH} \\
\mathrm{AH} \\
\mathrm{AH} \\
\mathrm{AH} \\
\mathrm{AH} \\
\mathrm{AH} \\
\mathrm{AH} \\
\mathrm{AH} \\
\mathrm{AH} \\
\mathrm{AH} \\
\mathrm{AL} \\
\mathrm{AL} \\
\mathrm{AH} \\
\mathrm{AL} \\
\mathrm{AL} \\
\mathrm{AH} \\
\mathrm{AH} \\
\mathrm{AL} \\
\mathrm{AL} \\
\mathrm{AL} \\
\mathrm{AI} \\
\mathrm{AI} \\
\mathrm{VL} \\
\mathrm{I}\end{array}$ & 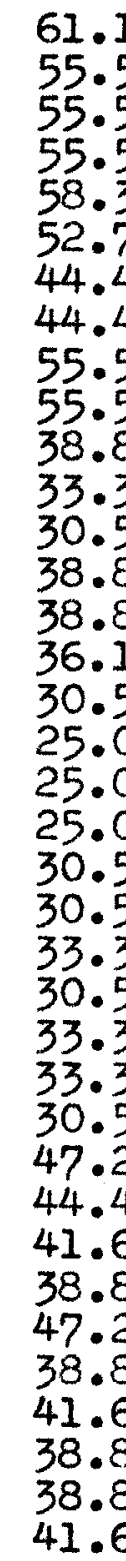 & $\begin{array}{l}A H \\
A H \\
A H \\
A H \\
A H \\
A H \\
A I \\
A I \\
A H \\
A H \\
A I \\
A I \\
A I \\
A I \\
A I \\
A I \\
A I \\
A I \\
A I \\
A I \\
A I \\
A I \\
A I \\
A I \\
A I \\
A I \\
A I \\
A I \\
A I \\
A I \\
A I \\
A I \\
A I \\
A I \\
A I \\
A I \\
A I\end{array}$ & $\begin{array}{r}6.14 \\
6.52 \\
6.02 \\
5.09 \\
4.34 \\
8.16 \\
11.69 \\
8.12 \\
5.01 \\
4.51 \\
9.63 \\
11.56 \\
13.41 \\
6.98 \\
7.66 \\
9.04 \\
7.53 \\
11.81 \\
13.58 \\
14.71 \\
11.14 \\
8.54 \\
5.64 \\
9.63 \\
7.28 \\
6.27 \\
7.36 \\
6.14 \\
4.63 \\
4.51 \\
4.63 \\
3.75 \\
3.75 \\
5.85 \\
8.79 \\
11.14 \\
12.32\end{array}$ & $\begin{array}{l}.05 \\
.05 \\
.05 \\
.10 \\
.02 \\
.01 \\
.02 \\
.10 \\
.01 \\
.01 \\
.01 \\
.05 \\
.05 \\
.02 \\
.05 \\
.01 \\
.01 \\
.001 \\
.01 \\
.02 \\
.10 \\
.01 \\
.05 \\
.05 \\
.05 \\
.05 \\
.10 \\
.10 \\
.05\end{array}$ \\
\hline
\end{tabular}


TABLE 6 continued

UTILITY INDICES (UI) AND UTIIITY LFVEIS (UL) FOR VERBALIZATION AND EXAMINER OBSERVATION ITEMS

\begin{tabular}{|c|c|c|c|c|c|c|c|c|}
\hline \multirow[b]{3}{*}{ Items } & \multicolumn{6}{|c|}{ Questions } & \multirow{3}{*}{$x^{2}$} & \multirow[b]{3}{*}{$P$} \\
\hline & \multicolumn{2}{|c|}{ Diagnosis } & \multicolumn{2}{|c|}{ Anxiety } & \multicolumn{2}{|c|}{ Intel11gence } & & \\
\hline & UI & UL & UI & UL & UI & UL & & \\
\hline $\begin{array}{l}1 \\
2 \\
3 \\
4 \\
5 \\
6 \\
7 \\
8 \\
9 \\
10 \\
11 \\
12 \\
13 \\
14 \\
15 \\
16 \\
17 \\
18 \\
19 \\
20 \\
21 \\
22 \\
23 \\
24 \\
25 \\
26 \\
27 \\
28 \\
29 \\
30 \\
31 \\
32 \\
33 \\
34 \\
35 \\
36 \\
37\end{array}$ & $\begin{array}{l}33.3 \\
38.8 \\
36.1 \\
33.3 \\
30.5 \\
36.1 \\
30.5 \\
22.2 \\
16.6 \\
19.4 \\
22.2 \\
19.4 \\
13.8 \\
13.8 \\
13.8 \\
16.6 \\
19.4 \\
22.2 \\
19.4 \\
16.6 \\
16.6 \\
16.6 \\
27.7 \\
19.4 \\
22.2 \\
16.6 \\
19.4 \\
13.8 \\
22.2 \\
13.8 \\
16.6 \\
13.8 \\
13.8 \\
2.7 \\
0.0 \\
0.0 \\
0.0 \\
19\end{array}$ & $\begin{array}{l}A L \\
A L \\
A L \\
A L \\
A L \\
A L \\
A L \\
A L \\
A L \\
A L \\
A L \\
A L \\
I \\
L \\
L \\
A L \\
A L \\
A L \\
A L \\
A L \\
A L \\
A L \\
A L \\
A L \\
A L \\
A L \\
A L \\
I L \\
A L \\
A L \\
V L \\
V L\end{array}$ & $\begin{array}{r}47.2 \\
41.6 \\
47.2 \\
27.7 \\
27.7 \\
22.2 \\
27.7 \\
38.8 \\
27.7 \\
19.4 \\
22.2 \\
25.0 \\
27.7 \\
19.4 \\
16.6 \\
25.0 \\
13.8 \\
27.7 \\
27.7 \\
36.1 \\
25.0 \\
16.6 \\
16.6 \\
11.1 \\
11.1 \\
13.8 \\
19.4 \\
11.1 \\
22.2 \\
19.4 \\
11.1 \\
8.3 \\
11.1 \\
16.6 \\
2.7 \\
0.0 \\
0.0\end{array}$ & 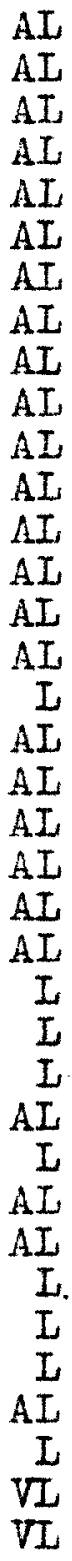 & $\begin{array}{l}30.5 \\
30.5 \\
25.0 \\
22.2 \\
16.8 \\
19.4 \\
22.2 \\
22.8 \\
25.6 \\
22.3 \\
16.6 \\
13.8 \\
11.1 \\
16.6 \\
13.8 \\
13.8 \\
11.1 \\
8.3 \\
8.3 \\
8.3 \\
11.1 \\
11.1 \\
11.1 \\
13.8 \\
13.8 \\
11.1 \\
11.1 \\
19.4 \\
16.6 \\
13.8 \\
13.8 \\
19.4 \\
16.6 \\
13.8 \\
16.6 \\
16.6 \\
16.6 \\
13\end{array}$ & 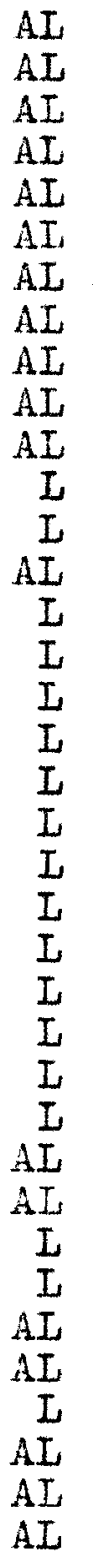 & $\begin{array}{l}4.76 \\
4.00 \\
5.47 \\
3.96 \\
4.34 \\
4.76 \\
3.75 \\
4.97 \\
4.00 \\
3.50 \\
3.62 \\
3.96 \\
4.76 \\
3.58 \\
3.50 \\
4.00 \\
3.75 \\
5.09 \\
5.01 \\
6.77 \\
4.25 \\
3.62 \\
4.63 \\
3.75 \\
4.00 \\
3.58 \\
3.83 \\
3.75 \\
3.62 \\
3.62 \\
3.58 \\
3.96 \\
3.58 \\
4.34 \\
4.76 \\
4.97 \\
4.97\end{array}$ & $\begin{array}{l}.10 \\
.10 \\
.10 \\
.10\end{array}$ \\
\hline
\end{tabular}


TABLE 6 continued

UTIIITY INDICES (UI) AND UTILITY LEVESS (UL) FOR INDIVIDUAI LOCATION ITMMS

\begin{tabular}{|c|c|c|c|c|c|c|c|c|}
\hline \multirow[b]{3}{*}{ Items } & \multicolumn{6}{|c|}{ questions } & \multirow{3}{*}{${ }^{x} r^{2}$} & \multirow[b]{3}{*}{$\mathrm{P}$} \\
\hline & \multicolumn{2}{|c|}{ Diagnosis } & \multicolumn{2}{|c|}{ Anxiety } & \multicolumn{2}{|c|}{ Intelligence } & & \\
\hline & UI & UL & UI & UL & UI & UL & & \\
\hline $\begin{array}{l}1 \\
2 \\
3 \\
4 \\
5 \\
6 \\
7 \\
8 \\
9 \\
10 \\
11 \\
12 \\
13 \\
14 \\
15 \\
16 \\
17 \\
18 \\
19 \\
20 \\
21 \\
22 \\
23 \\
24 \\
25 \\
26 \\
27 \\
28 \\
29 \\
30 \\
31 \\
32 \\
33 \\
34 \\
35 \\
36 \\
37\end{array}$ & $\begin{array}{r}16.6 \\
30.5 \\
19.4 \\
22.2 \\
19.4 \\
13.8 \\
11.1 \\
8.3 \\
16.6 \\
5.5 \\
19.4 \\
16.6 \\
8.3 \\
11.1 \\
8.3 \\
16.6 \\
19.4 \\
19.4 \\
8.3 \\
11.1 \\
11.1 \\
8.3 \\
13.8 \\
8.3 \\
16.6 \\
11.1 \\
13.8 \\
5.5 \\
19.4 \\
13.8 \\
16.6 \\
5.5 \\
8.3 \\
0.0 \\
0.0 \\
0.0 \\
0.0\end{array}$ & 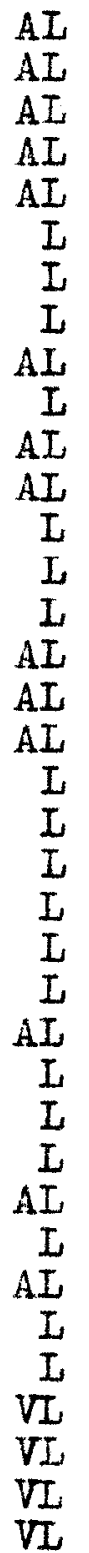 & $\begin{array}{r}8.3 \\
25.0 \\
25.0 \\
22.2 \\
25.0 \\
22.2 \\
22.2 \\
25.0 \\
8.3 \\
13.8 \\
13.8 \\
27.7 \\
47.2 \\
41.6 \\
22.2 \\
8.3 \\
8.3 \\
11.1 \\
16.6 \\
13.8 \\
8.3 \\
11.1 \\
5.5 \\
13.8 \\
11.1 \\
11.1 \\
13.8 \\
11.1 \\
8.3 \\
8.3 \\
11.1 \\
8.3 \\
11.1 \\
5.5 \\
0.0 \\
0.0 \\
0.0\end{array}$ & 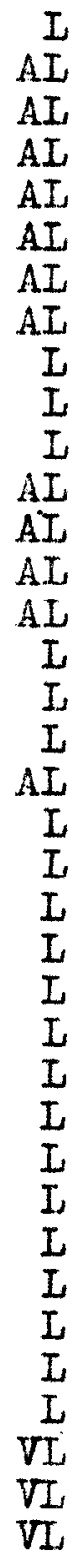 & $\begin{array}{r}5.5 \\
5.5 \\
5.5 \\
13.8 \\
2.7 \\
5.5 \\
8.3 \\
8.3 \\
16.6 \\
5.5 \\
11.1 \\
8.3 \\
8.3 \\
16.6 \\
2.7 \\
5.5 \\
8.3 \\
5.5 \\
5.5 \\
5.5 \\
5.5 \\
5.5 \\
5.5 \\
5.5 \\
5.5 \\
5.5 \\
5.5 \\
5.5 \\
8.3 \\
8.3 \\
8.3 \\
13.8 \\
8.3 \\
13.8 \\
8.3 \\
11.1 \\
8.3\end{array}$ & 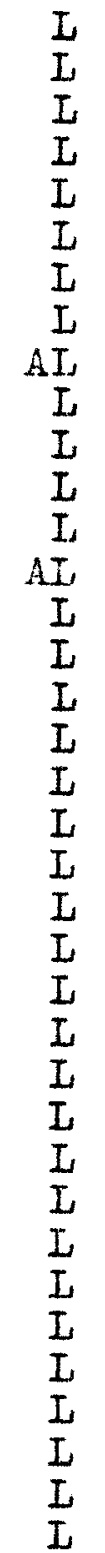 & $\begin{array}{l}4.00 \\
6.27 \\
5.09 \\
3.83 \\
5.64 \\
4.59 \\
4.34 \\
4.97 \\
3.83 \\
3.83 \\
3.75 \\
5.01 \\
11.69 \\
7.78 \\
5.09 \\
4.00 \\
4.13 \\
4.25 \\
4.00 \\
3.75 \\
3.58 \\
3.58 \\
3.83 \\
3.75 \\
3.96 \\
3.62 \\
3.83 \\
3.62 \\
4.13 \\
3.62 \\
3.75 \\
3.75 \\
3.50 \\
4.25 \\
3.83 \\
4.13 \\
3.83\end{array}$ & $\begin{array}{l}.05 \\
.10 \\
.10 \\
.10\end{array}$ \\
\hline
\end{tabular}


TABLE 6 continued

UTILITY INDICDS (UI) AND UTILITY IEVELS (UL) FOR CAIRD SUMMARY ITEMS

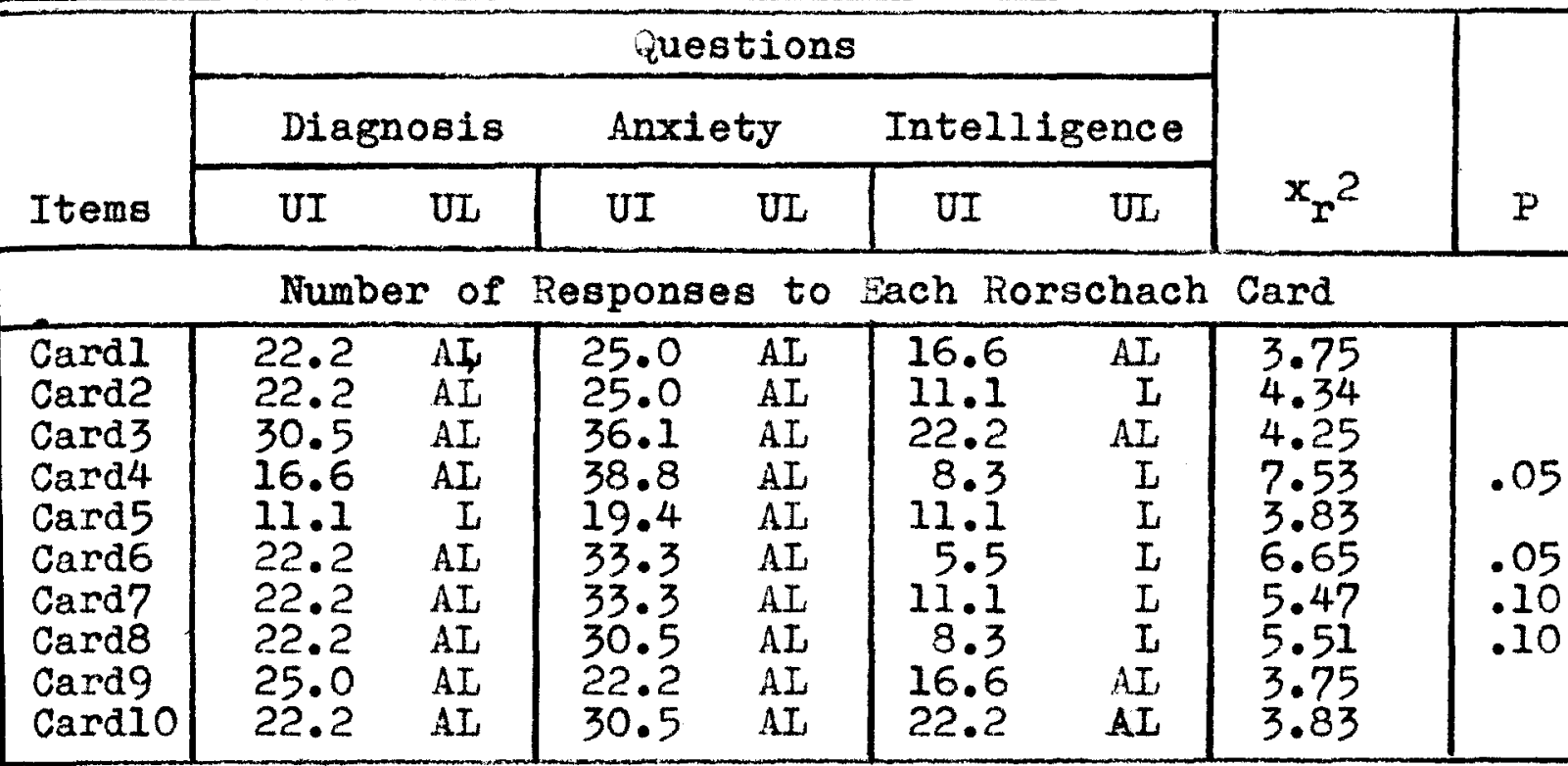

Reaction Time to Each Rorschach Card

\begin{tabular}{|l|cc|cc|cc|c|c|}
\hline Card1 & 25.0 & AI & 19.4 & AI & 8.3 & I & 4.63 & .10 \\
Card2 & 22.2 & AL & 19.4 & AI & 8.3 & I & 4.34 & \\
Card3 & 19.4 & AI & 16.6 & AI & 8.3 & I & 4.00 & \\
Card4 & 13.8 & I & 13.8 & I & 5.5 & I & 3.83 & \\
Card5 & 13.8 & I & 13.8 & I & 5.5 & I & 3.83 & \\
Card6 & 13.8 & I & 16.6 & AL & 5.5 & I & 4.00 & \\
Card7 & 13.8 & I & 16.6 & AL & 5.5 & I & 4.00 & \\
Card8 & 16.6 & AL & 19.4 & AI & 5.5 & I & 4.34 & \\
Card9 & 11.1 & I & 13.8 & I & 11.1 & I & 3.50 & \\
Card10 & 11.1 & I & 16.6 & AI & 11.1 & I & 3.62 & \\
\hline
\end{tabular}


Status, Sexual history, and Sibling Fosition. The Education card was selected significantly earlier for interpretation of the Intelligence question. which also ellcited little interest in information concerning Mother and Father. The Diagnosis question elicited relative interest in occupation, then hilitary history, Siblin description, and Religion, with all of the latter only approaching significance at the .10 level.

It was predicted that Location scores would be given greates emphasis on Protocol III. The prediction was conirmed. The utility value of this category was highest for the Intelligence question ( $U I=26.2$ ), and lowest for the Anxiety and Diagnosis questions (UI $=23.4$ ). The use of Beck's Zsum and $W$ scores reached sienificance here, with $Z f$ and Approach nearing significance at the .10 level. Also approaching signiflcance were the selections of Beck's Affective Ratio for the Anxiety question, and of $S$ for that of Diagnosis.

The prediction for the Determinant sategory was that it would recelve greatest emphasis on the Anxiety question. The prediction was confirmed only partially, due to differential use of subgroups of determinents within the category. The general ut1lity value of the category was lowest for protocol III (UI = 11.5), and highest for I (UI $=36.5)$ over II (UI $=31.0)$. Howoror, as expected, the sheding determinants $Y$, YF, and FY were relected significantly more often and earlier for the Anxlety question. along with earlier selections of the pure shading 
scores $V$ and $T$. Earlier selections of $V F$ and FV approached the .10 sicniflcance level. Unexpected was the greater emphasis placed on the shading scores TF and FT in relation to the question of Diagnosis, suggesting that these items have interpretat1ve utility beyond that of "anxlety 1ndicators." The color scores $0, C F$, and $F C$ also were selected significantly more often and earlier on the Diagnosis protocol, with Ft, F-, and Blend scores approaching signiflcance at the .10 level in frequency of vsase. The Intelligence question eliclted sieniflcantly earlier, but not more often, than did the two other questions.

No predictions were made concernire the Content category. The findings indicate that this category was highest in utility for protocol I (UI = 17.7), next highest for protocol. II (UI = 13.3), and lowest for Protocol III (UI $=6.8)$. onIy two of the cards in this catecory showed differential utility. The Anatomy card wes selected most often for the Anxiety question, where, along with $\mathrm{Fd}$, it also approached sienificance as being selected earliest. Hd was used least for the Intelligence question. Cards $\mathrm{H}$ and Ad approached sienificance in amount of usage on the Diacrasis question.

No specific prediction was made for the Iotals catesory. There wes, however, the zeneral hypotinesis that quantitative data would be eiven ereater emphasis in interpretation on protocol III than on Protocol II, and least emphasis on Protocol I. The eeneral hypothesis was not supported. The Totals category showed 
lowest utility value for the Intell18ence question (UI $=22.4$ ), highest utility for the Diagnosis question (UI = 32.9), and middie utility for that of Anxiety (UI $=31.2$ ). The number of populor responses (P) was elicited signirlcarity more often and earIier by the Diagnosis question, with reaction time information (AVgRT, RTAch, RTChr) approaching signiflcance at the .10 level. The Intelilence question elicited earlier selection of F+\%, and little concern with RTAch and RTChr. Approaching significance on the Anxiety question was the Rejections item.

Beck Totals ranked third out of the sixteen categories in 1ts overall Utility Index (UI $=28.8$. AI), behind the Qualltative $(U I=53.0, A H)$ and Personal Data (UI $=40.7, A L)$ categorles, based on the percentage of cards selected within each category. This finding supports the prediction that initial but temporary emphasis would be given to quantitative data, geared toward general orientation to the protocol. The finding is consistent with the early results appearing in Tables 2 and 3.

No prediction was made regarding the relative utility of the Quantitative scoring category, which provided Beck and Klopfer scorings of each of the free associations. The utility level of this category was Low overall (UI $=13.0$ ), but relatively higher for Protocols I $(U I=15.7)$ and II $(U I=14.7)$ than for Protocol III $(U I=11.7)$. Of interest concerning this category were three Beck scorings which approached significance at the .10 level in differential frequency and sequence of usage. The clinicians 
TABLE 7

MEAN RANOS (NR) AND REIATIVE RANKS (RR)

FOR SEQUENTIAL SELECTION OF

PERSONAL DATA ITENS

\begin{tabular}{|c|c|c|c|c|c|c|c|c|}
\hline \multirow[b]{3}{*}{ Items } & \multicolumn{6}{|c|}{ Questions } & \multirow[b]{3}{*}{$x_{r^{2}}$ * } & \multirow[b]{3}{*}{$p$} \\
\hline & \multicolumn{2}{|c|}{ Diagnosis } & \multicolumn{2}{|c|}{ Anxiety } & \multicolumn{2}{|c|}{ Intelligence } & & \\
\hline & $\operatorname{MR}$ & $\mathrm{RR}$ & $\mathrm{HiR}$ & $\mathrm{RR}$ & $\mathrm{MR}$ & $\mathrm{RH}$ & & \\
\hline $\begin{array}{l}\text { Sex } \\
\text { Age } \\
\text { Ed } \\
\text { Occ } \\
\text { Nty } \\
\text { ReI } \\
\text { Max } \\
\text { SPo } \\
\text { S1bs } \\
\text { Mo } \\
\text { Fa } \\
\text { Sxl } \\
\text { Mty } \\
\text { Int }\end{array}$ & $\begin{array}{r}52 \\
47 \\
68 \\
89 \\
142 \\
146 \\
109 \\
138 \\
141 \\
129 \\
128 \\
111 \\
144 \\
138\end{array}$ & $\begin{array}{r}5 \\
1 \\
8 \\
16 \\
65 \\
74 \\
33 \\
56 \\
63 \\
48 \\
46 \\
35 \\
71 \\
58\end{array}$ & $\begin{array}{r}48 \\
40 \\
89 \\
113 \\
153 \\
162 \\
81 \\
141 \\
154 \\
137 \\
137 \\
96 \\
171 \\
141\end{array}$ & $\begin{array}{r}3 \\
1 \\
18 \\
31 \\
88 \\
114 \\
15 \\
62 \\
91 \\
56 \\
57 \\
23 \\
142 \\
60\end{array}$ & $\begin{array}{r}61 \\
45 \\
48 \\
118 \\
150 \\
173 \\
164 \\
166 \\
172 \\
161 \\
161 \\
150 \\
172 \\
143\end{array}$ & $\begin{array}{c}3 \\
1 \\
2 \\
20 \\
61 \\
164 \\
102 \cdot 5 \\
111 \\
144 \\
86 \\
88 \\
62 \\
147 \\
48\end{array}$ & $\begin{array}{r}4.56 \\
4.73 \\
12.19 \\
5.82 \\
3.62 \\
5.02 \\
16.22 \\
5.65 \\
4.90 \\
5.01 \\
4.90 \\
9.04 \\
5.40 \\
3.64\end{array}$ & $\begin{array}{l}.10 \\
.01 \\
.10 \\
.10 \\
.001 \\
.10 \\
.10 \\
.10 \\
.10 \\
.02 \\
.10\end{array}$ \\
\hline
\end{tabular}

*Friedman two-way analysis of variance 
TABLE 7 continued

NEAN RANKS (MR) AND REIATIVE RANKS (RR)

FOR SEQUENTIAL SELECTION OF

LOCATION ITEMS

\begin{tabular}{|c|c|c|c|c|c|c|c|c|}
\hline \multirow[b]{3}{*}{ Items } & \multicolumn{6}{|c|}{ Questions } & \multirow[b]{3}{*}{$\mathrm{x} r^{2}$} & \multirow[b]{3}{*}{$p$} \\
\hline & \multicolumn{2}{|c|}{ Dlagnosis } & \multicolumn{2}{|c|}{ Anxiety } & \multicolumn{2}{|c|}{ Intell1gence } & & \\
\hline & $M R$ & $\mathrm{RR}$ & $\mathrm{MR}$ & $\mathrm{RR}$ & $M R$ & $\mathrm{RR}$ & & \\
\hline \multicolumn{9}{|c|}{ Klopfer } \\
\hline $\begin{array}{l}W \\
D \\
d \\
D d \\
S \\
W \% \\
D \% \\
d \% \\
D d+S \% \\
\text { Succ }\end{array}$ & $\begin{array}{l}180 \\
182 \\
192 \\
187 \\
191 \\
192 \\
192 \\
196 \\
192 \\
198\end{array}$ & $\begin{array}{l}193 \\
202 \\
257 \\
233 \\
254 \\
259 \\
261 \\
281 \\
262 \\
309\end{array}$ & $\begin{array}{l}185 \\
181 \\
190 \\
186 \\
190 \\
192 \\
198 \\
198 \\
198 \\
195\end{array}$ & $\begin{array}{l}213 \cdot 5 \\
184 \\
248 \\
222 \\
245 \\
269 \\
303 \\
304 \cdot 5 \\
306 \\
280\end{array}$ & $\begin{array}{l}153 \\
163 \\
172 \\
177 \\
186 \\
168 \\
182 \\
189 \\
186 \\
177\end{array}$ & $\begin{array}{c}71 \\
67 \\
154.5 \\
197 \\
323 \\
119 \\
260 \\
327 \\
324 \\
198\end{array}$ & $\begin{array}{l}4.34 \\
3.68 \\
3.51 \\
3.51 \\
3.64 \\
3.72 \\
3.51 \\
3.50 \\
3.64 \\
3.55\end{array}$ & \\
\hline \multicolumn{9}{|c|}{ Beck } \\
\hline $\begin{array}{l}\text { W } \\
D \\
D d \\
\text { S } \\
\text { App } \\
\text { Seq } \\
\text { AffR } \\
\text { Zf } \\
\text { ZSum }\end{array}$ & $\begin{array}{l}131 \\
152 \\
142 \\
138 \\
154 \\
164 \\
160 \\
189 \\
184\end{array}$ & $\begin{array}{r}49 \\
86 \\
64 \\
57 \\
87 \\
104 \\
96 \\
245 \\
216\end{array}$ & $\begin{array}{l}143 \\
143 \\
148 \\
151 \\
151 \\
169 \\
149 \\
190 \\
177\end{array}$ & $\begin{array}{r}66 \\
68 \\
79 \\
87 \\
85 \\
133 \\
81 \\
242 \\
171\end{array}$ & $\begin{array}{l}105 \\
149 \\
152 \\
162 \\
133 \\
155 \\
174 \\
150 \\
102\end{array}$ & $\begin{array}{c}16 \\
58 \\
66.5 \\
91 \cdot 5 \\
35 \\
73 \\
168 \\
60 \\
15\end{array}$ & $\begin{array}{r}8.01 \\
3.68 \\
3.47 \\
4.00 \\
5.57 \\
3.97 \\
5.51 \\
5.53 \\
15.65\end{array}$ & $\begin{array}{l}.10 \\
.10 \\
.10 \\
.001\end{array}$ \\
\hline
\end{tabular}


TABLE 7 continued

MHAN RANKS (MR) AND RELATIVE RANTE (RR)

FOR BEQUENTIAL SELECTION OF

DETIRMINANT ITEMS

\begin{tabular}{|c|c|c|c|c|c|c|c|c|}
\hline \multirow[b]{3}{*}{ Items } & \multicolumn{6}{|c|}{ uestions } & \multirow[b]{3}{*}{$x \mathbf{r}^{2}$} & \multirow[b]{3}{*}{$P$} \\
\hline & \multicolumn{2}{|c|}{ Diagnosis } & \multicolumn{2}{|c|}{ Anxiety } & \multicolumn{2}{|c|}{ Intelligence } & & \\
\hline & MR & $R R$ & MR & $\mathrm{RR}$ & MR & $\mathrm{RR}$ & & \\
\hline \multicolumn{9}{|c|}{ Klopfer } \\
\hline $\begin{array}{l}M \\
\text { mi } \\
m \\
k \\
k \\
k \\
F \\
F \\
F C \\
c \\
C \\
F C \\
C F \\
C\end{array}$ & $\begin{array}{l}170 \\
165 \\
178 \\
187 \\
187 \\
187 \\
187 \\
183 \\
193 \\
188 \\
176 \\
176 \\
184\end{array}$ & $\begin{array}{l}130 \\
111 \\
177 \\
235 \\
236 \\
234 \\
238 \\
208 \\
266 \\
241 \\
162 \\
161 \\
210.5\end{array}$ & $\begin{array}{l}177 \\
170 \\
165 \\
183 \\
182 \\
183 \\
188 \\
182 \\
183 \\
179 \\
180 \\
184 \\
191\end{array}$ & $\begin{array}{l}170 \\
135 \\
121 \\
196 \\
193 \\
195 \\
235 \\
194 \\
200 \\
175 \\
180 \\
202 \\
257\end{array}$ & $\begin{array}{l}152 \\
154 \\
163 \\
186 \\
186 \\
186 \\
181 \\
186 \\
186 \\
186 \\
181 \\
186 \\
136\end{array}$ & $\begin{array}{l}66.5 \\
72 \\
100 \\
312 \\
313 \\
314 \\
248 \\
315 \\
316 \\
317 \\
256 \\
318 \\
319\end{array}$ & $\begin{array}{l}3.75 \\
4.97 \\
3.55 \\
3.81 \\
3.75 \\
3.72 \\
3.47 \\
3.83 \\
3.62 \\
3.95 \\
3.81 \\
4.35 \\
3.81\end{array}$ & .10 \\
\hline \multicolumn{9}{|c|}{ Beck } \\
\hline $\begin{array}{l}M \\
C \\
C F \\
F C \\
Y \\
Y F \\
F Y \\
T \\
T P \\
T P \\
P T \\
V \\
V P \\
P V \\
P+ \\
P- \\
P O \\
D D I \\
D b I \\
D b I \\
D\end{array}$ & $\begin{array}{l}100 \\
106 \\
111 \\
111 \\
135 \\
135 \\
128 \\
147 \\
144 \\
139 \\
143 \\
144 \\
144 \\
155 \\
151 \\
163 \\
149 \\
151 \\
151\end{array}$ & $\begin{array}{c}25 \\
31 \\
37 \\
38 \\
53 \\
52 \\
47 \\
78 \\
68 \\
60 \\
66 \\
72 \\
70 \\
89 \\
84.5 \\
103 \\
80 \\
81 \\
83\end{array}$ & $\begin{array}{l}106 \\
125 \\
122 \\
127 \\
112 \\
117 \\
118 \\
146 \\
155 \\
147 \\
142 \\
146 \\
143 \\
157 \\
157 \\
175 \\
157 \\
201 \\
201\end{array}$ & $\begin{array}{c}28 \\
44 \\
40 \\
47 \\
30 \\
34 \\
35 \\
72 \\
92 \\
73 \\
63 \\
71 \\
65 \\
100 \\
101 \\
159 \\
99 \\
319.5 \\
319.5\end{array}$ & $\begin{array}{r}89 \\
161 \\
162 \\
166 \\
130 \\
180 \\
180 \\
185 \\
185 \\
180 \\
179 \\
175 \\
175 \\
172 \\
172 \\
176 \\
171 \\
171 \\
171\end{array}$ & $\begin{array}{l}99 \\
85 \\
89 \\
110 \\
237 \\
237 \\
237 \\
299 \\
300 \\
230.5 \\
224 \\
176 \\
178 \\
150 \\
151 \\
184 \\
135 \\
137.5 \\
139\end{array}$ & $\begin{array}{r}9.10 \\
8.89 \\
8.89 \\
11.03 \\
12.21 \\
9.94 \\
10.40 \\
7.53 \\
6.86 \\
7.28 \\
6.77 \\
5.74 \\
5.74 \\
4.25 \\
4.59 \\
3.85 \\
4.25 \\
6.61 \\
6.61\end{array}$ & $\begin{array}{l}.02 \\
.02 \\
.02 \\
.01 \\
.01 \\
.01 \\
.01 \\
.05 \\
.05 \\
.05 \\
.05 \\
.10 \\
.10\end{array}$ \\
\hline
\end{tabular}


TABIS 7 continued

MEAN RANKS (MR) AND RILAMTVE RANKS (RR) FOR SEQUENTIAL SELECTION OF CONTENT ITAMS

\begin{tabular}{|c|c|c|c|c|c|c|c|c|}
\hline \multirow[b]{3}{*}{ Items } & \multicolumn{6}{|c|}{ uestions } & \multirow[b]{3}{*}{$x_{r} 2$} & \multirow[b]{3}{*}{$F$} \\
\hline & \multicolumn{2}{|c|}{ Diagnosis } & \multicolumn{2}{|c|}{ Anxiety } & \multicolumn{2}{|c|}{ Intelifgence } & & \\
\hline & $\mathrm{MR}$ & RR & MR & $R R$ & MR & $\mathrm{RR}$ & & \\
\hline \multicolumn{9}{|c|}{ Klopfer } \\
\hline $\begin{array}{l}\text { H } \\
\text { Hd } \\
\text { A } \\
\text { Ad } \\
\text { At } \\
\text { Adt } \\
\text { AObj } \\
\text { Art } \\
\text { Cl } \\
\text { Fd } \\
\text { Fire } \\
\text { Geo } \\
\text { Na } \\
\text { Cbj } \\
\text { Pl } \\
\text { Sc } \\
\text { Sex }\end{array}$ & $\begin{array}{l}188 \\
193 \\
184 \\
193 \\
196 \\
196 \\
200 \\
191 \\
200 \\
196 \\
192 \\
200 \\
196 \\
196 \\
200 \\
200 \\
183\end{array}$ & $\begin{array}{l}244 \\
267 \\
215 \\
269 \\
287 \\
285 \cdot 5 \\
319 \cdot 5 \\
255 \\
319.5 \\
291 \\
256 \\
319 \cdot 5 \\
288 \\
284 \\
319 \cdot 5 \\
319 \cdot 5 \\
209\end{array}$ & $\begin{array}{l}185 \\
185 \\
185 \\
190 \\
189 \\
198 \\
201 \\
197 \\
201 \\
197 \\
192 \\
201 \\
201 \\
201 \\
201 \\
201 \\
194\end{array}$ & $\begin{array}{l}210 \\
211 \\
213.5 \\
250 \\
237 \\
309 \\
319.5 \\
291 \\
319.5 \\
292 \\
268 \\
319.5 \\
319.5 \\
319.5 \\
319.5 \\
319.5 \\
273\end{array}$ & $\begin{array}{l}171 \\
176 \\
177 \\
181 \\
189 \\
184 \\
184 \\
184 \\
184 \\
184 \\
184 \\
189 \\
184 \\
184 \\
134 \\
184 \\
179\end{array}$ & $\begin{array}{l}140 \\
189 \\
191 \\
257 \\
327 \\
290 \\
283 \\
284 \\
286 \\
287 \\
288 \\
327 \\
282 \\
276.5 \\
279 \\
281 \\
220\end{array}$ & $\begin{array}{l}3.72 \\
3.75 \\
3.64 \\
3.62 \\
3.85 \\
3.46 \\
3.50 \\
3.47 \\
3.50 \\
3.47 \\
3.50 \\
3.46 \\
3.50 \\
3.50 \\
3.50 \\
3.50 \\
3.64\end{array}$ & \\
\hline \multicolumn{9}{|c|}{ Beck } \\
\hline $\begin{array}{l}\mathrm{H} \\
\mathrm{Hd} \\
\mathrm{A} \\
\mathrm{Ad} \\
\mathrm{An} \\
\text { Anal } \\
\mathrm{Ar} \\
\mathrm{Art} \\
\mathrm{Ay} \\
\mathrm{Bt} \\
\mathrm{Cl} \\
\mathrm{Pd} \\
\mathrm{PI} \\
\mathrm{Ge} \\
\mathrm{Hh} \\
\mathrm{Mr} \\
\mathrm{Ma} \\
\mathrm{Od}\end{array}$ & $\begin{array}{l}144 \\
147 \\
156 \\
154 \\
155 \\
169 \\
186 \\
173 \\
186 \\
178 \\
173 \\
175 \\
170 \\
186 \\
183 \\
182 \\
178 \\
186\end{array}$ & $\begin{array}{l}69 \\
77 \\
93 \\
88 \\
91 \cdot 5 \\
126 \\
227 \\
152 \\
228 \\
178 \\
145 \\
160 \\
133 \\
230 \\
203 \\
199 \\
181 \\
231\end{array}$ & $\begin{array}{l}148 \\
148 \\
167 \\
162 \\
148 \\
175 \\
191 \\
191 \\
191 \\
191 \\
183 \\
187 \\
174 \\
191 \\
191 \\
187 \\
191 \\
192\end{array}$ & $\begin{array}{l}77 \cdot 5 \\
75 \\
125 \\
115 \\
76 \\
157 \\
261 \cdot 5 \\
261 \cdot 5 \\
261 \cdot 5 \\
261 \cdot 5 \\
201 \\
226 \\
153 \cdot 5 \\
261 \cdot 5 \\
261 \cdot 5 \\
225 \\
257 \\
265\end{array}$ & $\begin{array}{l}165 \\
179 \\
156 \\
170 \\
179 \\
179 \\
166 \\
133 \\
183 \\
183 \\
179 \\
183 \\
174 \\
174 \\
184 \\
129 \\
184 \\
184\end{array}$ & $\begin{array}{l}106 \\
208 \\
77 \\
132 \\
211 \\
217 \\
109 \\
268 \\
269 \\
270 \\
216 \\
272 \\
170 \\
172 \\
274 \\
215 \\
276.5 \\
279\end{array}$ & $\begin{array}{l}4.35 \\
6.02 \\
3.72 \\
3.96 \\
5.74 \\
3.89 \\
4.14 \\
4.52 \\
3.64 \\
4.14 \\
3.85 \\
4.31 \\
3.68 \\
3.72 \\
3.85 \\
3.55 \\
4.14 \\
3.64\end{array}$ & $\begin{array}{l}.05 \\
.10\end{array}$ \\
\hline
\end{tabular}


TABLi: 7 continued

MEAN RANKS (MR) AND REIATIV RANKS (RR)

POR 3.2OUENTIAL SELECTION OF TOTALS ITENS

\begin{tabular}{|c|c|c|c|c|c|c|c|c|}
\hline \multirow[b]{3}{*}{ Items } & \multicolumn{6}{|c|}{ uestions } & \multirow[b]{3}{*}{$x_{r^{2}}$} & \multirow[b]{3}{*}{$P$} \\
\hline & \multicolumn{2}{|c|}{ Diagnosis } & \multicolumn{2}{|c|}{ Anxiety } & \multicolumn{2}{|c|}{ Intelligence } & & \\
\hline & $\mathrm{MR}$ & $\mathrm{RR}$ & $M R$ & $R R$ & $M R$ & $\mathrm{RR}$ & & \\
\hline \multicolumn{9}{|c|}{ Klopfer } \\
\hline $\begin{array}{l}\text { R } \\
\text { AVgRT } \\
\text { RMAch } \\
\text { RTChr } \\
\text { F\% } \\
\text { FI +\% } \\
A \% \\
\text { P } \\
\text { SumC } \\
8-10 \% \\
\text { Add } \\
\text { Rej }\end{array}$ & $\begin{array}{l}170 \\
192 \\
191 \\
191 \\
185 \\
193 \\
185 \\
183 \\
167 \\
193 \\
196 \\
191\end{array}$ & $\begin{array}{l}131 \\
264 \\
250 \\
251 \\
219 \\
270 \\
221 \\
205.5 \\
116 \\
271 \\
294 \\
248.5\end{array}$ & $\begin{array}{l}171 \\
191 \\
190 \\
190 \\
180 \\
186 \\
186 \\
185 \\
175 \\
180 \\
198 \\
189\end{array}$ & $\begin{array}{l}139 \\
254 \\
240 \\
241 \\
179 \\
217 \\
218 \\
212 \\
161 \\
183 \\
307 \\
238\end{array}$ & $\begin{array}{l}144 \\
177 \\
186 \\
186 \\
172 \\
186 \\
179 \\
172 \\
172 \\
179 \\
189 \\
189\end{array}$ & $\begin{array}{r}49 \\
194 \\
320 \\
321 \\
153 \\
322 \\
193 \\
148 \\
146 \\
200 \\
327 \\
327\end{array}$ & $\begin{array}{l}4.48 \\
3.47 \\
3.62 \\
3.62 \\
3.62 \\
3.64 \\
3.50 \\
3.47 \\
4.51 \\
3.64 \\
3.50 \\
3.72\end{array}$ & \\
\hline \multicolumn{9}{|c|}{ Beck } \\
\hline $\begin{array}{l}\mathrm{R} \\
\mathrm{F} \% \\
\mathrm{XF} \% \\
\mathrm{~F}+\% \\
\mathrm{XF}+\% \\
A \% \\
\mathrm{P} \\
\text { AvgRT } \\
\text { RTACh } \\
\text { RTChr } \\
\text { Add } \\
\text { Rej }\end{array}$ & $\begin{array}{r}88 \\
132 \\
179 \\
67 \\
147 \\
144 \\
110 \\
151 \\
167 \\
167 \\
176 \\
155\end{array}$ & $\begin{array}{r}15 \\
51 \\
184 \\
7 \\
76 \\
67 \\
34 \\
82 \\
119 \\
120 \\
164 \\
91.5\end{array}$ & $\begin{array}{l}101 \\
135 \\
175 \\
96 \\
144 \\
136 \\
128 \\
172 \\
168 \\
168 \\
183 \\
144\end{array}$ & $\begin{array}{r}27 \\
53 \\
160 \\
22 \\
69 \\
55 \\
49 \\
143 \\
129 \\
131 \\
199 \\
70\end{array}$ & $\begin{array}{r}89 \\
147 \\
164 \\
83 \\
131 \\
146 \\
146 \\
180 \\
184 \\
184 \\
172 \\
174\end{array}$ & $\begin{array}{c}11 \\
54 \\
101 \\
5 \\
30 \\
51 \\
53 \\
225.5 \\
292 \\
293 \\
145 \\
169\end{array}$ & $\begin{array}{l}4.35 \\
3.81 \\
3.46 \\
8.87 \\
3.51 \\
3.47 \\
8.26 \\
5.01 \\
4.63 \\
4.63 \\
3.75 \\
5.32\end{array}$ & $\begin{array}{l}.02 \\
.10 \\
.10 \\
.10 \\
.10\end{array}$ \\
\hline
\end{tabular}


PBIE 7 continued

MEN RATKS (MR) AND RTIATVE RANKS (RR)

FOR SEQUENTIAL SEL ECTION OF

QUANTIPATIE SCORINGS-ORIOPFER

\begin{tabular}{|c|c|c|c|c|c|c|c|c|}
\hline \multirow[b]{3}{*}{ Items } & \multicolumn{6}{|c|}{ questions } & \multirow[b]{3}{*}{$x_{r^{2}}$} & \multirow[b]{3}{*}{$\mathrm{p}$} \\
\hline & \multicolumn{2}{|c|}{ Diagnosis } & \multicolumn{2}{|c|}{ Anxiety } & \multicolumn{2}{|c|}{ Intelligence } & & \\
\hline & $M R$ & $\mathrm{RR}$ & $\mathrm{MR}$ & $\mathrm{RR}$ & $M R$ & $\mathrm{RR}$ & & \\
\hline $\begin{array}{l}1 \\
2 \\
3 \\
4 \\
5 \\
6 \\
7 \\
8 \\
9 \\
10 \\
11 \\
12 \\
13 \\
14 \\
15 \\
16 \\
17 \\
18 \\
19 \\
20 \\
21 \\
22 \\
23 \\
24 \\
25 \\
26 \\
27 \\
28 \\
29 \\
30 \\
31 \\
32 \\
33 \\
34 \\
35 \\
36 \\
37\end{array}$ & $\begin{array}{l}194 \\
194 \\
195 \\
195 \\
195 \\
195 \\
191 \\
191 \\
195 \\
195 \\
191 \\
195 \\
196 \\
196 \\
196 \\
196 \\
196 \\
196 \\
196 \\
192 \\
192 \\
192 \\
188 \\
197 \\
197 \\
197 \\
197 \\
197 \\
197 \\
197 \\
197 \\
197 \\
197 \\
200 \\
200 \\
200 \\
200\end{array}$ & 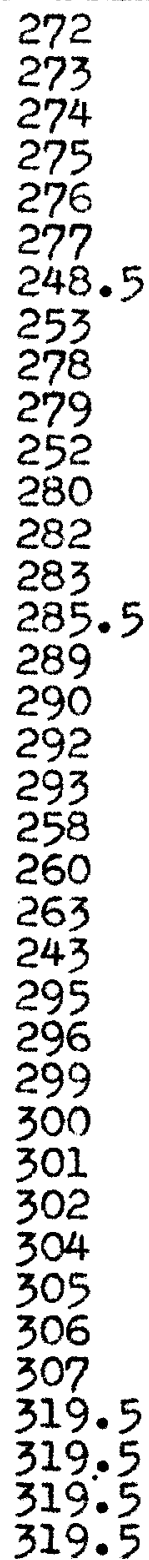 & $\begin{array}{l}184 \\
194 \\
194 \\
195 \\
195 \\
195 \\
195 \\
190 \\
186 \\
186 \\
190 \\
186 \\
190 \\
196 \\
196 \\
196 \\
196 \\
196 \\
196 \\
196 \\
196 \\
196 \\
196 \\
197 \\
197 \\
197 \\
197 \\
197 \\
194 \\
197 \\
181 \\
197 \\
197 \\
198 \\
201 \\
201 \\
201\end{array}$ & 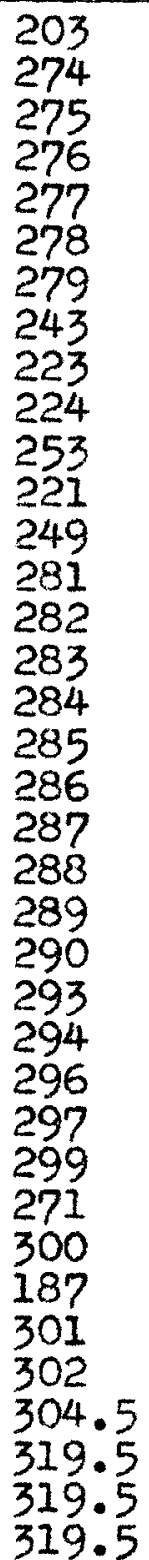 & $\begin{array}{l}179 \\
173 \\
179 \\
179 \\
183 \\
183 \\
183 \\
184 \\
184 \\
180 \\
184 \\
184 \\
179 \\
184 \\
180 \\
184 \\
184 \\
184 \\
180 \\
185 \\
185 \\
185 \\
185 \\
185 \\
185 \\
185 \\
185 \\
185 \\
185 \\
185 \\
182 \\
178 \\
182 \\
182 \\
182 \\
182 \\
182\end{array}$ & 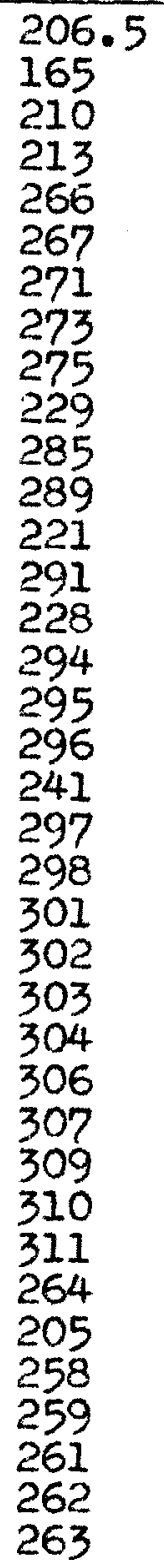 & $\begin{array}{l}3.75 \\
3.58 \\
3.55 \\
3.55 \\
3.51 \\
3.51 \\
3.47 \\
3.55 \\
3.85 \\
3.81 \\
3.55 \\
3.85 \\
3.64 \\
3.51 \\
3.55 \\
3.51 \\
3.51 \\
3.51 \\
3.55 \\
3.47 \\
3.47 \\
3.47 \\
3.51 \\
3.51 \\
3.51 \\
3.51 \\
3.50 \\
3.51 \\
3.55 \\
3.51 \\
4.25 \\
3.85 \\
3.54 \\
3.54 \\
3.62 \\
3.62 \\
3.62\end{array}$ & \\
\hline
\end{tabular}


TABLE 7 continued

MEAN RANKS (MR) AND RELATIVE RAHRS (RR) FOR SESUENTIAL BELECTION OF UARTITATIVE SCORTING --BECK

\begin{tabular}{|c|c|c|c|c|c|c|c|c|}
\hline \multirow[b]{3}{*}{ Items } & \multicolumn{6}{|c|}{ duestions } & \multirow[b]{3}{*}{$x_{r} 2$} & \multirow[b]{3}{*}{$P$} \\
\hline & \multicolumn{2}{|c|}{ Diagnosis } & \multicolumn{2}{|c|}{ Anxiety } & \multicolumn{2}{|c|}{ Intelligence } & & \\
\hline & MR & $\mathrm{RR}$ & $M R$ & $\mathrm{RR}$ & $\mathrm{TR}$ & $R R$ & & \\
\hline $\begin{array}{l}1 \\
2 \\
3 \\
4 \\
5 \\
6 \\
7 \\
8 \\
9 \\
10 \\
11 \\
12 \\
13 \\
14 \\
15 \\
16 \\
17 \\
18 \\
19 \\
20 \\
21 \\
22 \\
23 \\
24 \\
25 \\
26 \\
27 \\
28 \\
29 \\
30 \\
31 \\
32 \\
33 \\
34 \\
35 \\
36 \\
37 \\
\end{array}$ & $\begin{array}{l}166 \\
161 \\
171 \\
158 \\
164 \\
155 \\
169 \\
166 \\
165 \\
174 \\
178 \\
178 \\
179 \\
174 \\
179 \\
172 \\
173 \\
177 \\
176 \\
185 \\
185 \\
185 \\
173 \\
177 \\
173 \\
178 \\
182 \\
183 \\
171 \\
180 \\
184 \\
188 \\
180 \\
197 \\
200 \\
200 \\
200\end{array}$ & 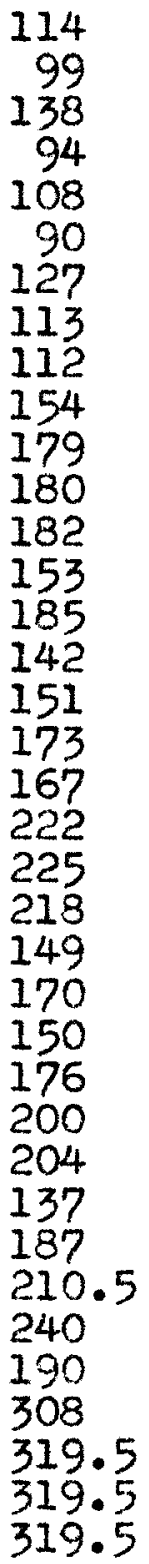 & $\begin{array}{l}161 \\
168 \\
159 \\
173 \\
173 \\
173 \\
174 \\
161 \\
170 \\
180 \\
167 \\
172 \\
164 \\
171 \\
172 \\
168 \\
181 \\
173 \\
182 \\
179 \\
180 \\
177 \\
190 \\
182 \\
190 \\
187 \\
183 \\
187 \\
182 \\
189 \\
187 \\
191 \\
192 \\
192 \\
198 \\
201 \\
201\end{array}$ & 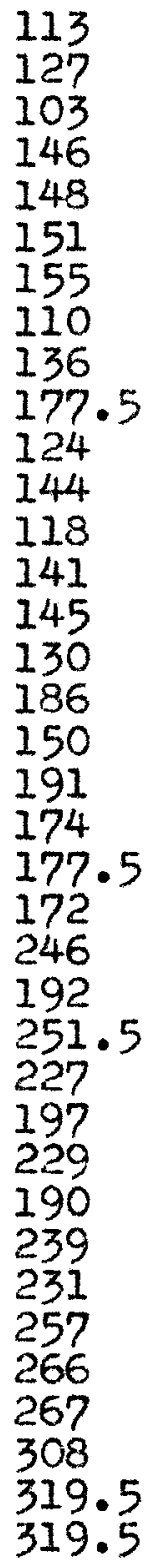 & $\begin{array}{l}165 \\
160 \\
160 \\
151 \\
156 \\
156 \\
162 \\
162 \\
158 \\
172 \\
167 \\
176 \\
180 \\
176 \\
176 \\
176 \\
185 \\
181 \\
181 \\
181 \\
181 \\
181 \\
185 \\
173 \\
177 \\
181 \\
180 \\
172 \\
164 \\
172 \\
169 \\
161 \\
165 \\
169 \\
169 \\
169 \\
170\end{array}$ & 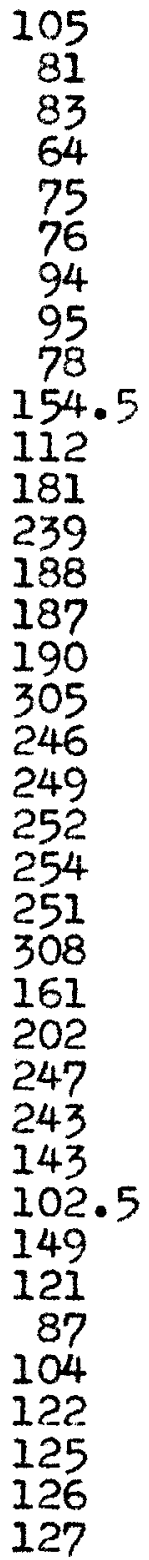 & $\begin{array}{l}3.55 \\
3.50 \\
3.89 \\
3.96 \\
3.81 \\
4.31 \\
3.62 \\
3.50 \\
3.62 \\
3.47 \\
3.97 \\
3.96 \\
5.01 \\
3.83 \\
3.97 \\
4.18 \\
5.32 \\
4.52 \\
4.35 \\
4.14 \\
4.00 \\
4.00 \\
4.73 \\
3.68 \\
4.31 \\
3.85 \\
3.72 \\
3.47 \\
3.47 \\
3.47 \\
3.51 \\
3.83 \\
3.62 \\
4.00 \\
4.34 \\
4.51 \\
4.51\end{array}$ & $\begin{array}{l}.10 \\
.10\end{array}$ \\
\hline
\end{tabular}


TABLE 7 continued

MEAN RANKG (IRR) AWD REIATIVZ RANKS (RR) FOR BEOULNIAL BELECTIOR OE WREE ASBOCIATIONS

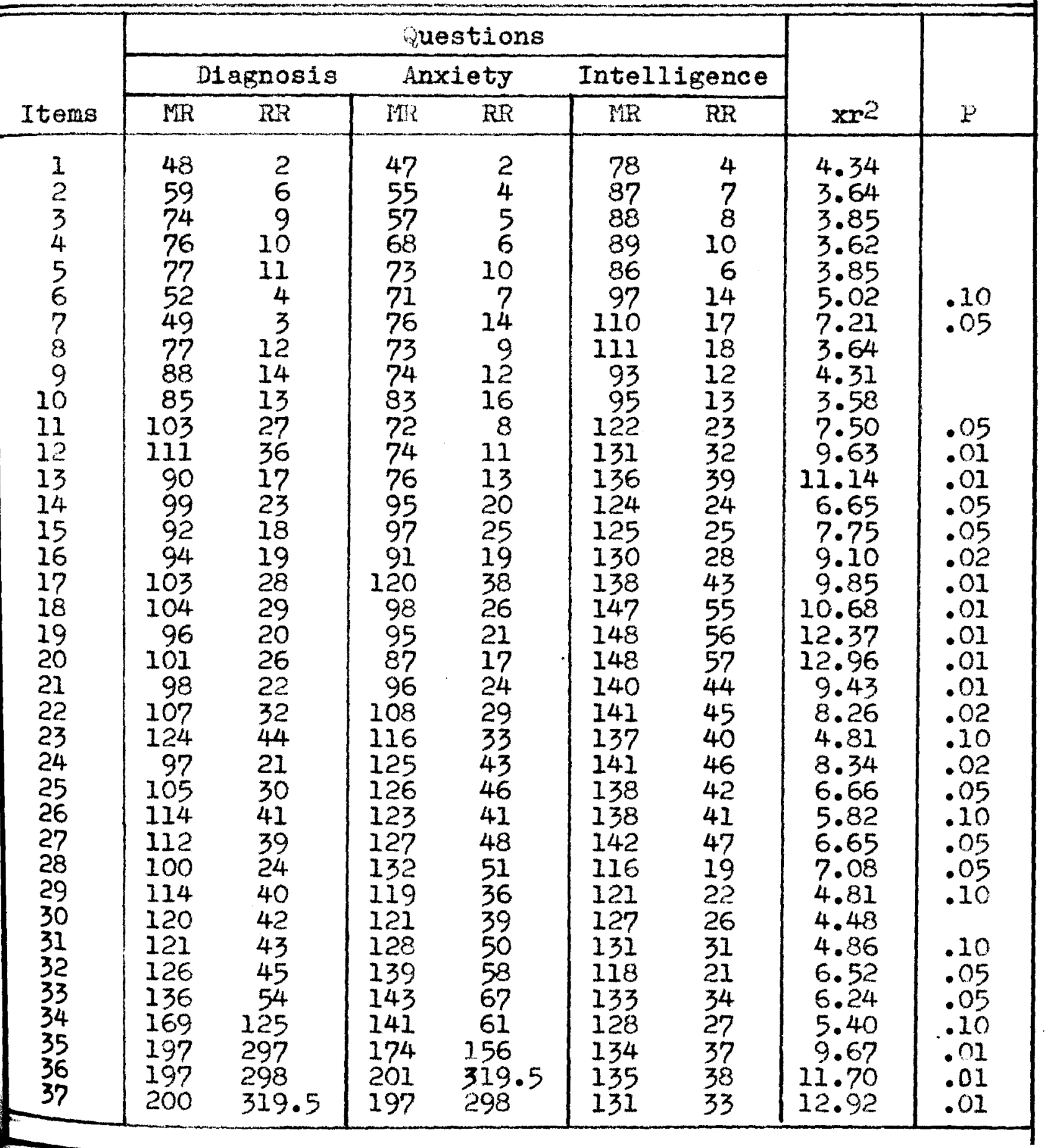


TABIS 7 continued

MEAN RUKS (WR) AND RIATIV RANS (RR)

FOR BOUNTTAL BEIECTIOR OF

VERBALIZITIONS AND

OBSERVATIONS

\begin{tabular}{|c|c|c|c|c|c|c|c|c|}
\hline \multirow[b]{3}{*}{$I+e m s$} & \multicolumn{6}{|c|}{ ruestions } & \multirow[b]{3}{*}{$x_{x^{2}}$} & \multirow[b]{3}{*}{$P$} \\
\hline & \multicolumn{2}{|c|}{ D1agnosis } & \multicolumn{2}{|c|}{ Anxiety } & \multicolumn{2}{|c|}{ Intel Isence } & & \\
\hline & $M$ & Al & $M R$ & $\mathrm{RP}$ & $M$ & $R$ & & \\
\hline $\begin{array}{l}1 \\
2 \\
3 \\
4 \\
5 \\
6 \\
7 \\
8 \\
9 \\
10 \\
11 \\
12 \\
13 \\
14 \\
15 \\
16 \\
17 \\
18 \\
19 \\
20 \\
21 \\
22 \\
23 \\
24 \\
25 \\
26 \\
27 \\
28 \\
29 \\
30 \\
31 \\
32 \\
33 \\
34 \\
35 \\
36 \\
37\end{array}$ & $\begin{array}{l}139 \\
132 \\
137 \\
141 \\
147 \\
139 \\
148 \\
163 \\
171 \\
167 \\
164 \\
169 \\
177 \\
177 \\
177 \\
175 \\
171 \\
168 \\
172 \\
175 \\
177 \\
176 \\
160 \\
173 \\
170 \\
177 \\
175 \\
182 \\
172 \\
193 \\
130 \\
184 \\
184 \\
197 \\
200 \\
200 \\
200\end{array}$ & $\begin{array}{l}59 \\
50 \\
55 \\
62 \\
75 \\
61 \\
79 \\
102 \\
139 \\
121 \\
106 \\
128 \\
168 \\
172 \\
175 \\
157 \\
136 \\
124 \\
143 \\
159 \\
15 \\
169 \\
169 \\
\end{array}$ & $\begin{array}{l}113 \\
124 \\
119 \\
150 \\
151 \\
162 \\
151 \\
134 \\
153 \\
168 \\
164 \\
160 \\
156 \\
170 \\
175 \\
161 \\
179 \\
159 \\
160 \\
148 \\
165 \\
176 \\
176 \\
185 \\
185 \\
181 \\
174 \\
186 \\
170 \\
176 \\
185 \\
191 \\
187 \\
180 \\
197 \\
201 \\
201\end{array}$ & 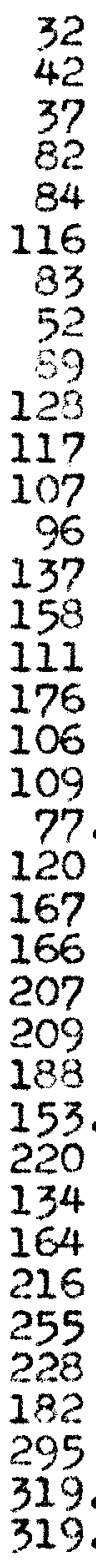 & $\begin{array}{l}130 \\
134 \\
145 \\
149 \\
159 \\
155 \\
151 \\
151 \\
146 \\
153 \\
162 \\
166 \\
171 \\
162 \\
167 \\
169 \\
172 \\
176 \\
176 \\
176 \\
172 \\
173 \\
173 \\
169 \\
169 \\
173 \\
174 \\
160 \\
165 \\
170 \\
170 \\
163 \\
167 \\
171 \\
167 \\
167 \\
168\end{array}$ & $\begin{array}{l}29 \\
36 \\
50 \\
59 \\
80 \\
74 \\
65 \\
53 \\
52 \\
69 \\
93 \\
108 \\
133 \\
91.5 \\
114 \\
116 \\
142 \\
183 \\
135 \\
186 \\
157 \\
159 \\
162 \\
120 \\
123 \\
166 \\
167 \\
84 \\
107 \\
128 \\
130 \\
93 \\
113 \\
137.5 \\
115 \\
117 \\
113\end{array}$ & $\begin{array}{l}7.36 \\
4.98 \\
5.35 \\
3.64 \\
3.95 \\
3.54 \\
3.72 \\
6.20 \\
5.23 \\
4.14 \\
3.62 \\
4.13 \\
5.23 \\
3.39 \\
3.51 \\
4.13 \\
3.75 \\
5.19 \\
4.39 \\
6.91 \\
4.51 \\
3.47 \\
4.48 \\
3.51 \\
3.53 \\
3.50 \\
3.72 \\
4.51 \\
3.62 \\
3.72 \\
3.68 \\
4.31 \\
3.97 \\
4.31 \\
4.76 \\
4.97 \\
4.97\end{array}$ & $\begin{array}{r}.10 \\
.05\end{array}$ \\
\hline
\end{tabular}


TABIT 7 continued

TEAH TAHS (MR) HW REJATIVE RARS (RR)

FOR SE TINTIAL SETECTION OT

IVDIVIDUAI LOCAIIONS

\begin{tabular}{|c|c|c|c|c|c|c|c|c|}
\hline \multirow[b]{3}{*}{ Items } & \multicolumn{6}{|c|}{ questions } & \multirow[b]{3}{*}{$x_{r^{2}}$} & \multirow[b]{3}{*}{$P$} \\
\hline & \multicolumn{2}{|c|}{ Diagnosis } & \multicolumn{2}{|c|}{ Anxiety } & \multicolumn{2}{|c|}{ Intelligence } & & \\
\hline & MR & $R R$ & $M R$ & RR & $\mathbb{R}$ & $R R$ & & \\
\hline $\begin{array}{l}1 \\
2 \\
3 \\
4 \\
5 \\
6 \\
7 \\
8 \\
9 \\
10 \\
11 \\
12 \\
13 \\
14 \\
15 \\
15 \\
17 \\
18 \\
19 \\
20 \\
21 \\
22 \\
23 \\
24 \\
25 \\
26 \\
27 \\
28 \\
29 \\
30 \\
31 \\
32 \\
33 \\
34 \\
35 \\
36 \\
37\end{array}$ & $\begin{array}{l}171 \\
145 \\
164 \\
160 \\
167 \\
176 \\
180 \\
185 \\
172 \\
190 \\
167 \\
173 \\
186 \\
181 \\
186 \\
174 \\
170 \\
170 \\
187 \\
184 \\
184 \\
187 \\
179 \\
188 \\
176 \\
185 \\
181 \\
192 \\
175 \\
182 \\
180 \\
193 \\
190 \\
200 \\
200 \\
200 \\
200\end{array}$ & 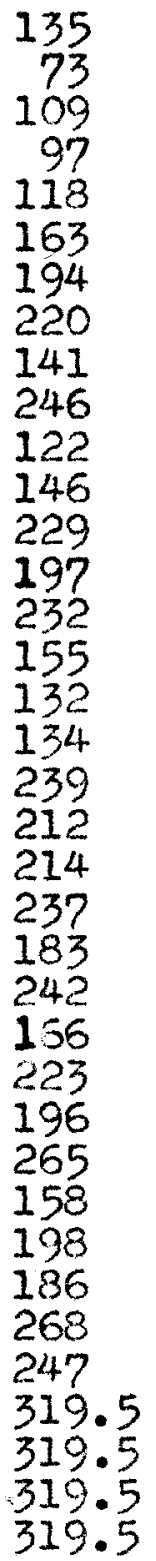 & $\begin{array}{l}184 \\
156 \\
155 \\
159 \\
155 \\
160 \\
161 \\
158 \\
186 \\
176 \\
178 \\
155 \\
126 \\
136 \\
166 \\
188 \\
183 \\
183 \\
175 \\
182 \\
188 \\
185 \\
192 \\
180 \\
185 \\
185 \\
181 \\
185 \\
190 \\
190 \\
187 \\
190 \\
183 \\
194 \\
201 \\
201 \\
201\end{array}$ & 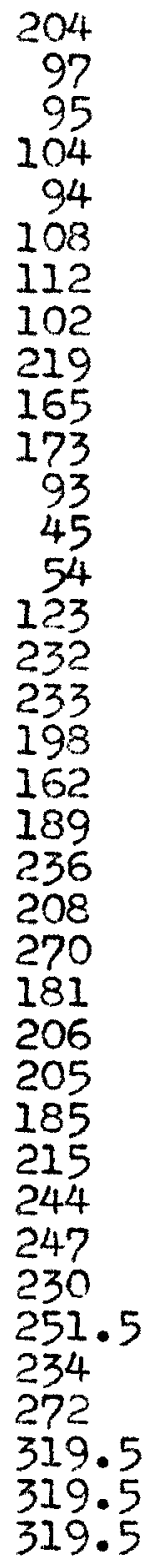 & $\begin{array}{l}177 \\
177 \\
177 \\
163 \\
183 \\
177 \\
172 \\
173 \\
159 \\
180 \\
169 \\
175 \\
175 \\
162 \\
134 \\
179 \\
176 \\
180 \\
180 \\
180 \\
180 \\
180 \\
180 \\
180 \\
181 \\
181 \\
181 \\
181 \\
177 \\
178 \\
178 \\
171 \\
179 \\
171 \\
179 \\
175 \\
180\end{array}$ & 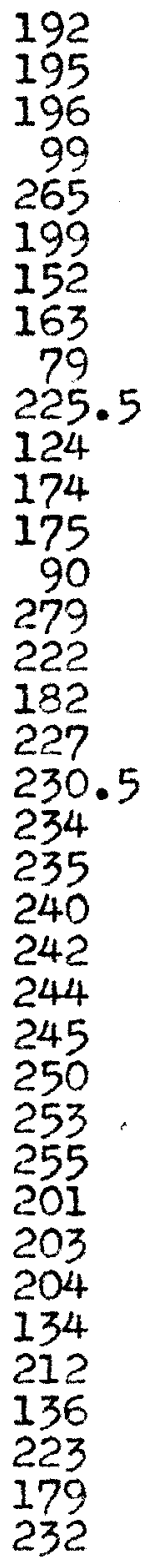 & $\begin{array}{r}4.52 \\
6.49 \\
4.97 \\
3.75 \\
5.53 \\
4.00 \\
4.06 \\
3.85 \\
4.81 \\
3.55 \\
4.14 \\
5.01 \\
10.11 \\
6.58 \\
4.35 \\
4.73 \\
4.98 \\
4.63 \\
3.89 \\
3.89 \\
3.85 \\
3.64 \\
4.31 \\
3.72 \\
4.39 \\
3.75 \\
4.00 \\
3.55 \\
4.52 \\
3.97 \\
3.72 \\
3.75 \\
3.47 \\
4.39 \\
3.83 \\
4.13 \\
3.83\end{array}$ & $\begin{array}{l}.10 \\
.10 \\
.01 \\
.05 \\
.10 \\
.10 \\
.10\end{array}$ \\
\hline
\end{tabular}


TiBLP 7 continued

MIAN RLNKS (RR) AND REIATIVE RANS (RR) FOR SEUVENTAE, SIJ JCTION OF CARD SUHUSRY ITFS

\begin{tabular}{|c|c|c|c|c|c|c|c|c|}
\hline \multirow[b]{3}{*}{ Items } & \multicolumn{6}{|c|}{ uestions } & \multirow[b]{3}{*}{$x_{r^{2}}$} & \multirow[b]{3}{*}{$p$} \\
\hline & \multicolumn{2}{|c|}{ Diagnosia } & \multicolumn{2}{|c|}{ Anxiety } & \multicolumn{2}{|c|}{ Intelligence } & & \\
\hline & & $\mathrm{RR}$ & & $R R$ & MT? & $R R$ & & \\
\hline
\end{tabular}

Thumber of Responses to Each Rorschach Card

\begin{tabular}{|l|ll|lr|rr|r|r|}
\hline Card 1 & 161 & 101 & 156 & 98 & 160 & 82 & 3.55 & \\
Card 2 & 164 & 105 & 159 & 105 & 170 & 129 & 4.48 & \\
Card 3 & 151 & 84.5 & 143 & 64 & 153 & 68 & 3.51 & \\
Card 4 & 173 & 148 & 139 & 59 & 175 & 177 & 6.49 & .05 \\
Card 5 & 183 & 205.5 & 170 & 138 & 170 & 131 & 3.89 & \\
Card 6 & 164 & 107 & 148 & 80 & 130 & 233 & 6.16 & .05 \\
Card 7 & 166 & 115 & 147 & 74 & 171 & 141 & 4.63 & .10 \\
Card 8 & 165 & 110 & 151 & 86 & 175 & 180 & 4.98 & .10 \\
Card 9 & 161 & 100 & 167 & 126 & 163 & 96 & 3.72 & \\
Card 10 & 168 & 123 & 154 & 90 & 153 & 70 & 3.96 & \\
\hline
\end{tabular}

Reaction Time to 3ach Rorschach Card

\begin{tabular}{|l|llll|ll|l|l|}
\hline Card 1 & 159 & 95 & 164 & 119 & 173 & 160 & 4.97 & .10 \\
Card 2 & 167 & 117 & 165 & 122 & 174 & 171 & 4.56 & \\
Card 3 & 171 & 140 & 171 & 140 & 175 & 173 & 4.14 & \\
Card 4 & 180 & 189 & 176 & 163 & 179 & 206.5 & 4.14 & \\
Card 5 & 180 & 191 & 177 & 169 & 179 & 209 & 4.06 & \\
Card 6 & 180 & 192 & 173 & 147 & 179 & 214 & 4.48 & \\
Card 7 & 131 & 195 & 173 & 149 & 179 & 218 & 4.48 & \\
Card 8 & 177 & 171 & 169 & 132 & 179 & 219 & 4.73 & .10 \\
Card 9 & 185 & 224 & 176 & 163 & 172 & 156 & 4.00 & \\
Card 10 & 185 & 226 & 174 & 152 & 172 & 158 & 4.34 & \\
\hline
\end{tabular}


conslaered three of the rree essociations 112 ereater detall than they did the other responses. Looked at more closely were two reaponses on the Dlagnosis protocolt

Response 17. Card VII--"proflie of cen's face. In 11lustrations of ramous legends, storles. (Nose. old shriveled up mouth and chin. Back of head.)" (Scored D F+ Id $P$

Response 23. Card VIII-"Ice, (Convent1onal rend1t1on. Smeared. Large chunks. Casualness of rendering.)" (Soored D F+ Na)

The response looked at more closely on the Anxiety question was the rollowing

Besponse 13. Card III--"People standing on their hoads. Arrs. Fand extending for each arm." (Scored $D$ Wt $H$ $3.0)$

Differential interest in the latter response was influenoed by a technlcal factor-the same verbal response appeared tw10e in the protocol but recelved two scorings $\left(M_{-}, N_{+}\right)$aue to differences In location. Interest in the two Dlagnosis responses was influenced by needs for information regardins the location and accuracy of the percopts, mich would have meaning for ovaluating type and sever1ty of patholosy. The phrases "conventional render1ne... asualness of renderlng" in nesponse 17 ello1ted introspeotive compents from cliniclans that the response was "unusual" or "strange". at least.

The gual1tat1ve response category ranked first anong all of the sixteen catecories in overall ut111ty for the three questions $(U I=53.0)$. The prediction that Qualitative responses would bo dron exeatest emphasis in interpretation on protocol I compared 
With Protocols II and III was not confirmed. The utility value of these free associations was highest for the Anxicty question $(U I=59.7)$. followed closely by the Diacnocls question (UI = 58.8), and was lowest for the Intelligence question (UI $=40.6$ ). A second prediction that qualitative information would show sequentielly later emphasis on the Anxiety question, while showing ereater balance with quantitative data, also was not confirmed. The Qualitative category, howerer, did contrlbute the strongest evidence in support of the major hypothesis that information choices rould be influenced by the clinical question asked. E1ght of the free associations were selected signiflcantly more frequently and earlier for Diagnosis, while eleven were selected more frequently and/or earlier for Anxiety. For Intelligence estimation, three cards were selected significantly earlier and three significantly later. Five additional items approached s18niflcance at the .10 level for tre three questions.

A common influence vas discernible as underlying the pattern of significances for the free assoclations. Differentially high ut1lity resulted for responses on the Dlagnosis question which were given to Borsohach Cards II, III, VII, and IX. Responses slenificantly highest in utility on the Anxiety question were those given to Rorschach Cards III, IV, VI, and VIII. Responses approaching signiflcantly high ut1lity on the Intelligence questIon were those assoclated with Rorschach Cards IX and $X$. The important influence of qualitative features of responses 
was highlighted especially on the Intelligence question. Introspective comments ind lcated that some responses had high "attraction" value for cliniclans in estimating intelilgence, especially in the direction of above average and superior. Four associat1ons were prominent here, "section of tree. Sunlight through 1t. Follage.....Beautifully blue satin plilows.... Dellolous orange and strawberry sundaes....Surrealist painting." Cues related to vocabulary usage and syntax were viewed to be operative in eliciting the "attraction" comments.

Verbalizations and Examiner Observations were predicted to have greatest utility value for the Diagnosis question, but this prediction was not confirmed. The category had highest ut111ty for the Anxiety question (UI = 21.4), next highest utility for the Dlagnosis question $(U I=19.2)$, and lowest ut1l1ty for the Intelilgence question $(U I=16.4)$. The sole 1tem selected signiflcantly more often and earliest in this category was that accompanying the first response to Rorschach Card VII on the Anxiety protocol, "Iittle rabbits. Running in wrong alrection." As nelther the Klopfer nor Beck scoring of this response showed differential ut111ty in the Quantitative category, the suggestion Is that add1tional qual1tative data was judged comparat1vely more useful in meeting the clinicians" need for a "closer look" at the free association in question. Selected significantly earlier for the Anxlety question was the Verbalization accompanying the last response to Card I. "Mouse-shaped things. Plercing the 
central body of a bat. (BIting.)." Introspective comments by some of the clinicians indlcated that this response conveyed qual1tat1ve overtones of "anxiety" or "disturbance." The first Verbalization to Card I on the Intelligence question also was selected significantly earlier, at the .05 level. The response was "Eagle. (Wide spread of wings.)." Nine other Verbal1zation 1 tems approached signiflcance at the .10 level, appearing on Forschach color Cards II and VIII for the Dlagnosis question, Cards I, III, and VI for Anxiety, and Cards I and III for Intelligence. However, the Influence of the Rorschach Cards was seen to be secondary to that of the particular free associations involved.

The Individual Location category proved to have highest ut1lity value for Protocol II (UI $=14.8$ ), middle utillty for Protocol I (UI $=12.3$ ), and lowest ut1l1ty for III (UI $=7.8$ ). The Anxiety question elicited significant interest in the third and fourth responses to Rorschach Card III, "People standing on their heads. Arms. Hand extending from each arm. $(\Lambda, V) . "$ The Dlagnosis question elicited significant attention to the second response to Card I, "Large pair of wings. Of flying red horse...." Three of the four responses to Card VII approached the .10 level in earlier sequence of selection. "Caterpillar... Profile of man's face....Vertebrae," while a similar tendency oharacterized two responses to Card I and one to Card III on the Anxiety protocol. Significantiy earlier interest occurred on the Intelligence protocol for the first assoclation to Card III. 
TABLE 8

UTILITY INDICES (UI) AND VEAN RANKS (NR) OF INFORYATION CATEGORIES FOR THREE QUESTIONS

\begin{tabular}{|c|c|c|c|c|c|c|c|c|}
\hline \multirow[b]{3}{*}{ Categories } & \multicolumn{8}{|c|}{ Questions } \\
\hline & \multicolumn{2}{|c|}{ Diagnosis } & \multicolumn{2}{|c|}{ Anxiety } & \multicolumn{2}{|c|}{ Intell1gence } & \multicolumn{2}{|c|}{ ALL } \\
\hline & UI* & $M R^{* *}$ & UI & MR & UI & $\mathrm{HiR}$ & UI & $\mathrm{MR}$ \\
\hline Personal Data & 46.4 & 113 & 46.6 & 119 & 29.2 & 135 & 40.7 & 122 \\
\hline Locations $K^{* * *}$ & 6.4 & 190 & 7.2 & 191 & 9.2 & 175 & 7.6 & 186 \\
\hline Locations $B^{*+*}$ & 23.4 & 157 & 23.4 & 158 & 26.2 & 142 & 24.4 & 152 \\
\hline Determinants $K$ & 12.2 & 182 & 12.6 & 181 & $7 \cdot 3$ & 178 & 10.7 & 180 \\
\hline Determinants $B$ & 36.5 & 137 & 31.0 & 145 & 11.5 & 170 & 26.4 & 151 \\
\hline Content $K$ & 3.9 & 194 & 4.1 & 195 & 3.9 & 182 & 4.0 & 191 \\
\hline Content $B$ & $17 \cdot 7$ & 171 & 13.3 & 178 & 6.8 & 177 & 12.6 & 175 \\
\hline Totals K & 9.5 & 186 & 10.6 & 185 & 7.6 & 177 & 9.2 & 183 \\
\hline Totals B & 32.9 & 140 & $31 \cdot 2$ & 146 & 22.4 & 150 & 28.8 & 145 \\
\hline Quantitat1ve $\mathrm{K}$ & 3.1 & 195 & 3.8 & 194 & 4.0 & 183 & 3.6 & 191 \\
\hline Quantitative B & $15 \cdot 5$ & 177 & 14.7 & 179 & 11.7 & 171 & 14.0 & 176 \\
\hline Qualitative & 58.8 & 106 & 59.7 & 105 & 40.6 & 123 & 53.0 & 111 \\
\hline Verbalizations & 19.2 & 170 & 21.2 & 167 & 16.4 & 163 & 18.9 & 167 \\
\hline Locations & $12 \cdot 3$ & 181 & 14.8 & 177 & 7.8 & 176 & 11.6 & 178 \\
\hline Number Responses & 21.7 & 165 & 29.4 & 154 & 13.3 & 167 & $21 \cdot 5$ & 162 \\
\hline Beaction Time & 16.1 & 177 & 16.7 & 172 & 7.5 & 176 & 13.4 & 175 \\
\hline
\end{tabular}

* Based on percentage of cards selected within category.

* Rounded off to nearest whole number.

** $K$ Indlcates KIopfer category and $B$ Indicates Beck category. 
TABLE 9

SOME ITEMS SHOWING DIFFERENTIAL UTILITY* AMONG QUESTIONS

\begin{tabular}{|c|c|c|c|}
\hline & \multicolumn{3}{|c|}{ Questions } \\
\hline & D1agnosis & Anxiety & Intel11gence \\
\hline Categories & \multicolumn{3}{|c|}{ Items } \\
\hline Personal Data & & $\begin{array}{l}\text { Mar1tal status } \\
\text { Sexual H1story } \\
\text { S1b Position }\end{array}$ & Educetion \\
\hline Locations & & & $2 \underset{W}{\text { Sum }}$ \\
\hline Determinants & $\begin{array}{l}\mathrm{C} \\
\mathrm{CF} \\
\mathrm{FC} \\
\mathrm{TF} \\
\mathrm{FT}\end{array}$ & $\begin{array}{l}Y \\
Y F \\
F Y \\
T \\
V\end{array}$ & \\
\hline Content & & $\begin{array}{l}\mathrm{Hd} \\
\mathrm{At}\end{array}$ & \\
\hline Totals & $p$ & & $F+\%$ \\
\hline $\begin{array}{l}\text { Free } \\
\text { Assoc1at1ons } \\
\text { to Cards }\end{array}$ & $\begin{array}{l}I I \\
I I I \\
V I I \\
I X\end{array}$ & $\begin{array}{l}I I I \\
I V \\
V I \\
V I I I\end{array}$ & $\begin{array}{l}I X \\
X\end{array}$ \\
\hline $\begin{array}{l}\text { Number of } \\
\text { Responses } \\
\text { to Cards }\end{array}$ & & $\begin{array}{l}I V \\
V I\end{array}$ & \\
\hline
\end{tabular}

${ }^{*} \mathrm{p}<.05$, at least. 
"skeleton."

The category Number of Responses per Card conta1ned information indicating the number of free associations to each of the ten Rorschach Cards, along with the numbers of these responses, so that the cliniclans would be able to focus directly on a single Rorschach Card if desired. The category ranked sixth in overal1 utility (UI $=21.5$ ), and evidenced highest ut1lity for Protocol II $(U I=29.4)$, then $I(U I=21.7)$, and lowest ut111ty for Protocol III (UI = 13.3). Differential significances were obtained for Rorschach shading Cards IV and VI in relation to the Anxiety question, with Rorschach Cards VII and VIII approaching signiflcance at the .10 level.

The initial Reaction Time category was of nearly equal ut111 ty value for Protocols II and I (UI = 16.7.16.1), and lowest for Protocol III $(U I=7.5)$. The Reaction Time to Horschach Card I approached significance at the .10 level for the question of Diagnosis. The Reaction Time to Card VIII approached signif1cance for earlier selection on the Anxiety question.

In summarizing the findings in Tables $6,7,8$, and 9 , the following generalizations appear to be supported.

1. The utility levels of different sources of information used in Rorschach interpretation do vary.

2. Varlations in the utility levels of information are primarily a function of the type of clinical question asked for only certain sources of information.

a. The more specific the source of information, the more sienificant its variation as a function of the clinical question asired (e.s.. free association $\$ 1$ or $/ 2$ or $a$ single numerical score such as $R$ or $W$ ). 
b. The more general the source of information, the less s1gnificant its variation as a function of the question asked (e.g.. Determinants as a category, or "qualitative" vs. "quant1tative" groupings of information).

c. Traditional Rorschach categorles of information show relatively constant utility levels arross questions, with highest constancy occurrine for the Anxiety and Diagnosis questions, especially when compared agalnst the Intell1gence question.

d. Free essociations, personal data, and summary scores show highest utility as information categorles in Rorschach interpretation.

e. Individual locations, content summary scores, initial reaction times, and individual response scorings show lowest utility as categorles of information, for experienced cliniclans.

3. The Dlagnos1s question ellc1ted relatively greater use of the Determinant, Content, Totals, and individual Quantitative scorings and Location categories. Differentlally high ut1I1 ty was found for color and textural determinants, popular response total, and free assoclations to Rorschach Cards II, III, VII, and IX.

4. The Anxiety question elicited relatively greater use of the Personal Data, Qual1tative response, Verbalizations, Number of Responses Per Card, and Reaction Time categorles. Differentially high utility was found for sexual and interpersonal. background information. 11ght and dark shading determinants. pure shading determinants, Hd and Anatomy content scores, and free assoclations to Cards IV, VI, III, and VIII.

5. The Intelligence question elicited relatively greater use only of the Location category. Differentlaliy high ut1lity was found for educational backeround information, $z$ Sum, $W$. $N$, and $F+\%$ scores, and for free associations to Caris IK and $X$.

6. The clinicians approaches to interpretation were most similar for the questions of Dlagnosis and Anxiety estimation. The Intelligence question was most influential in determining the differential ut1lity of information across the three protocols. While requiring the least amount of information and time to answer, the Intelligence estimation question was the one most accurately answered. 
7. Part1cular Rorschach responses were able to "attract" detalled attention from clinicians. Cliniclans would seek further clarification of individual responses, sometimes using the Quantitative scoring or Location of the response, and sometimes the accompanyine Verbalization. Individual responses also were able to ellcit immediate reactions and hypotheses from cliniclans, such as "That's a superior response.... I don't think this gal is merried.... I was expecting something healthier than that."

8. The influence of certain Rorschach cards in gulding the clinicians' interpretative approach was clearly discernible. Interest in the color shock (II), interpersonal (III, VII), and most complex (IX) carcs was high for the Diagnosis question. The shading and masculine cards (IV, VI), and color cerds (III, VIII) guided information selections on the Anxiety question. The differential approach to the Intelisence question was guided by the two difficult W cards (IX, X).

The degree to which the cliniclans in this study showed common agreement in their cerd selections for each of the clinical questions was determined by computing Kendall coefflclents of concordance (W). Table 10 summarizes the Kendall results for the cliniclans' sequence of card selections for each of the three questlons. Kendall W's for the seleoted-not selected dimension were not computed due to the excessive ties which would have been involved.

TABLE 10

KENDALL COEFFICIENTS OF CONCORDANCE (W) FOR THREE QUESTIONS BASED ON SEQUENCE OF CARD SELECTIONS

\begin{tabular}{|l|ccc|}
\hline \multirow{2}{*}{ Clinicians } & \multicolumn{3}{|c|}{ Questions } \\
\cline { 2 - 4 } Total & DLagnosis & Anxiety & Intelligence \\
\cline { 2 - 4 } Beck & .27 & .27 & .20 \\
Klopfer & .35 & .34 & .26 \\
& .34 & .33 & .28 \\
\hline
\end{tabular}


Table 10 shows that the correlations generally ranged in the $.20 ' \mathrm{~s}$ and $10 \mathrm{w} \cdot 30 \mathrm{~s}$. However, using chl square values and a moaification of Fisher's $Z$ distribution, the W's resulting for the total clinlclan group all were slenlficant at or above the .01 hevel. Agreement among clinicians interpreting from a sinele orientation would be expected to be higher than when two orlentations were combined. Higher agreement in fact did result when separate W's were computed for the Beck and KIopfer groups. No clear pattern of significances for the latter H's was obtained. However, both orientations showed similar degrees of agreement In their approaches to all three protocols, with least agreement shown in relation to the Intelligence question.

It was stated in Hypothesis II that clinlolans would show alstinguishable patterns of approach to Rorschach interpretation. That is, some cliniclans would employ a basically quantitative approach which emphasized summary scores, numerical ratios and percentages, and determinants, while other clinicians would employ a basloally qualitative approach which emphaslzed free assoclations, background data, and accompanying sibject verbalizations and examiner observations.

Although the majority of clinicians in this study maintained a general balance between qualitative and quant1tative sources of Information in their interpretations, it was possible to identify a small subgroup of nine cliniclans who focused mainly on qualltative data and another small subgroup of four cliniclans who focused 
mainly on quantitative data. These 1dentifications were made by jetermining the mean per cent usage of the three categories Qual1tative. Personal Data, and Verbalizations for the thirty-six cliniclans (Nean usage $=52.8 \%$ ), and then separating those aliniclans falline above and below the first standard deviation $(S D=14.4 \%)$. Those cliniclans whose qualitative information usage represented at least 67.2 per cent of the $1 r$ total card selections were separated from the group as high qualitative users $(\mathrm{N}=9)$. CIIniclans whose usage of qualitative information represented 38.4 per cent or lower of their total card selections were separated out as high quantitative users $(N=4)$. The finding that twice as many cliniclans were ldeitifled as qualitative rather than quantitative users may point to the generally higher utility value of this information in Rorschach interpretation.

An attempt was made to determine some of the characteristics of the above two subgroups. However. in view of the small number of cliniclans represented in the subgroups, generalizations drawn from the following descriptions mist be evaluatod with caution. The intent of the discussion is to suggest research ideas for rurther investigation.

Five of the nine high qualitative users and all four of the high quant1tative users employed Beck's method. The remaining tour qualitative users represented 36 per cent of the Klopfer ample. None of the high users were among the five cliniclans 
who answered all three clinical questions according to the criteria, although one of the high quantitative users appeared amone the top elght most accurate clinicians. Compared with the total Eroup mean of 266 Rorschachs administered or supervised durine the past five years, the mean number for the quartitative users was 244, while that for the qualitative users was 183.

Systematic differences in ovtcome characterized the two subgroups. Of the fourteen cliniclans who checked the alternative "Neurotic" on the Diacnostic question, seven were high qualitative users and three were high quantitative users, together accountine for 70 per cent of the cliniclans responding to this alternative. The fourth quantitat1ve user checked the alternat1ve "Basically Adjusted." while the two remainine qualitative users checked "Personal1ty Disturbance." The criterion answer for the Diagnosis question tras "Psychotic."

On the Anxiety question. seven of the nine qualitative users and three of the four quantitative users answered by checkine elther of the acceptable categories "Wuch" or "Severe" anxiety. The numbers here represented 77 per cent accuracy for the two subgroups comb1ned, which was only slightly below that of the remainder of the cIInician group ( $87 \%$ accuracy), and not meaningrully different from the latter.

Hypothesis IIB stated that clinicians characterized by a quantitative approach to interpretation would show relatively lower success in estimating the severity of anxiety on Protocol 
II, due to the absence of determinant indicators of anxiety in the protocol (shading scores, $m$ ). The hypothesis, not supported by the outcomes of the high quantitative subgroup identified in this study, could not be tested due to the fact that determinants and free associations had been used by nearly every non-qual1tative clinician in interpreting this protocol. Sugcestive only was the observation that the two clinicians in the high qualitative group who underestimated the severity of anxiety ("Normal") were those who had selected the determinant anxiety indlcators. The remaining qualitative cliniclans selected almost none of these 1ndicators. of the twenty-three clinicians characterized by a more balanced approach in their use of quantitative and qual1tative information, only three underestimated the criterion level of anxiety. No features common to these latter three cliniclans were discernible.

On the InteIIIgence question, the mean estimation of IQ by the total group was $115.3(S D=8.5)$. Th1s result was less than three points away from the stanford-Binet criterion IQ of 118 . Eight of the thirty-six clinicians specified their IQ answers to within \pm 1 point of 118 . with an additional eleven specifying the IQ to vithin \pm 5 points. The specific accuracy of this result is especially noteworthy when it is considered, first, that use of the Rorschach for intelligence estimation traditionally has been disadvised, and, second, that nearly 80 per cent of the experionoed clinicians in this study rated the Rorschach as having low-et ut1lity for intelligence questions, compared with highest 
ut1lity for diagnosis (72\%). The Diagnosis question was the one on which the cliniclans showed least agreement in outcome. Compar1son of the outcomes of the two subgroups on the Intelligence question showed that their estimates were equivalent to those of the majority group of clinicians who used a balanced approach to interpretation. The mean IQ estimates for the major1ty, high quant1tative, and high qualitat1ve groups were 116. 117, and 114, respect1vely. Differences between these means were not statistically significant. However, of the elght clinicians who answered with the alternative "Average," four were from the high qualitative subgroup, as were two other cliniclens whose estimates were the most extreme ( $I Q=135,130)$.

One conclusion which can reasonably be drawn from the above discussion is that an interpretative approach which was belanced between qualitative and quantitative sources of information generally resulted in greater accuracy of outcome. Although a high quantitat1ve approach tended to de the "safer" of the two extremes, resulting in equivalent accuracy on the Intelligence and Anxiety questions compared with the majority group, no cliniclans in this subgroup appeared among the five cliniclans who met the criterion answers for all three questions. A high qualItative approach was by far the most varlable and the least acourate approach, although somewhat "safer" in relation to the Anxiety question. A relationghlp was suggested between high qualitative usage and relatively lower Rorschach administration 
and supervision by clinicians.

Table 11 shows the outcomes obtained for the three clinical questions asked of the clinicians in this study. Hypothesis IIIB stated that clinical accuracy would be higher for Protocol III than for Protocols I and II. The hypothesis was only partial1y supported.

TABLE 11

PERCENTAGE OF CLINICIANS ANSWERING EACH ALTERNATIVE FOR THREE QUESTIONS

Diagnosis

Basloally

Adjusted

$5 \%$
Neurot1c

$39 \%$

\section{Personality}

Disturbance

$42 \%$

Anxiety

No

Littie

Normal

$6 \%$

$11 \%$

$0 \%$
Psychot1c*

$14 \%$
Organic

$0 \%$

\begin{tabular}{cc}
$11 \%$ & $6 \%$ \\
\hline
\end{tabular}

Below

Average

$0 \%$
Average

$22 \%$
Above

Average*

$78 \%$

* Criterion answer 


\section{8}

The Intelligence question was answered far more accurately than that of Diagnosis, but slightly less accurately than that of Anxiety estimation. In order to test the significance of the difference between the outcomes on the Anxiety and Intelligence questions, the answer alternatives for both questions were collapsed to two, rieht or wrong. The acceptable answer for the Intelligence question was "above averave" whereas both "much" and "severe" were acceptable for Anxlety estimation, the equivalent of "above average." Computation of ch1 square in a $2 \times 2$ contingency table falled to show signiflcance between the accuracy of outcome for the two questions $\left(x^{2}=.18\right.$, df $\left.=1\right)$.

Hypothesis IIIA stated that cIinica? accuracy would be higher at the more general levels of interpretation than at more specific levels. The hypothesis was supported by the outcomes to the Anxiety and Intelligence questions, but less so by the outcomes to the Diagnosis question. For example, although only five of the clinicians answered the Diagnosis question with the criterion alternative "Psychotic," five other clinicians who had checked the alternative "Personality Disturbance" specifled this general level conclusion with the statements "Sohizold PersonalIty....marginal adjustment..... Incipient schizophrenia." The latter specifications could be viewed as being more in the direction or the criterion answer "Schizophrenia," than would be "Personality Disturbance." A number of clinicians in fact questioned the Five-category format employed in relation to the Dlagnosis question. 
A second instance which highlighted the difflculty of determining answers to clinical questions at Eeneral levels occurred with the Anxiety question. Two common reactions were expressed by the cliniclans. First, that the judgment Iine between the alternatives "Wuch" and "Severe" anxiety seemed quite arbitrary. with the determining factor related to the presence of sufficlent evidence of the subject's being totaliy "overwhelmed" by anxiety or being without adequate defenses. Second, there was a more immediate question concerning what was meant by "anxlety." The latter concern could be reduced to two considerations--manifest anxiety or latent anxiety, 1.e., anxiety as consclous or unconscious.

The accuracy of the specific IQ estimates made by the major1ty of the experienced clinicians in this study (Mean estinate = 115.3. criterion $I Q=118$ ) is indeed noteworthy, especially when consideration is given to the amount of potential information lost in clinical judgment studies which utilize only general levels of interpretation.

Hypothes Is IIIC stated that cIinicians interpreting from e1thex the Beck or Klopfer methods would show slmilar levels of success in their final conclusions. The hypothesis was supported In all three cases. Again using the dichotomous framework "right" or "rrone," chl squares obtained for accuracy of outcome between Beck and Klopfer orientations on Diagnosis $\left(x^{2}=.23\right)$. Anxiety estimation $\left(x^{2}=.03\right)$, and Intelligence estimation $\left(x^{2}=.30\right)$ 
all felled to reach sienificance.

Eypothesis IV stated that clinicians in the present study would show a lower derree of self-constancy across protocols than res shom by clinicians in Tabor's 1959 study, because of the three different questions asked. The hypothesis was conflrmed partialzy. The mean number of cards selected by the thirty clinIclans in Tabor's study for three diagnostic questions were 22 , 20, and 23 (cards avaliable $=52$ ). The mean number of cards selected for the three questions in the present study were 71 . 72 , and 48 (cards avaliable = 329). The similarity between the means on the Diagnosis and Anxiety protocols supports Tabor's conclusion that the number of cards selected by oliniclans was more a factor of their personal needs than of variations of complexity of the Rorschach problems. However, the clear dissimilerity of both of these means in comparison with the Intelligence mean supports the present conclusion regarding the influence of the type of question asked in Rorschach interpretation. 


\section{SUMMARY AND CONCLUSIONS}

Recent surveys have shown the Rorschach technique to be the most widely used psychological test in American clinical settings, the psychologlcal instrument used most in reseerch, and the clinical tool given most emphasis in the American graduate curriculum. Despite wide evidence of Rorschach use, however, the valldity of the technique has not been experimentally demonstrated. The purpose of the present research was to clarify the discrepancy between Rorschach ut1lity and validity by examining Implementation of the Rorschach through the interpretative approaches of experienced clinical psychologists. Rorschach valldation research has largely falled to incorporate the critiesl influence of the clinlcian.

The present study attempted to determine the sources of vtility in Rorschach interpretation. Ut1lity was defined in two ways. First, what data is used by clinlclans in Rorschach interpretation and, second, how or when this data is used by cliniclans. Two general hypotheses were established. The major hypothesis stated that the utility value of different sources of Information used in Rorschach interpretation would vary primariiy as a function of the type of clinical question asked. A second hypothesis indicated that the sources of utillty in Rorschach interpretation would vary as a function of the clinician's 
approach. quantitative or qualitative.

Thirty-six experienced psychologists interpreted three Rorschach protocols, under conditions which permitted control over access to Rorschach information. The clinicians interpreted each protocol by selecting information cards they considered to be necessary and sufficlent for answering each of three clinical questions, one question per protocol. Diagnosis. Anxiety, and Intell1gence.

The major hypothesis was confirmed partially. on the general level, the Hypothesis was clearly supported when comparisons were made between the Intelligence question and the Diagnosis or Anxiety questions, but not when the comparisons were between Diagnosis and Anxiety. The Intelligence question required s1gniflcantly less information and time to answer, yet it was the question most accurately answered.

on the speoiflc level, only certain of the category and 1tem sources of information were found to vary primarily in relation to the clinical question asked. The majority of the Rorschach information avallable for selection in this study evidenced average utility, or lower. Category sources consiatently highest In ut1l1ty were free assoclations, background data, and numerlcal summarles and ratios. Category sources composed of individual response scorings and locations, content summary scores, and inttial reaction times showed consistently lowest utility value in Borschach interpretation. 
Differential utility across the three questions was found for 58 of the total 329 items, at or beyond the .05 level of significance. These findings were on the combined results of the frequency and sequence of selection dimensians. The number of significant items obtained accounted for about 18 percent of the total, and may be considered a conservative finding. First, the Klopfer sample was too limited to produce signifloant regults in speciflcally Klopfer categorles. None of the Klopfer scoring 1tems, for example, contributed to the 58 signifisant items cited above. The Klopfer determinant FM was used sufficiently often by Beck-orlented cliniclans to approach significance. This exception suggests that cliniclans interpreting from Beck's orientation do find Klopfer's animal movement score to have utility, as Klopfer-oriented cliniclans find utility in Beck's F+ and Fscores. It is predicted that greater support for the major hypothesis would be obtalned if the number of Klopfer clinicians were doubled. Second, if those 1tems whlch approached significance at the .10 level were to be added to the or 1 ginal result, the number of 1 tem sources of information varying primarily in relation to the clinical question asked wovld be ralsed to 83 . or 25 percent of the total.

The second hypothesis also was conflrmed partlally. Sources or utility were found to vary as a function of the clinician's interpretative approach, but secondary to that of a generally qualitative approach, and mainly for small subgroups of clini- 
clans. Cliniclans characteristically proceeded in their interpretations from qualitative to quantitative sources of information, evidencing a significantly high degree of agreement in this 1nitial approach. Ninety percent of the Rorschach free associations were selected earliest, within the upper 15 percent range, along. with nearly 50 percent of the background information 1tems. Also included here were occasional appearances of Beck summary, determinant, and location scores, $F+\%, R, P, M, C, C F, F C$, and W.

Clearly, experlenced cliniclans found qualitative forms of Rorschach data, especially the free associations, to have the highest ut1lity value in Rorschach interpretation. On the assumption that tentat1ve personality hypotheses are formulated early in the interpretative process and progressively verified or "checked out" in the data analysis. quantitative Rorschach scores may be viewed as functioning in a secondary. supportive capacity. The verballzed approach of many of the cliniclans in this study in fact was one of "checking out" hypotheses, accompanied by comments which expressed confldence or surprise with the selection of a confirming or contraindicating datum, or by anticipatory predictions about what information the card would contain.

As a group, the cliniclans also showed much greater agreement conceming information which was least useful in interpretation than data which was most useful. None of the 329 information ourds avaliable was selected at the Very High or High levels of 
utility, defined in this study as $85-100$ percent frequency of selection, whereas 185 of the 1tems, or 56 percent of the total number avallable, were selected at the Low or Very Low ut1lity levels, defined as 0-15 percent frequency of selection.

The majority of the cliniclans in this study malntalned a general balance in their use of qualitative and quantitative Rorschach information. Consistent with the second hypothesis, however, was the Identification of nine clinicians who focused malnly on qualitative information sources and four who focused mainly on quantitative sources. The observation that twice as many cliniclans could be identifled as high qualitative users than as high quantitative users again pointed to the higher utility value of qualitative category sources in Rorschach interpretation.

Among the two non-Rorschach factors seen as influencing the utility value of information sources in this study was the prominentiy high degree of variation in interpretative style and data needs of individual clinlcians. For example, while the free association category proved to have highest utility for the cliniclans as a group, five cliniclans using the Beck method found this category to have Low utility value. Four clinicians used no Personal Data, which represented the second highest utility category for the group as a whole, while nine cliniclans used no, or less than one, Verbalization 1tem on the average. murther, one clinlclan required an average of only elght infor- 
mation items for his interpretations, whereas another required 144 items. Both of these cliniclans were among the five cliniclans who answered all three questions according to the criterla. The second non-Rorschach influence concerned the placement of Information on the experimental apparatus, as it would appear In traditional Rorschach summary sheets. That is, the mere fact of certain Rorschach information preceding other information, as w1th $R_{1}$ appearing before $R_{2}$, or $W$ prior to $D$, enhanced the Iikelihood that the earliex appearing item would be selected more frequently and earlier in Rorschach interpretation.

The generality of these findings may be Ilmited somewhat by the particular conditions Imposed by the desien of the study-"blind" Rorschach interpretation, atomistic access to the data-and by the moderately unequal representation of the Klopfer and Beck samples.

The theoretical intent of this study was to account for the discrepancy existing between Rorschach utility and validity. The following observations based on the findings of the study are sugeested.

First, the large majority of past Rorschach validation studles have focused their attention on quantitative Rorschach scores. Number of Rorschach responses, movement and color scores. number of popular responses, Ft. W\%, frequency of eye and water percepts, and other numerical summaries, percentages, and ratios have been employed in numerous validation studies. These same 
quantitative scores also have been specially grouped into multiple recression equations, have been reduced by factor analytic techniques into two or three basic dimensions, and otherwise have been weighted statist1cally to predict one criterion sroup. while falling on the cross-validation to predict its counterpart. Characteristic of these studies, however, has been the nonincorporation of the orisins of the quantitative scores, the free associations. In the present study, it was the free associations which the experienced clinicians fourit to have highest utility as a source of information, supported in the greatest number of instances by statistical significance concerning their utility for different clinical questions. The finding highlights the need to combine quantitative and qualitative information in Rorschach validation studies.

The fallure of past Rorschach valldation studies to incorporate free assoclation material in their designs, although unfortunate, 1ikely has had some realistic bases. Quantitative scores lend themselves more naturally to the experimenter's methodological goals of maximum definition and control of the veriables he selects. Also, the key elements in verbal responses frequently are difflcult to specify. The meaning of a Rorschach association, for example, is apt to be amb1guous, surrounded by subtle contextual and grammatical cues and influenced by selective factors in interpretation. The "important" elements may rary from one clinician to another. The dilemma posed by this 
simultaneous striving for experimental control and representative Rorschach variables frequently has not met with a balanced resoIution. Experimenters too often have opted in favor of the methodological consideration.

Continued fallure to incorporate free assoclation responses in Rorschach validation studies may require qualification of the findings as involving a distortion of the Rorschach's character1stic pattern of implementation. Conolusions about the "fallure" of numerical signs, ratios, and summary scores to valldate the Rorschach also may require qualification. Quantitative soores contribute only partially to the data typlcally used by experienced clinicians in Rorschach interpretation. In addition. quantitative scores serve in a secondary, supportive capacity for some cliniclans, as a means of checking out tentative hypotheses initially established on the basis of free associations or Individual Rorschach Card performances.

Characteristic of the majority of cliniclans in the study was a balanced approach to interpretation, with high agreement shown concerning the earlier importance of qual1tative information in the interpretation process. Especially did those clinicians characterized by consistently acourate outcomes ut111ze a balanced approach to interpretation. Cliniclans who basically employed one or the other of the approaches proved to be the most varlable and least accurate in thelr outcomes. 
A second observation is related to the above discussion. Past validation research has for the most part focused on general sources of Rorschach information, usins totalied or summary scores or holistic clinical judgments. However, experienced cliniclans regularly attended to particular responses, especialiy In the context of a given Rorschach Card. Individual responses in this study showed a capacity for eliciting immediate clinical hypotheses from cliniclans and for directing clinicians to other sources of information which might clarify or "check out" a hypothesis. Investigation of individual sources of Rorschach ut1lity, and inclusion of these sources of information in val1dation studies, also is seen as a necessary complement to strictly quantitative approaches of past studies.

Th1rd, the results of the present study support the concept of Rorschach-and-cliniclan as a single working un1ty. H1gh accuracy of judgments was obtained for the three different c1inical questions asked, against a variety of criteria. The experienced clinicians in this study showed $83 \%$ accuracy in estimating severity of anxiety, $78 \%$ accuracy in estimating level of intelligence--including a mean $I Q$ estimate of $115 \pm 8$ points against a Stanford-Binet IQ of 118, and a $11 \mathrm{kely} 56 \%$ accuracy in diagnosing a dificult psychiatric case.

The conditions under which the cliniclans achieved their high degree of accuracy could not have been less favorable to successful outcome for Rorschach judgments. The interpretations were 
done "blind." The experimental apparatus allowed information to be known only atomistically, one item at a time. The protocols used in the study were difflcult ones, not of the typloal "textbook" variety. The protocol employed for the Anxiety question, for example, was unusual in that traditlonal shading ind1cators of anxiety were entirely absent. Also, the psychiatric status of Gregor, whose Rorschach record was used for the Dlagnosis question, was not definitively psychotic. Diagnoses made by 22 different psychological test experts and psychlatrists encompassed not only "Psychot1c," but "Personality D1sturbance" (Klopfer) and "Neurosis" as well. Finally, the number of Rorschach responses (R) was controlled for in the three protocols. As for the Horschach method per se. 1t was clear that the clinlclans were belng gulded in their data selectlons by traditional hypotheses about the relationship of the data to the question asked. Shading determinants and information on Rorschach Cards IV and VI-- the shading Cards--were selected for the Anxiety question. Location, organization, and scores were selected for the Intel11gence question. Contrary to recent conceptualizations of the Rorschach as a dsgulsed interview, the cliniclans did not pely on secondary verbalizations of test subjects and examiner observations of behavior. The latter information had been separated from the actual free assoclations.

Fourth, if the research worker finds it desirable nevertheless to remain within the framework of quantitative and general 
sources of Rorschach information, findings of the present study suggest that the framework may prove more successful for some clinical questions than others. For example, a high quantitative approach to Interpretation was least successful in relation to the dlagnostic question and relatively more successful for the question of intelligence estimation. Use of the quantitative framework for validation of the Rorschach as an intelligence measure likely would moet with greater success, as has been reported in the 11terature.

Finally, although the Rorschach technique has never been baslcally intended nor accepted as a measure of intelligence, the consistentiy successful outcomes which have been obtained in studies employing it for this purpose cannot be 1gnored. The success conveys importance for Rorschach practice as well as research. First, the criterion measure for the intelligence question. which provided the most specific accuracy of outcome in this study, was itself the most objective of the three criterla employed. Compared with psychologlcal or psychiatric diagnostic judgments and with projective test measures of diagnosis or anxiety, the standard 1ntelligence test repeatedly has been shown to have the hlghest rellability and validity. Fallures in Rorschach validation research may bear a direct relation to the objectivity of the criterion measure used. Second, Blalick and Hamin's (1954) judgment that intelligence represents the variable that clinlclans know best is vlewed as sound. Clinicians' 
concepts concerning what is meant by "Intelifgence" evidenco greater clarity and consensual validation than do their concepts of elther "anxiety" or "diagnosis." No clinician in the present study asked for clariflcation of the intelligence question, while clariflcations of the diagnosis and anxlety questlons were requested. Clinicians evidence greater agreement in describing what they look for in estimating 1ntell1gence, and the operations involved, than in describing similar processes for diagnosis and anxiety estimation. Although intelilence is admittediy less multidimensional then personality, intelligence dimensions have been given more concrete definitions and there are a number of different measures of intelligence avaliable for cliniclans to use. More prec1se definttions and measures of anxiety, along with more reliable ways of describing severities of pathology. would be expected to increase success in outcomes for the latter two clinical questions. 
ABSTRACT

In an attempt to determine sources of ut111ty in Forschach interpretation, 36 experienced cliniclans were asked to interpret three Borschach protocols under conditions which controlled access to information. The cliniclans interpreted each protocol by selecting any of 329 information items they considered to be necessary and sufficient for answering Diagnosis. Anxiety, or Intelligence questions. Cliniclans typlcally proceeded from verbal to numerlcal information sources. Free associations and background data had highest utility, followed by the scores F+\%, $R, P, M, C, C F, F C$, and $W$. The hypothesis that utility of information would vary acoording to the question asked gained partial confirmation. Application of Friedman's analysis of variance test resulted in significant differences in utility for 58 of the 329 Items. The Intelligence question required least information and time to answer. Accuracles of $83 \%, 78 \%$, and $56 \%$ were obtained for the Anxiety. Intell1gence, and Diagnosis questions, respect1vely. Discussion noted that many unsuccessful Rorschach val1dation studies falled to incorporate free assoclations and cliniclans in their designs. 


\section{BIBLIOGRAPHY}

Abt, L. A. \& Bellak, L. (eds.) 1950. Projective Psychology. Grove Press: New York.

Allport, G. W. 1955. Becoming. Yale University Press: New Haven.

Ainsworth, M. D. Problems of Validation. In: Klopfer, B. et al. 1954. Pp. 405-500.

American Psychological Association. 1954. Technical Recommendations for Psychological Tests and Diagnostic Techniques. A.P.A.: Washington, D. C.

Anderson, H. H. \& Anderson, G. L. (eds.) 1951. An Introduction to Projective Techniques. Prentice Hall: Anglewood Cliffs, New Jersey.

Armitage, S. G., Greenberg, P. D., Pearl, D., Berger, D. G. \& Daston, F. G. 1955. Predicting Intelligence from the Rorschach. I. Consult. Psychol. 19:321-329.

Armitage, S. G. \& Pearl, D. 1957. Unsuccessful Differential Diagnosis from the Rorschach. J. Consult. Psychol. 21: $479-484$.

Baughman, E. E. 1954. A Comparative Analysis of Rorschach Forms with Altered Stimulus Characteristics. J. Proj. Techs. 18:151-164.

Baughman, E. E. 1958. A New Method of Rorschach Inquiry. I. Prof. Techs. 22:381-389.

Baughman, E. F. The Role of Stimulus in Rorschach Responses. In: Murstein, B. I. 1965. Pp. 221-255.

Beck, S. J. 1935. Problems of Further Research in the Rorschach Test. Amer. J. Orthopsychi. 5:100-115.

Beck, S. J. 1942. Error, Symbol and Method in the Rorschach Test. J. Ab. \& Soc. Psychol. 37:83-103.

Beck, S. J. 1945. Rorschach's Test, II. A Variety of Personality Pictures. Grune \& Stratton: New York. 


\section{5}

Beck, S. J. 1951. The Rorschach Test: A Multi-Dimensional Test of Personality. In: Anderson, $H$. H. \& Anderson, G. I.

Beck, S. J. 1952. Rorschach's Test, III. Advances in Interpretation. Grune \& Stratton: New York.

Beck, S. J. 1952. The Bxperimental Validation of the Rorschach Test. IV. Discussion and Critical Evaluation. Amer. J. Orthopsychi. 22:771-775.

Beck, 3. J. Review of the Rorschach. In: Buros, O. K. 1959. Pp. 273-276.

Beck, S. J. 1960. The Rorschach Bxperiment. Ventures in Blind Diagnosis. Grune \& Stratton: New York.

Beck, S. J. et al. 1961. Rorschach's Test, I. Basic Processes. Grune se Stratton: New York.

Bell, J. E. 1948. Projective Techniques. Longmans, Green, \& Co.: New York.

Bell, J. E. 1949. Case Studies. The Case of Gregor: Interpretation of Test Data. Ror. Res. Exch. 13:155-168.

Bialick, I. \& Hamlin, R. M. 1954. The Clinician as Judge: Details of Procedure in Judging Projective Material. J. Consult. Psychol. 18:239-242.

Binder, A. 1964. The Rorschach Test: A Ferceptual Bias. Percept. \& Motor Skills. 18:225-226.

Bochner, R. \& Halpern, F. 1942. The Clinical Application of the Rorschach Test. Grune \& Stratton: New York.

Bosquet, K. T. \& Stanley, W. C. 1956. Discriminative Powers of Rorschach Determinants in Children Referred to a Child Guidance Clinic. J. Consult. Psychol. 20:17-21.

Bower, P. A., Testin, R., \& Roberts, A. 1960. Rorschach Diagnosis by a Systematic Combining of Content, Thought Process, and Determinant Scales. Genet. Psychol. Monogr. 62:105183.

Bradway, K. \& Heisler, V. 1953. The Relation between Diagnoses and Certain Types of Extreme Deviations and Content on the Rorschach. J. Proj. Techs. 17:70-74.

Brockway, A. I., Gleser, G. C. \& Ulett, G. A. 1954. Rorschach Concepts of Normality. J. Consult. Psychol. 18:259-265. 
Brown, F. 1953. An Exploratory Study of Dynamic Factors in the Content of the Rorschach Protocol. I. Proj. Techs. 17: $251-279$.

Brown, F. 1953. Reply to a Critique of "An Exploratory Study of Dynamic Factors in the Content of the Rorschach Protocol." J. Proj. Techs. $17: 462-464$.

Bruner, J. S. 1948. Perceptual Theory and the Rorschach Test. J. Person. 17:157-168.

Buros, O. K. (ed.) 1959. The Fifth Mental Measurements Yearbook. Gryphon Press: Highland Park, New Jersey.

Caldwell, B. M., Ulett, G. A., Mensh, I. N. \& Granick, 3. 1952. Ievels of Data in Rorschach Interpretation. J. Clin. Paychol. $8: 374-379$.

Challman, R. C. 1951. Clinical Methods: Psychodiagnostics. Ann. Rev. Psychol. 2:239-258.

Chambers, G. S. \& Hamlin, R. M. 1957. The Validity of Judgments Based on "Blind" Rorschach Records. J. Consult. Psychol. 21:105-109.

Charen, S. 1953. A Critique of "An Exploratory Study of Dynamic Factors in the Content of the Rorschach Protocol." J. Proj. Tech. 17:460-462.

Cooper, G. W., Bernatein, L. \& Hart, C. 1965. Predicting Suicidal Ideation from the Rorschach: An Attempt to Cross-Validate. J. Proj. Tech. 29:168-170.

Corsini, R. J., Severson, W. E. Tunney, T. E. \& Uehling, H. F. 1955. The Separation Capacity of the Rorschach. I. Consult. Psychol. 19:194-196.

Cronbach, L. J. 1949. Stat1stical Methods Applied to Rorschach scores. Psychol. Bull. 46:393-429.

Cronbach, I. J. 1950. Statistical Methods for Multi-Score Tests. J. Clin. Psychol. 6:21-25.

Cronbach, L. J. \& Meehl, P. E. 1955. Construct Validity in Psychological Tests. Psychol. Bull. 52:281-302.

Cronbach, I. J. 1956. Assessment of Individual Differences. Ann. Rev. Psychol. 7:173-196. 
Cummings, S. T. 1954. The Clinician as Judge: Judgments of Adjustment from Rorschach Single-Card Performance. J. Consult. Psychol. 18:243-247.

Davis, H. S. 1961. Judgments of Intellectual Level from Various Features of the Rorschach Including Vocabulary. J. Proj. Tech. 25:155-157.

Elizur, A. 1949. Content Analysis of the Rorschach with Regard to Anxiety and Hostility. J. Proj. Tech. 13:247-284.

Eschenbach, A. E. \& Borgatta, E. F. 1955. Testing Behavior Hypotheses with the Rorschach: An Exploration in Validation. J. Consult. Psychol. 19:267-273.

Eysenck, H. J. 1957. Sense and Nonsense in Psychology. Penguin: Baltimore.

Fiske, D. W. \& Baughman, E. E. Relationships between Rorschach Scorlng Categorles and the Total Number of Responses. In: Murstein, B. I. 1965. Pp. 257-271.

Frank, J. D. 1961. Persuasion and Healing. Shocken Books: New York.

George, C. E. 1955. Stimulus Value of the Rorschach Cards: A Composite Study. I. Proj. Techs. 19:17-20.

Gleser, G. C. 1963. Projective Methodologles. Ann. Rev. Psychol. 14:391-422.

Goldfried, M. R. 1963. The Connotative Meaning of Some AnImal Symbols for College Students. J. Prof. Tech. 27:60-67.

Gordon, J. 1959. Rorschach Responses as Verbal Behavior. J. Proj. Tech. 23:426-428.

Grant, M. Q., Ires, V. \& Ranzon1, J. H. 1952. Reliability and Validity of Judges' Ratings of Adjustment on the Rorschach. Psycho1. Monogr. 66:20pp.

Grauer, D. 1954. Homosexuality in Paranold Schizophrenia as Revealed by the Rorschach Test. I. Consult. Psychol. 18: 459-462.

Griffith, R. M. \& Dimmick, J. B. 1949. Differentiating Rorschach Responses of Alcoholics. Quart. J. Stud. Alcohol. $10: 430-433$. 
Griffith, R. M. 1961. Rorschach Water Percepts: A Study in Conflicting Results. Amer. Fsychol. 16:307-311.

Gunn, H. E. 1962. An Analysis of Thought Processes Involved in Solving Glinical Problems. Unpublished Doctoral Dissertation. Loyola University: Chicago.

Haley, J. V. 1963. Effects of Training on Diagnostic Skills. Joyola Psychometric Laboratory. Publication No. 30. Loyola University: Chicago.

Halpern, F. 1953. A Clinical Approach to Children's Rorschachs. Grune \& Stratton: New York.

Halpern, H. M. 1957. A Rorschach Interview Technique: Clinical Validation of the Examiner's Hypothesis. I. Proj. Techs. $21: 10-17$.

Hamlin, R. M. 1954. The Clinician as Judge: Implications of a Series of Studies. J. Consult. Psychol. 18:233-238.

Hamlin, R. M. \& Powers, W. T. 1958. Judging Rorschach Responses: An Illustrative Protocol. J. Clin. Psychol. 14:240242 .

Harris, J. G. Validity: The Search for a Constant in a Universe of Variables. In: Rickers-Ovsiankina, M. A. 1960. Pp. $380-439$.

tarrower, M. R. \& Steiner, M. E. 1945. A Manual for Fsychodiagnostic Inkblots. Grune \& Stratton: New York.

Hertz, M. R. 1942. Rorschach: Twenty Years After. Psychol. Bull. 39:529-572.

Hertz, M. R. 1951. Current Problens in Rorschach Theory and Technique. J. Proj. Techs. 15:307-338.

fertz, M. R. The Rorschach: Thirty Years After. In: Bower, D. \& Abt, I. E. 1952. Progress in Clinical Psychology. Grune \& Stratton: New York. Pp. 108-148.

fertz, M. R. 1959. The Use and Misuse of the Rorschach Method: I. Variations in Rorschach Procedure. J. Proj. Techs. $23: 33-48$.

lirt, M. 1962. Rorschach Science, Readings in Theory and Method. The Free Press of Glencoe: Glencoe. 
Holtzman, W. H. 1958. The Inkblot Test. University of Texas Press; Austin.

Hunt, W. A. 1946. The Future of Diagnostic Testing in Clinical Psychology. I. Clin. Psychol. 2:311-317.

Fiunt, H. F. 1950. Clinical Methods: Psychodiagnostics. Ann. Rev. Psychol. 1:207-220.

Hunt, W. A., Schwartz, M. I. \& Walker, R. E. 1965. Rellabllity of Clinical Judgments as a Function of Range of Pathology. I. Ab. Psychol. 70:32-33.

Ives, V., Grant, M. A. \& Ranzon1, J. H. 1953. The "Neurotic" Rorschachs of Normal Adolescents. I. Genet. Psychol. 83: 31-61.

Jackson, C. W., Jr. \& Wohl, J. 1965. A Survey of Rorschach Teaching in the University. I. Prof. Techs. 30:115-134.

Jensen, A. R. 1958. Personality. Ann. Rev. Psychol. 9:295322.

Kaplan, B., Rickers-Ovsiankina, M. A. \& Joseph, A. An Attempt to Sort Rorschach Records from Four Cultures. In: Murstein, B. I. 1965. Pp. 293-306.

Kelly, G. A. 1958. The Theory and Techniques of Assessment. Ann. Rev. Paychol. 9:323-352.

Klopfer, B., Ainsworth, M., Klopfer, G. \& Holt, R. Developments In the Rorschach Technique. Vol. I, Technique and Theory. World Book Co.: New York.

Klopfer, W. G., Allen, B. V. \& Effer, D. 1960. Content Diversity on the Rorschach and "Range of Interests." J. Prof. Techs. 24:290-291.

Knopf, I. J. 1956. Rorschach Summary Scores in Differential Diagnosis. I. Consult. Psychol. 20:99-104.

Lazarus, R. S. 1949. The Influence of Color on the Protocol of the Rorschach Test. I. Ab. \& Soc. Psychol. 44:506-516.

Levine, D. 1959. Rorschach Genetic-Level and Mental Disorder. J. Proj. Techs. 23:436-439.

Levy, L. H. Manual of Projective and Cognate Techniques. In: Zubin, J. \& Young, K. M. 1948. 
Levy, L. H. \& Orr, T. B. 1958. The Soclal Paychology of Rorschach Validity Research. J. Ab. \& Soc. Psychol. 58: 7983.

Lindner, R. M. The Content Analysie of the Rorschach Frotocol. In: Abt, I. A. \& Bellak, I. 1950. Pp. 75-90.

Loevinger, J. 1959. The Theory and Techniques of Assessment. Ann. Rev. Psychol. 10:287-316.

Lorenz, M. 1959. Language as Index to Perceptual Viodes. J. Proj. Techs. 23:440-452.

Margaret, A. 1952. Clinical Methods: Psychodiagnostics. Ann. Rev. Fsychol. 3:283-320.

Marks, J. B. 1952. Rorschach Water Responses in Alcoholics: Levels of Content Analysis and Consensual Validation. J. Proj. Techs. 23:69-71.

McCully, R. 3. 1965. Frocess Analysis: A Tool in Understanding Ambiguity in Diagnostic Problems in Forschach. J. Prof. Techs. 29:436-444.

Mensh, I. N. \& Matarazzo, J. D. 1954. Rorschach Card Rejection in Psychodiagnosis. J. Consult. Psychol. 18:271-275.

Mills, D. H. 1965. The Research Use of Projective Techniques: A Seventeen Year Survey. J. Eroj. Techs. 29:513-515.

Mitchell, M. B. 1952. Preferences for Rorschach Cards. I. Proj. Techs. 16:203-211.

Mohrbacher, J. W. 1961. The Diagnostic Approach of Three Disc1plines to Minimal Intracranial Pathology in Chilaren. Unpub ilshed Doctoral Dissertation. Loyola University: Chicago.

Munroe, R. I. 1944. Inspection Technique. Ror. Res. Ixch. $8: 46-70$.

Murray, H. A. 1943. Manual for the Thematic Apperception Test. Harvard University Press: Cambridge.

Murstein, B. I. 1963. Theory and Research in Projective Techniques. Wiley: New York.

Murstein, B. I. 1965. Handbook of Projective Techniques. Basid Books: New York. 
Neuringer, C. 1965. The Rorschach Test as a Research Device for the Identification, Prediction and Understanding of Suicidal Ideation and Behavior. J. Proj. Techs. 29:71-82.

Newton, R. L. 1954. The Clinician as Judge: Total Rorschachs and Clinical Case Material. J. Consult. Psychol. 18:248250.

Osgood, C. E. 1952. The Nature and Measurement of Meaning. Paychol. Bull. 49:197-273.

Pauker, J. D. 1963. Relationship of Rorschach Content Categories to Intelligence. J. Proj. Techs. 27:220-221.

Phillips, I. \& Smith, J. G. 1953. Rorschach Interpretation: Advanced Technique. Grune \& Stratton: New York.

Powers, W. T. \& Hamlin, R. M. 1957. The Validity, Bases, and Process of Clinical Judgment, Using a Iimited Amount of Projective Test Data. I. Iroj. Techs. 21:286-293.

Rabin, A. I. Validating and Experimental Studies with the RorBchach Method. In: Anderson, H. H. \& Anderson, G. L. 1951. Pp. 123-146.

Ranzoni, J. H., Grant, M. Q. \& Ives, V. 1950. Rorschach "CardFuil" in a Normal Adolescent Population. J. Proj. Pechs. 14:107-133.

Reidel, R. G. 1963. A Study of the Relationship between Complex Problem Solving Ability and a Measure of Scholastic Aptitude. Loyola Paychometric Laboratory. Publication No. 32. Ioyola University: Chicago.

Richards, T. W. \& Murray, D. C. 1958. Global Evaluation of Rorschach Performance versus Scores: Sex Differences in Rorschach Performance. J. Clin. Psychol. 14:61-64.

Rickers-Ovsiankina, M. A. 1960. Rorschach Psychology. Wiley: New York.

Kimoldi, H. J. A. 1955. A Technique for the Study of Problem Solving. Educ. Psychol. Meas. 15:450-451.

Rimoldi, H. J. A. 1956. A New Technique for Appraising Diagnostic Ablitty. Unpublished Paper. Loyola University: Chicago

Rimoldi, H. J. A., Devane, J. R. \& Grib, T. F. 1958. Testing Skills in Medical Diagnosis. Commonwealth Fund Project. Unpublished Paper. Ioyola University: Chicago. 
Rimoldi, H. J. A. \& Devane, J. R. 1961. Training in Problem Solving. Ioyola Psychometric Laboratory. Publication No. 21. Loyola University: Chicago.

Rimoldi, H. J. A., Haley, J. V. \& Fogliatto, H. M. 1962. The Test of Diagnostic Skills. Loyola Psychometric Laboratory. Publication No. 25. Loyola University: Chicago.

Rodgers, D. A. 1957. Sources of Variance in Students' Rorschach Interpretations. J. Proj. Techs. 21:63-68.

Rorschach, H. 1942. (Trans. Lemkau, P.) Psychodiagnostics. Hans Huber: Berne.

Ross, W. D. 1950. Relationships between Rorschach Interpretations and Clinical Diagnoses. J. Proi. Techs. 14:5-14.

Rychlak, J. F. 1959. Forced Assoctations, Symbolism, and Rorschach Constructs. J. Consult. Psychol. 23:455-460.

Sacks, J. M. \& Lewin, H. S. 1950. Limitations of the Rorschach as Sole Diagnostic Instrument. J. Consult. Psychol. 14: 479-481.

Sapolsky, A. 1963. An Indicator of Sulcidal Ideation on the Rorschach Test. I. Prof. Techs. 27:332-335.

Sarason, S. B. 1954. The Clinical Interaction. Harper: New York.

Sargent, H. D. 1954. Projective Methods: Their Origins, Theory and Applications in Personality Research. Psychol. Bull. $42: 257-293$.

Schafer, R. 1954. Psychoanalytic Interpretation in Rorschach Testing. Grune \& Stratton: New York.

Schneider, I. I. 1950. Rorschach Validation: Some Methodolog1cal Aspects. Pgychol. Bull. 47:493-508.

Shapiro, D. 1959. The Integration of Determinants and Content in Rorschach Interpretation. J. Proj. Techs. 23:365-373.

Shereshevsk1, S. E. \& Lasser, I. M. 1952. An Evaluation of Water Responses in the Rorschachs of Alcoholics. J. Proj. Techs. 16:489-495.

Sherman, M. 1952. A Comparison of Formal and Content Factors in the Diagnostic Testing of Schizophrenia. Genet. Psychol. Monogr. $46: 183-234$. 
Siipola, E. 1950. The Influence of Color on Reactions to Inkblots. J. Pers. 18:358-382.

Singer, J. L. 1956. The Non-Projective Aspects of the Rorschach Experiment: V. Discussion of the Clinical Implications of the Non-Projective Aspects of the Rorschach. J. Soc. Psychol. 44:207-214.

Sommer, R. 1958. Rorschach M Responses and Intelligence. J. Cin. Psychol. 14:58-61.

Sundberg, N. D. 1961. The Practice of Psychological Testing in Clinical Services in the United States. Amer. Psychol. $16: 79-83$.

Symonds, P. M. 1955. A Contribution of Our Knowledge of the Validity of the Rorschach. I. Froj. Tech. 19:152-162.

Tabor, A. B. 1959. Process Analysis of Rorschach Interpretation. Unpublished Doctoral Dissertation. Loyola University Chicago.

Trier, T. R. 1958. Vocabulary as a Basis for Estimating Intelilgence from the Rorschach. I. Consult. Psychol. 22:289291.

Vassiliou, V. 1961. Rorschach Content Analysis, a Survey of the Literature. Unpublished Manuscript. Loyola University: Chicago.

Wagoner, R. A. 1963. The Rorschach Test: A Perceptual or a Grammatical Device? Percep. \& Mot. Skills. 17:419-422.

Wagoner, R. A. 1964. Comment: "The Rorschach Test: A Perceptual Bias." Percep. \& Mot. Skills. 18:282.

Wheeler, W. M. 1949. An Analysis of Rorschach Indices of Male Homosexuality. J. Proj. Tech. 13:97-126.

Weiner, I. B. 1961. Three Rorschach Scores Indicative of Schizophrenia. J. Consult. Psych. 25:436-439.

Weiner, I. B. 1962. Forschach Tempo as a Schizophrenic Indicator. Percep. \& Mot. Skills. 15:139-141.

Weiner, I. B. 1964. Pure $C$ and Color Stress as Rorschach Indicators of Schizophrenia. Percep. \& Mot. Skills. 18:484.

Weiner, I. B. 1965. Follow-up Valldation of Rorschach Tempo and Color Use Indicators of Schizophrenia. J. Proj. Tech. 29: 387-391. 
Wittenborn, J. R. 1950. Statistical Tests of Certain Rorschach Assumptions-The Internal Consistency of Scoring Categories. J. Consult. Esychol. 14:1-9.

Wittenborn, J. R. 1957. The Theory and Techniques of Assessment. Ann. Rev. Psychol. 8:331-356.

Wyatt, F, 1952. Prediction in the Rorschach Test. I. Proj. Techs. 16:252-258.

Wysocki, B. A. 1956. Rorschach Card Preferences as a Diagnostic Aid. Paychol. Monogr. 70:6.

Zubin, J. \& Windle. 1953. J. Ab. \& Soc. Psychol. Pp. 272-281. Zubin, J. 1954. Failures of the Rorschach Technique. J. Proj. Techs. 18:305-315.

Zubin, J. 1956. The Non-projective Aspects of the Rorschach Experiment: I. Introduction. J. Soc. Psychol. 44:179-192.

Zubin, J., Eron, L. D. \& Sultan, F. 1956. A Psychometric Evaluation of the Rorschach Experiment. Amer. J. Orthopsychi. $26: 773-782$.

Zulliger, H. 1952. Der Behn-Rorschach Test. Hans Huber: Berne. 


\section{APPENDIX I}

Apparatus Used in

the Present Study 


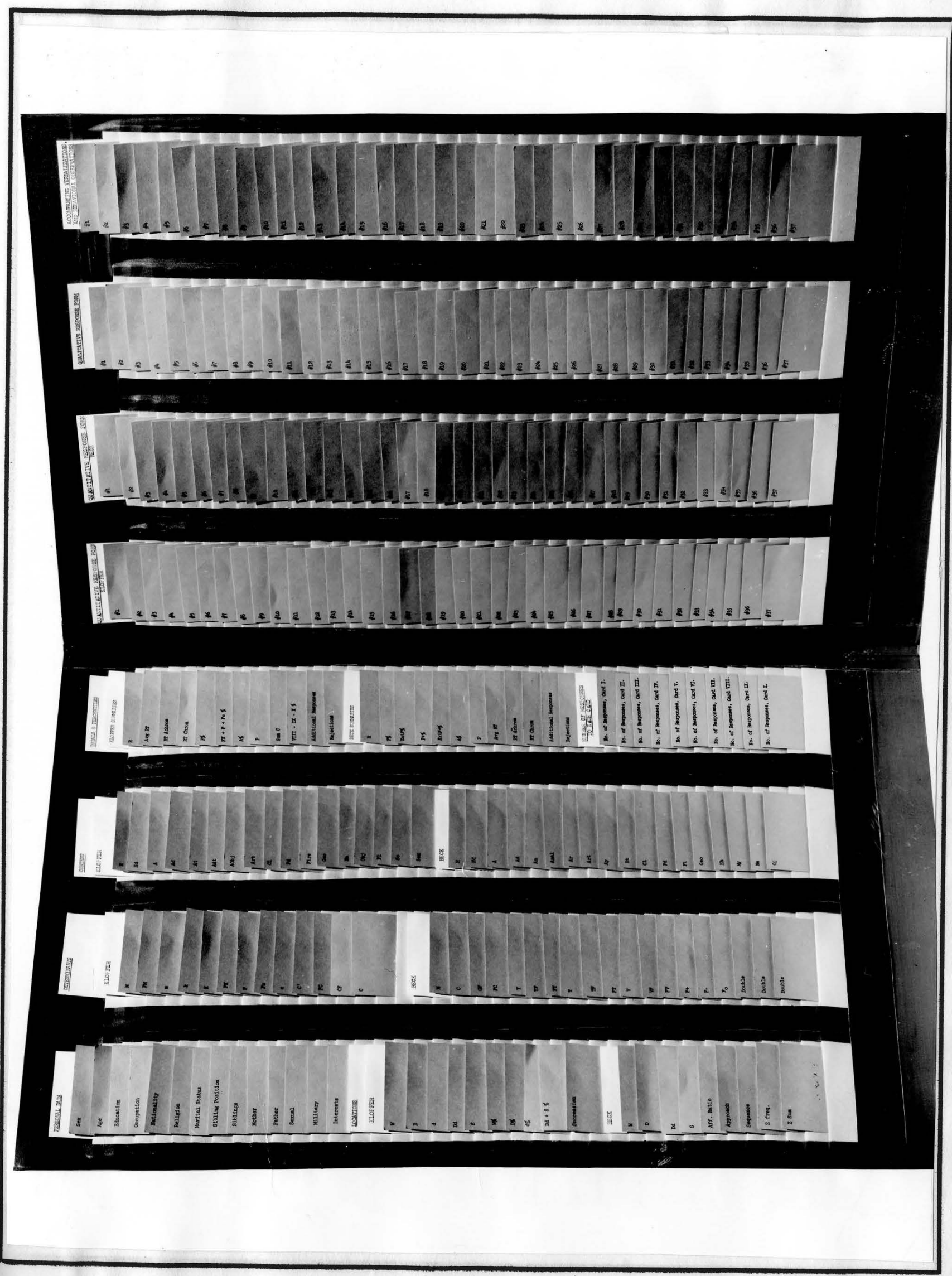




\section{APPENDIX II}

Question Forms for

Protocols A, B, and $\underline{C}$ 


\section{Protocol A.}

Question: Determine the clinical diagnosis of this individual, on the basis of the Rorschach data avallable.

As soon as you feel quite sure of the diagnosis, check one of the five diagnostic categories below and write your own more specific clinical impression.

Basically Adjusted

Neurotic

Personality Disturbance

Organic

Psychotic

Specific Clinical Impression 


\section{Protocol B}

Question: Estimate the severity of anxiety in this individual, name the types of events likely to heighten it, and name the defenses likely to be utilized in lowering it.

As soon as you feel quite sure of the estimated severity of anxiety, check one of the five categorles below, and write down the heightening events and the defenses.

No Anxiety

Iittle Anxiety

Normal Aaxiety

Much Anxiety

Severe Anxiety

Heightening Events

Defenses Against 


\section{Protocol $\mathrm{C}$}

Question: Estimate the present level of intellectual functionine of this individual, on the basis of the Rorschach data avallable.

As soon as you feel quite sure of the estimated intellectual level, check one of the three intellectual levels below and write your own more specific clinical impression.

Below Average Average (90-109)

Above Average

Specific Clinical Impression 


\section{APPENDIX III}

\section{Mater1als Available for \\ Use by Clinicians}




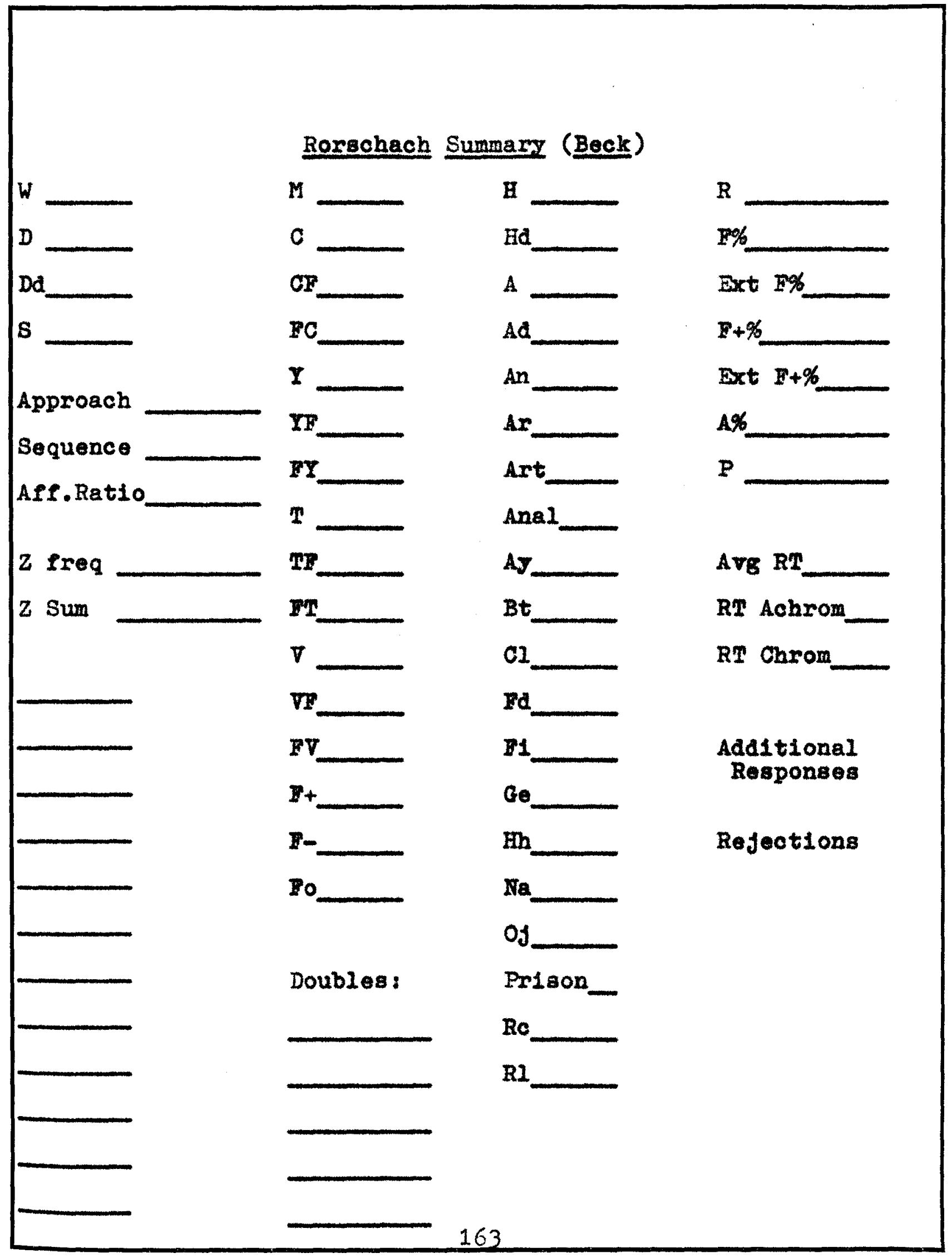




\begin{tabular}{|l|l|l|l|l|l|l|l|l|l|l|l|l|}
\hline$M$ & $F M$ & $m$ & $k$ & $K$ & $F K$ & $F$ & $F C$ & $c$ & $C^{\prime}$ & $F C$ & $C F$ & $C$ \\
\hline
\end{tabular}

BASIC RELATIONSHUPS: Main Responses Only

Tolal Responses

Tolal Time

Average Time per Response

Average Reachion Time:

Achromatic Cards $(I, U V, V, V I, V I I)$

Chromatic Cards (II, III, VIII, IX, X)

$\frac{F}{R}$

$F K+F+F C$

R

$\frac{A+A d}{R}$

$(H+A):(H d+A d)$

Popular Responses

Original Responses

$\mathrm{FC}+2 \mathrm{CF}+3 \mathrm{C}$

2

$M: \operatorname{sum} C$

$(F M+m):\left(F C+c+C^{\prime}\right)$

Responses to Cards VIII $+I X+X$

$\mathrm{R}$

11. SUPPLEMENTARY RELATIONSHIPS: Main $+\frac{1}{2} \mathrm{Add}$

$M: F M$

$M:(F M+m)$

$\frac{F K+F C}{F}$

$\left(\mathrm{FC}+\mathrm{CF}+\mathrm{C}+\mathrm{C}^{d}+\mathrm{C}^{\prime} \mathrm{F}+\mathrm{FC}^{\prime}\right):$

$(\mathrm{FC}+\mathrm{CF}+\mathrm{C})$

$(F K+F c+F k):(K+K F+k+k F+c+c F)$

$\mathrm{FC}:(\mathrm{CF}+\mathrm{C})$

III. MANNER OF APPROACH

\begin{tabular}{|c|c|c|c|c|}
\hline & \multicolumn{3}{|c|}{ Main Responses } & \multirow[b]{2}{*}{$\begin{array}{l}\text { No. Add. } \\
\text { Scores }\end{array}$} \\
\hline & No. & $\begin{array}{c}\text { Acrual } \\
\%\end{array}$ & $\begin{array}{c}\text { Expect. } \\
\%\end{array}$ & \\
\hline W & & & $20-30$ & \\
\hline D & & & $45-55$ & \\
\hline d & & & $5-15$ & \\
\hline $\mathrm{Dd}+\mathrm{S}$ & & & $<10$ & \\
\hline
\end{tabular}

IV. ESTIMATE OF

INTELLECTUAL

LEVEL

Capacity

V. SUCCESSION

Rigid

Orderly

Loose

Efficiency

Confused

VI. FORM LEVEL SUMMARY

Average Unweighted FLR

Average Weighted FLR 


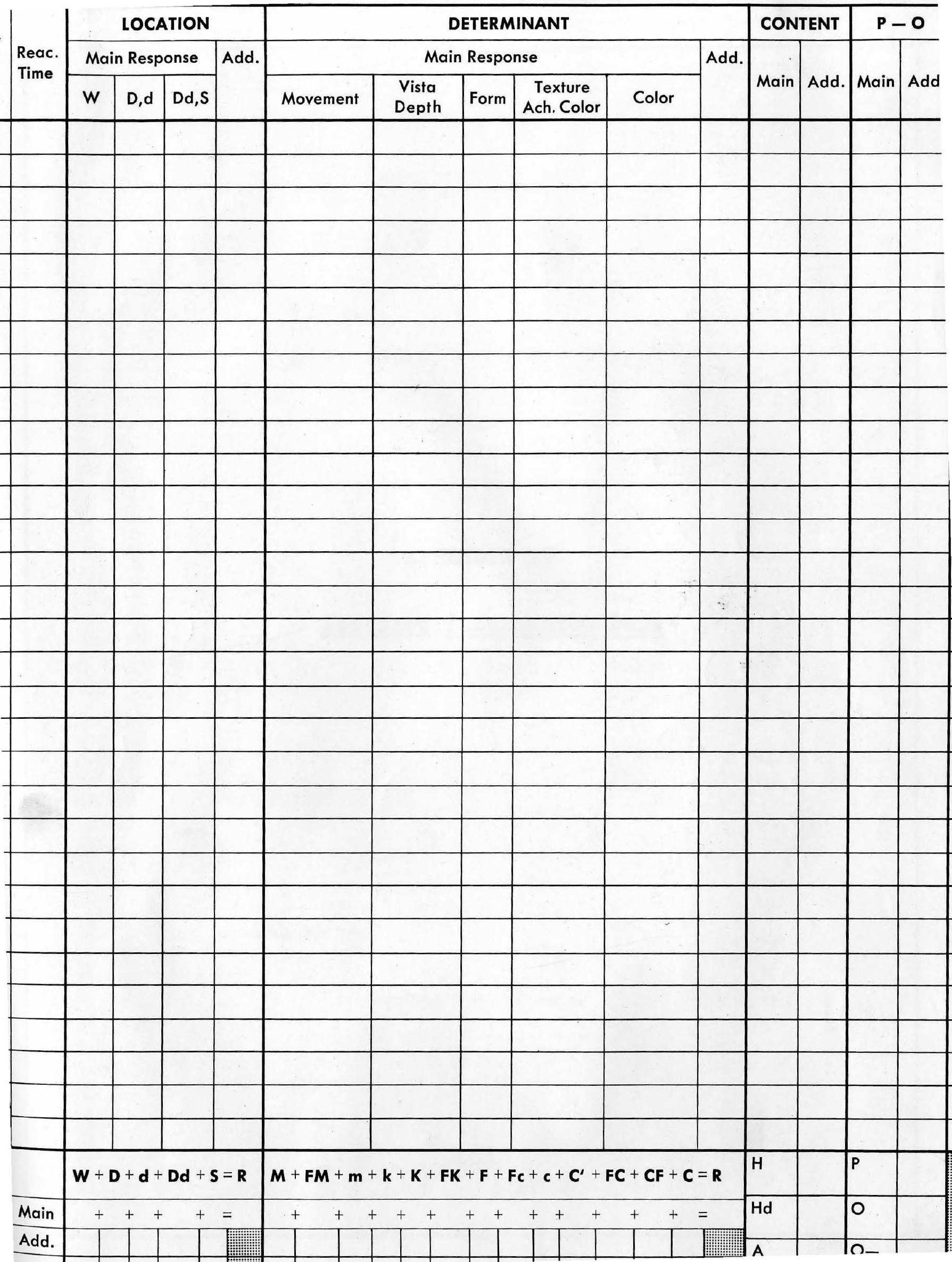




\section{APPENDIX IV}

Research Information Form 
Research Information

1) Primary setting Clinic Hospital Private Academic Research in which Rorschach is used Practice by $S$

Out-patient or in-patient

2) Primary age group Child Adoles- Young Adult Elderly with which Rorschach is used by $\mathrm{s}$ cont Adult

$\bullet \bullet \bullet$

Male or Pemale

Normal Neurotic Personal1ty Neuro- Psychot1c Disturbance logical

3) When $S$ administers a test battery, is the Rorschach used

4) How many Rorschachs would $S$ estimate having administered or Interpreted during the past five Jears?

5) S's personal view of the value of the Rorschach for clinical investigation
All of
Most of
Occasion-
Iittle the the
a.11y
time
time
None of the time

$$
\begin{array}{cccccc}
1-50 & 52- & 101- & 151- & 201- & 251+ \\
100 & 150 & 200 & \\
& & \#:
\end{array}
$$

Pavorable or Unfavorable

$$
\begin{gathered}
\text { Ranked usefulness for } \begin{array}{l}
\text { Diagnosis } \\
\text { Anxiety } \\
\text { Estimation } \\
\text { Intellectual } \\
\text { Estimation }
\end{array}
\end{gathered}
$$




\section{APPENDIX $\nabla$ \\ Form Used to Record \\ Interpretation Sequence}


APPENDIX VI

Statistical Formulae

170 


\section{STATISTICAL FORMULAE}

Ut1l1ty Index $=1_{j}=\frac{n_{j}}{N}$

$$
\begin{aligned}
& n_{\mathrm{J}}=\begin{array}{l}
\text { number of cliniclans } \\
\text { choosing card } \mathrm{j}
\end{array} \\
& N=\text { total number of } \\
& \text { cliniclans }
\end{aligned}
$$

$n+n_{s}+1$

$$
\text { Average Rank = } A_{r}=\frac{n}{2} \quad \begin{aligned}
n & =\text { total number of cards } \\
n_{S} & =\begin{array}{l}
\text { number of cards } \\
\text { selected }
\end{array}
\end{aligned}
$$

Spearman rho* $=r_{\mathrm{S}}$

$$
\left(\frac{N x^{3}-N x}{12}-2 \operatorname{Ties} x\right)+\left(\frac{N x^{3}-N y}{12}-2 \operatorname{Les} y\right)-2 d^{2}
$$

$$
=\sqrt{2 \sqrt{\left(\frac{N x^{3}-N x}{12}-\sum T 1 e s x\right) \cdot\left(\frac{N x^{3}-N y}{12}-2 T 1 e s y\right)}}
$$

$\mathrm{Nx}=$ total number of cards, tor frequency of selection

$\mathrm{Ny}=$ total number of cards, for sequence of selection

$d$ = difference between ranks of $\mathrm{Nx}$ and $\mathrm{Ny}$

*corrected for ties 


\section{STATISTICAL FORNULAE continued}

Friedman Two-Way

Analysis of Varlance $=x_{x^{2}}=$
12

$\mathrm{Nk}(k+1)$

$N=$ number of clinicians

$k=$ number of protocols

$R_{j}=$ sum of ranks of protocols

$d f=k-1$

Kendall Coefficient

of Concordance*

$$
\begin{aligned}
& =W=\frac{s}{\frac{1}{12} k^{2}\left(N^{3}-N\right)-k \leq T} \\
& s \text { = sum of squares of } \\
& \text { deviation from mean } \\
& \text { of card ranks } \\
& k \text { = number of clinicians } \\
& N=\text { number of cards } \\
& T=\frac{\sum(t 3-t)}{12} \\
& t=\text { number of ties for a } \\
& \text { given rank } \\
& \text { * corrected } \\
& \text { for ties } \\
& x^{2}=x(N-1) w \\
& d f=N-1
\end{aligned}
$$

Fisher $Z$ Distribution $=z=\sqrt{2 x^{2}}-\sqrt{2 v-1}$

$x^{2}=\operatorname{ch} 1$ square

$\mathbf{v}=$ number of cards 


\section{APPENDIX VII}

Table of

Item Abbreviations 


\section{TABLE OF ABBREVIATIONS}

A $B, K^{*}$

$A \% B, K$

AAt $K$

Ad $B, K$

Add $B, K$

AffR B

Age

An B

Anal B

AObj $K$

App B

Ar B

Art $B, K$

At $\mathrm{K}$

AVgRT $B, K$

Ay $B$

Bt $B$

C $\mathrm{B}, \mathrm{K}$

c $\mathrm{K}$

$C \cdot \mathrm{K}$

CF $B, K$

CI $B, K$
Anlmal content

Animal content percent

Animal anatomy content

Animel deta11 content

Additional responses

Affective ratio

Age information

Anatomy content

Anal content

Animal object content

Approach

Arch1tecture content

Art content

Anatomy content

Average reaction time

Anthropology content

Botany content

Undiluted chromatic color determinant

Shading as texture determinant

Achromatic surface color

Chromatio color modulated by form

cloud content 


\section{TABLE OF ABBREVIATIONS continued}

$D$ B.K Large usual detail location

$D \% \quad$ Large usval detall percent

$d K \quad$ Small usual deta11 location

d\% $K \quad$ Small usual detall percent

Db1 1, 2, 3 Double determinant or blend

Da $B, K_{L} \quad$ Unusual or rare detall location

$D d+S \% \quad K \quad$ Unusual detall and white space percent

Ed Education information

8-9-10\% K Percent responses to last three Rorschach cards

F K Pure form determinant

Fo $B, K$ Pure form percent

Fa Father information

FC $B, \pi$ Definite form dominant over chromatic color

Fc $K$ Differentiated shading determinant, as surface appearance

Fd B. Food content

F1 B Fire content

Fire $K \quad$ Fire content

FK $K$ Shading determinant, as three dimensional expanse of Viste or perspective

$F K+\% \quad$ Three dimensional shading percent

FM $K \quad$ Anlmal movement determinant

F- B Inaccurate form determinant

$F+B \quad$ Accurate form determinant

$F+\%$ Accurate form percent 


\section{TABLE OF ABBREVIATIONS continued}

Fo $B$

FT B

FV B

FY B

Ge B

Geo K

B $\mathrm{A}, \mathrm{K}$

Hd $B, K$

Fin $B$

Int

K K

is K

Loca 1 - 37 Location of individual responses \#1 through \#37. as appearing on the stendard location chart

$M B, K$

m $K$

Mar

Ho

Mty

My B

$\mathrm{Na} B, \mathrm{~K}$

Nty

obj $K$

Occ

Form determinant, accuracy not know

Form dominant over texture, determinant

Form dominant over vista, determinant

Form dominant over shading, determinant

Geography content

Geography content

Human content

Human deta11 content

Household content

Interests information

Shading as diffusion, determinant

Shading as three dimensional expanse on two dimensional plene, determinant

Human movement determinant

Inanimate movement determinant

Marital status information

Nother information

Military history information

Mythology content

Nature content

Nationality information

Man-made objects content

Occupation information 


\section{TABLE OF ABBREVIATIONS continued}

of B Man-made objects content

$P B, K \quad$ Popular percepts

PI K Plant content

Qual 1 - 37 Qualitative response form \#1 through \#37, the free assoclations (e.g.." "Bat")

Quan 1 - 37 Quantitative scoring of each qualitative response B. X \#1 through \#37 (e.g., W F A P)

$R B, K \quad$ Total number of scored responses

Rej $B, K$ Rejection of Card

ReI

Religion information

Res 1 - 10 Number of responses to each Rorschach card \#I through \#X (e.g., Card $I=$ four responses, $(1-4)$

RT 1 - 10 Initial reaction time to each Rorschach card \#I through \#X (e.g., Card $I=14 ")$

RTAch $B, K$ Average reaction time to achromatic cards

RTChr $B_{1} K$ Average reaction time to chromatic cards

$S B, K \quad$ White space Iocation

Sc $K \quad$ Sclence content

Seq $B \quad$ Sequence of locations

Sex Sex information

Sex $K \quad$ Sex content

Sexual Sexual information

Sibs Number of siblings information

SPO Sibline position information

Succ K Succession of locations 


\section{TABIE OF ABBREVIATIONS continued}

SumC $K \quad$ Sum of color detarminants

T B

Undiluted texture determinant

TF $B$

Texture modulated by form

$\mathrm{V} 3$

Undiluted vista determinant

VF $B$

Vista modulated by form

Verb 1 - 37 Subject verbalizations and examiner observations accompanying each qualitative response \#1 through $\# 3$ ? (e.8." "Oh what a pretty color" ... 5 Elegles)

W $B, K$ Whole location

W\% Whole location percent

$\mathrm{xF} \% \mathrm{~B}$ Percent of responses beginninE with form

$\mathrm{xF}+\%$ Percent of accurate form responses

I $B$ Undiluted shading doterminant

YF B ShadinE modulated by form, determinant

Zf B Frequency of organization scortings

ZSm B Sum of weighted organization scorings

* Information common to both Beck and Klopfer is Iisted once, with $B$ indicating Beck and $K$ indicating Klopfer. 
APPROVAL SHEET

The dissertation submitted by Charles $R$. Potkay has been read and approved by members of the Department of Psychology.

The final copies have been examined by the director of the dissertation and the signature which appears below verifies the fact that any necessary changes have been incorporated and that the dissertation is now given final approval with reference to content and form.

The dissertation is therefore accepted in partial fulfillmont of the requirements for the degree of Doctor of Philosophy.
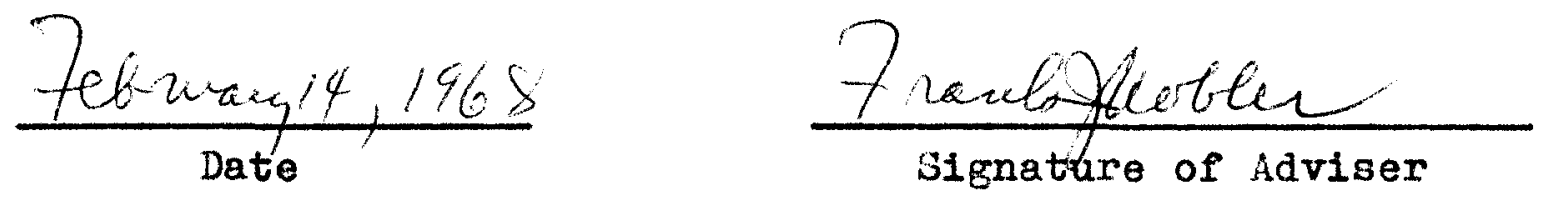